Portland State University

PDXScholar

1-19-1995

\title{
Analysis of Intermodulation Distortion for MESFET Small-signal Amplifiers
}

Imad Saleh Ahmad

Portland State University

Follow this and additional works at: https://pdxscholar.library.pdx.edu/open_access_etds

Part of the Electrical and Computer Engineering Commons Let us know how access to this document benefits you.

Recommended Citation

Ahmad, Imad Saleh, "Analysis of Intermodulation Distortion for MESFET Small-signal Amplifiers" (1995). Dissertations and Theses. Paper 4989.

https://doi.org/10.15760/etd.6865

This Thesis is brought to you for free and open access. It has been accepted for inclusion in Dissertations and Theses by an authorized administrator of PDXScholar. Please contact us if we can make this document more accessible: pdxscholar@pdx.edu. 


\section{THESIS APPROVAL}

The abstract and thesis of Imad Saleh Ahmad for the Master of Science in Electrical and Computer Engineering were presented January 19, 1995, and accepted by the thesis committee and the department.

COMMITTEE APPROVALS:

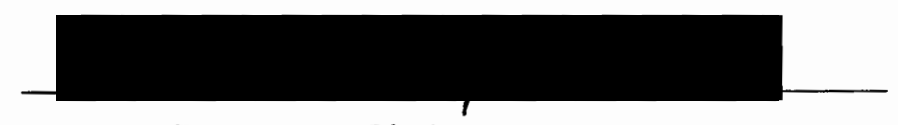

Lee W. Casperson, Chair

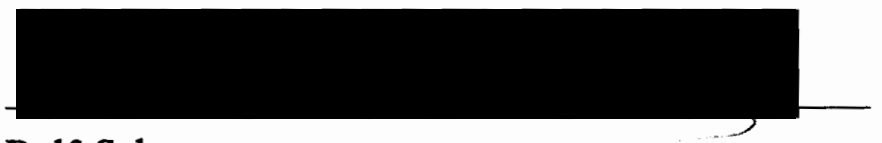

Rolf Schaumann

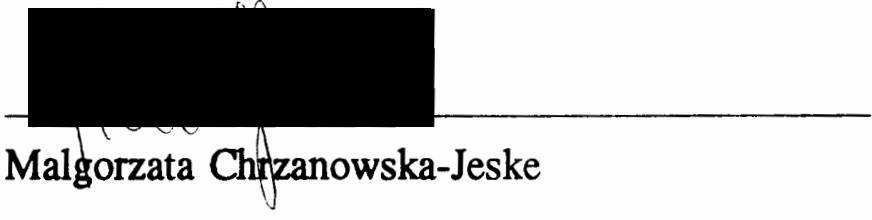

DEPARTMENT APPROVAL:
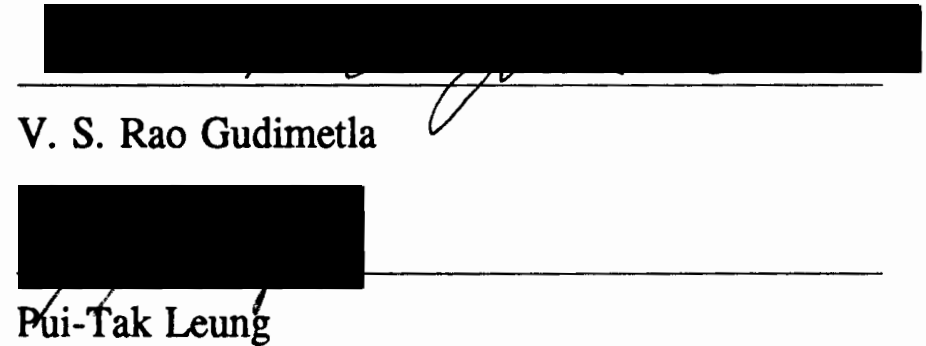

Representative of the office of Graduate Studies

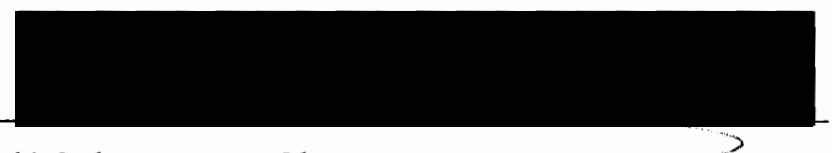

Rolf Schaumann, Chair

Department of Electrical Engineering

ACCEPTED FOR PORTLAND STATE UNIVERSITY BY THE LIBRARY by on 23 liaxch 1995 


\section{ABSTRACT}

An abstract of the thesis of Imad Saleh Ahmad for the Master of Science in Electrical and Computer Engineering presented January 19, 1995.

Title: Analysis of Intermodulation Distortion for MESFET Small-Signal Amplifiers

Using the nonlinear Volterra series representation, analytical expressions for the third-order intermodulation distortion power and intercept point for a MESFET small-signal amplifier are derived when its equivalent circuit is bilateral and includes the gate-to-drain capacitance $\left(\mathrm{C}_{\mathrm{gd}}\right)$ explicitly as a nonlinear element. Previously developed analytical expressions treated $\mathrm{C}_{\mathrm{gd}}$ as a linear element or incorporated it as part of gate-to-source and drainto-source capacitances $\left(\mathrm{C}_{\mathrm{gs}}\right.$ and $\left.\mathrm{C}_{\mathrm{ds}}\right)$. These new analytical expressions are then compared with experimental data and good agreement is obtained. The analytical expressions are also used to study the variation of intermodulation distortion with input power, frequency, and source and load impedances. It is shown that the nonlinearity of $\mathrm{C}_{\mathrm{gd}}$ contributes significantly to the 
intermodulation distortion power and the third-order intercept point and therefore should not be neglected in the analysis and design. 


\section{ANALYSIS OF INTERMODULATION DISTORTION FOR MESFET SMALL-SIGNAL AMPLIFIERS}

by

IMAD SALEH AHMAD

A thesis submitted in partial fulfillment of the requirements for the degree of

MASTER OF SCIENCE in

ELECTRICAL AND COMPUTER ENGINEERING

Portland State University

1995 


\section{ACKNOWLEDGMENT}

This thesis was written under the direction and supervision of Dr. Rao Gudimetla and Dr. Lee Casperson. I would like to express my sincere appreciation to them for their interest and many useful discussions given to me. Also, I would like to express my sincere gratitude to TriQuint Semiconductor at Beaverton, OR. ; especially to Mr. Dennis Criss for his encouragement and support, and Mr. George Steen for helping us with the device measurements. This thesis would not have been possible without their support. 


\section{TABLE OF CONTENT}

PAGE

ACKNOWLEDGEMENTS $\ldots \ldots \ldots \ldots \ldots \ldots \ldots$ iii

LIST OF TABLES $\ldots \ldots \ldots \ldots \ldots \ldots \ldots \ldots \ldots \ldots \ldots$ vi

LIST OF FIGURES $\ldots \ldots \ldots \ldots \ldots \ldots \ldots \ldots \ldots$ vii

CHAPTER

I INTRODUCTION $\ldots \ldots \ldots \ldots \ldots \ldots \ldots \ldots$

II DEVICE MODEL $\ldots \ldots \ldots \ldots \ldots \ldots \ldots$

Linear Elements . . . . . . . . . . . 7

Nonlinear Elements . . . . . . . . . . 7

Modeling of Nonlinear Capacitors

Modeling of Nonlinear Conductance

Modeling of Nonlinear Controlled Current

III NONLINEAR ANALYSIS USING VOLTERRA

SERIES REPRESENTATION . . . . . . . . . . 15

Volterra Series Representation . . . . . . . . . 15

First-Order Transfer Functions . . . . . . . . . . 19

Second-Order Nonlinear Transfer Functions . . . . 22

Third-Order Nonlinear Transfer Function . . . . . 27 
Computation of Intermodulation Distortion . . . . 33

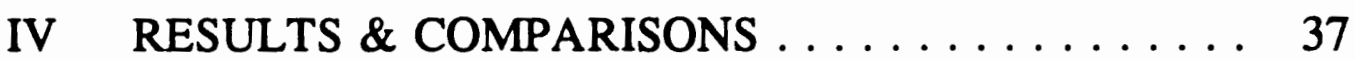

DC Experimental Measurements of the Device . . 37

Intermodulation Distortion Measurements . . . . 46

Comparison of Computed Distortion with

Experimental Results ............. 50

Comparison of Computed Distortion with

Minasian's Amplifier Results ........... 51

Variation of Intermodulation Distortion with

Frequency and Input Power .......... 56

Effect of Source and Load Impedances . . . . . . 59

Effect of Feedback Capacitance and Other

Nonlinear Elements of MESFET . . . . . . . 60

V CONCLUSIONS $\ldots \ldots \ldots \ldots \ldots \ldots \ldots \ldots, 63$

REFERENCES $\ldots \ldots \ldots \ldots \ldots \ldots \ldots \ldots \ldots \ldots \ldots \ldots$

\section{APPENDICES}

A CURVE FITTING MATLAB PROGRAM ...... 66

B INTERMODULATION DISTORTION

CALCULATIONS USING MATLAB PROGRAM . . 68

C ClASS PROJECT $\ldots \ldots \ldots \ldots \ldots \ldots \ldots \ldots 77$ 


\section{LIST OF TABLES}

TABLE

PAGE

I S-parameters Data Set at $\mathrm{V}_{\mathrm{DS}}=1.5 \mathrm{~V}$ and $\mathrm{V}_{\mathrm{Gs}}=-0.5 \mathrm{~V} \ldots 38$

II Linear Equivalent Circuit Element Values at $V_{D S}=1.5 \mathrm{~V}$ and $\mathrm{V}_{\mathrm{Gs}}=-0.5 \mathrm{~V} \ldots \ldots \ldots \ldots \ldots \ldots \ldots \ldots$

III Nonlinear Equivalent Circuit Element Values at Several Bias Points . . . . . . . . . . . . . 41

IV Taylor Series Coefficients of the Nonlinear Elements at

$$
\mathrm{V}_{\mathrm{DS}}=1.5 \mathrm{~V} \text { and } \mathrm{V}_{\mathrm{GS}}=-0.5 \mathrm{~V} \ldots \ldots \ldots \ldots
$$

$\mathrm{V}$ Intermodulation Distortion Measurements at $\mathrm{f}_{1}=729.75 \mathrm{MHz}$,

$$
\mathrm{f}_{2}=730.25 \mathrm{MHz} \text {, and } \mathrm{p}_{\text {in }}=-18 \mathrm{dBm} \text { and }-15 \mathrm{dBm} \text {. . }
$$

VI Comparison of Computed Values with Experimental

Results at $p_{\text {in }}=-18 \mathrm{dBm}, \mathrm{f}_{1}=729.75 \mathrm{MHz}$, and $\mathrm{f}_{2}=$ $730.25 \mathrm{MHz} \ldots \ldots \ldots \ldots \ldots \ldots \ldots \ldots 51$

VII Change in the Intermodulation Distortion Due to the

Effect of $\mathrm{C}_{\mathrm{gd}}$ on MESFET Amplifier ...... 61

VIII Change in the Intermodulation Distortion Power Due to

Linearizing of MESFET Elements . . . . . . 62 


\section{LIST OF FIGURES}

FIGURE

PAGE

2.1 Small-Signal Nonlinear Circuit Model of GaAs MESFET Device ............... 6

3.1. (a) Weakly Nonlinear Model. (b) Functional Expansion of the Weakly Nonlinear Circuit Model . . . . . 16

3.2 MESFET Equivalent Circuit $\ldots \ldots \ldots \ldots \ldots \ldots 20$

3.3 Second-Order Equivalent Circuit . . . . . . . . . 23

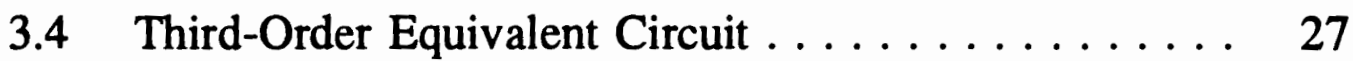

3.5 Intermodulation Frequency Spectrum . . . . . . . . 33

4.1 I/V Characteristics of $0.5 \mu \mathrm{m}$ MESFET Model ..... 37

4.2 Measured $\mathrm{C}_{\mathrm{gs}}\left(\mathrm{V}_{\mathrm{GS}}\right)$ Characteristics of MESFET Model . 40

4.3 Measured $\mathrm{C}_{\mathrm{gd}}\left(\mathrm{V}_{\mathrm{GD}}\right)$ Characteristics of MESFET Model . 42

4.4 Measured $\mathrm{g}_{\mathrm{m}}\left(\mathrm{V}_{\mathrm{GS}}\right)$ Characteristics of MESFET Model . 43

4.5 Measured $\mathrm{g}_{\mathrm{ds}}\left(\mathrm{V}_{\mathrm{DS}}\right)$ Characteristics of MESFET Model . 44

4.6 Measured $i_{d}\left(V_{G S}\right)$ Characteristics of MESFET Model . 45

4.7 Intermodulation Distortion Experimental Setup . . . . 48 
4.8 Comparison of Minasian's and Predicted Theory for

Frequency Dependency of Intermodulation

Distortion. x Indicates Minasian's Data ...... . 53

4.9 Comparison of Minasian's and Predicted Theory for the

Linear and Intermodulation Output Power

Responses for the Maximum Gain Load

Condition. x Indicates Minasian's Data . . . . . . 54

4.10 Comparison of Minasian's and Predicted Theory for the

Linear and Intermodulation Output Power

Responses for the Maximum Power Load. $x$

Indicates Minasian's Data . . . . . . . . . . 55

4.11 Frequency Dependency of Intermodulation Distortion

for an Input of $-18 \mathrm{dBm} \ldots \ldots \ldots \ldots 7$

4.12 Linear and Intermodulation Output Power Responses

at $730 \mathrm{MHz}, \mathrm{V}_{\mathrm{DS}}=1.5 \mathrm{~V}$, and $\mathrm{V}_{\mathrm{GS}}=-0.5 \mathrm{~V} \ldots \ldots 58$

4.13 Intercept Point as a Function of the Real and Imaginary

Parts of the Source Impedance . . . . . . . . . . 59

4.14 Intercept Point as a Function of the Real and Imaginary

Parts of the Load Impedance . . . . . . . . 60 


\section{CHAPTER I}

\section{INTRODUCTION}

The recent rapid developments in the communication industry have called for optimum performance in the microwave systems. One of the most critical and significant problems which has become an important consideration among researchers is intermodulation distortion arising from MESFET small-signal amplifier nonlinearities. Intermodulation distortion generated in MESFET amplifiers presents a very serious problem, because it represents spurious signals that interfere with, and can be mistaken for, desired signals.

Intermodulation distortion was investigated by many researchers [1][11]. Some researchers employed simplified, unilateral nonlinear equivalent circuits to arrive at simple analytical expressions to determine the intermodulation distortion [1]-[3]. For example, Tucker and Rauscher [1] used a simplified circuit model of a GaAs FET by taking the feedback capacitance $\left(\mathrm{C}_{\mathrm{gd}}\right)$ out of the equivalent circuit, which makes it unilateral. The circuit analysis used was based on power-series expansions of the device 
nonlinearities. An analytical expression for the third-order intermodulation distortion of a GaAs FET in terms of the load termination was derived. In another paper, Tucker [2] used the same simplified model and circuit analysis method but taking into consideration the effects of gain compression. Analytical expressions were obtained which relate the thirdorder intermodulation distortion and gain compression to the input power level and load admittance. Minasian [3] also used a simplified, unilateral circuit model of a MESFET by incorporating the gate-to-drain capacitance $\left(C_{g d}\right)$ into the gate-to-source and drain-to-source capacitance $\left(C_{g s}\right.$ and $\left.C_{g d}\right)$. Closed-form expressions for third-order intermodulation distortion and intercept point were derived using the Volterra series representation which enabled the identification of the major sources of distortion. In general, use of the Volterra series representation for intermodulation distortion calculation is superior to the use of power-series expansions.

Other researchers employed a complete, bilateral nonlinear equivalent circuit of a MESFET to determine the intermodulation distortion, but at each step numerical calculations were performed and no analytical expressions were available [4]-[9]. Khadar and Johnston [4] developed a high-frequency nonlinear FET model with all sources of nonlinearities accounted for. The 
proposed model was analyzed using the Volterra series representation. The results for the third-order intermodulation were left in terms of matrix equations which required a computer program for evaluation. The intermodulation distortion calculations were simplified by omitting some of the model nonlinearities. Lambrianou and Aitchison [5] analyzed a complete MESFET model using the Volterra series representation, but their work was based on small-signal measurements. Their analysis led to nonlinear transfer functions of order $\mathrm{n}$ which also required a computer program for evaluation [6]. Analytical expressions for the nonlinear power gain versus the frequency response, the output power, the gain compression factor, and the third-order intermodulation power in terms of the nonlinear transfer function were found. Maas [7] analyzed a bilateral MESFET model by first separating the nonlinear elements from the linear network and then using the admittance (Y) matrix approach to calculate the higher-order currents at each level of the analysis by using the Volterra series representation. Those calculations were very long and complex. Also, the effects of the nonlinearity of the feedback capacitance $\left(\mathrm{C}_{\mathrm{gd}}\right)$ was not examined and treated as a linear element. Crosmun and Maas [8] also used such an approach. They optimized the intermodulation distortion performance by designing the amplifier based on 
the available gain criteria. Pedro and Perez [9] presented a method to characterize the intermodulation distortion by including the cross terms of the drain-source current $\mathrm{I}_{\mathrm{ds}}\left(\mathrm{V}_{\mathrm{gs}}, \mathrm{V}_{\mathrm{ds}}\right)$ in the complete MESFET model.

Intermodulation distortion results based on the modeling of the nonlinear equivalent circuit have been useful in device engineering to improve intermodulation distortion [10]-[11]. For example, Williams and Shaw [10] showed that the use of graded channel profiles improved the third-order intermodulation distortion behavior of GaAs FET's. Higgins and Kuvas [11] showed that the intermodulation distortion could be reduced by tailoring the doping profiles of a GaAs FET. A reduction of about $6 \mathrm{~dB}$ in the third-order intermodulation distortion power levels was achieved.

However, nobody has addressed the use of a nonlinear Volterra series representation to analyze a complete MESFET model when the feedback capacitance $\left(\mathrm{C}_{\mathrm{gd}}\right)$ is included in the equivalent circuit and treated as a nonlinear element. At higher frequencies, the role of $\mathrm{C}_{\mathrm{gd}}$ in the amplifier gain is significant. Hence, a complete equivalent circuit of a MESFET model that includes $\mathrm{C}_{\mathrm{gd}}$ as a nonlinear element has been analyzed in this thesis by using the Volterra series representation. The assumed MESFET model includes four nonlinear elements $\left(\mathrm{C}_{\mathrm{gs}}, \mathrm{C}_{\mathrm{gd}}, \mathrm{i}_{\mathrm{d}}, \mathrm{g}_{\mathrm{ds}}\right)$. A new analytical expression for the 
third-order intermodulation distortion is derived. The effect of the source and load impedances on the transistor model can then be easily examined for optimum performance. Also, the effects of the nonlinear elements on MESFET amplifier behavior have been examined. The results from the analytical expression are compared with experimental data and previously published results, and good agreement was obtained in both cases. 


\section{CHAPTER II}

\section{DEVICE MODEL}

Figure 2.1 shows the small-signal nonlinear circuit model of a MESFET device. The circuit model contains linear and nonlinear elements.

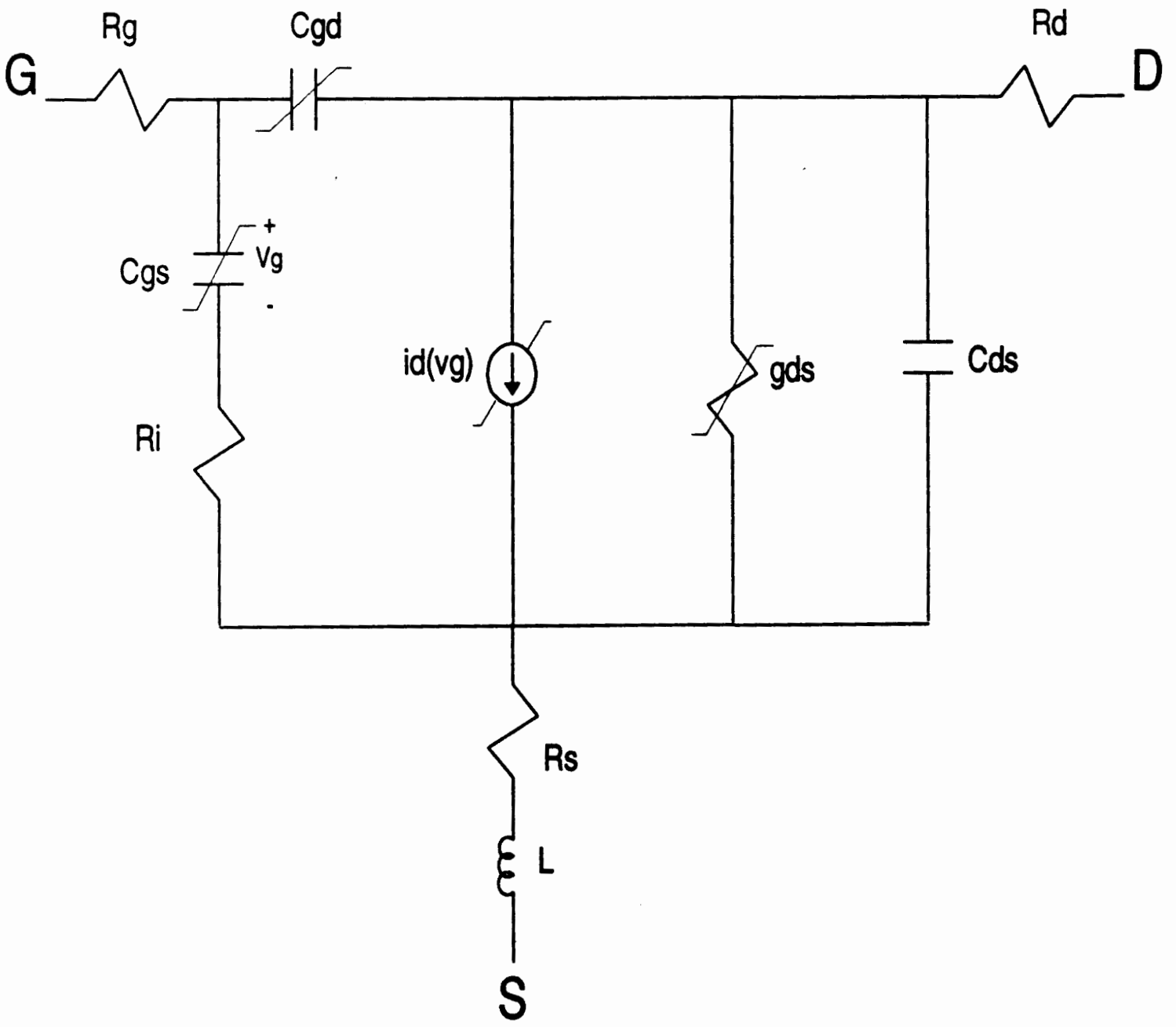

Figure 2.1. Small-signal nonlinear circuit model of a GaAs MESFET device. 


\section{Linear Elements}

The linear elements in the MESFET model consist of: 1) $R_{g}$ is the gate ohmic resistance, 2) $R_{d}$ is the drain ohmic contact resistance, 3) $R_{s}$ is the source ohmic resistance, 4) L is the source inductance, 5) $R_{i}$ is the charging resistance of the semiconductor region under the gate, and 6) $C_{d s}$ is the drainto-source capacitance. $R_{s}, R_{g}, R_{d}$, and $L$ represent the extrinsic parasitic elements. Source inductance $\mathrm{L}$ is treated as a separate element because it cannot be absorbed into the source or load impedances, and in some designs it is used for optimization of performance.

\section{Nonlinear Elements}

The MESFET model contains four nonlinearities: 1) gate-to-source capacitance $C_{g s}, 2$ ) gate-to-drain capacitance $C_{g d}, 3$ ) controlled drain current $i_{d}\left(v_{g}\right)$, and 4) drain-to-source conductance $g_{d s}$. The nonlinear elements can be characterized by the Taylor-series expansions of their $\mathrm{I} / \mathrm{V}$ or $\mathrm{Q} / \mathrm{V}$ characteristics measured at several DC bias points and they are modeled as follows:

Modeling of Nonlinear Capacitors. The nonlinear equivalent circuit contains two nonlinear capacitors $\left(\mathrm{C}_{\mathrm{gs}}\right.$ and $\left.\mathrm{C}_{\mathrm{gd}}\right)$. Each nonlinear capacitor charge depends on the voltage across the capacitor 


$$
Q_{c}=f_{d}(V)
$$

where $\mathrm{Q}_{c}$ is the capacitor charge. $\mathrm{V}$ is the $\mathrm{DC}$ control voltage. By expanding the charge function in a Taylor series, the small-signal component of the charge is

$$
q=\frac{d f_{d}(V)}{d V} v+\frac{1}{2} \frac{d^{2} f_{d}(V)}{d V^{2}} v^{2}+\frac{1}{6} \frac{d^{3} f_{d}(V)}{d V^{3}} v^{3}+\ldots
$$

where $q$ is the small-signal charge $(q(t)$ is written as $q$ for simplicity). $v$ is the small-signal AC voltage $(v(t)$ is written as $v$ for simplicity). Since $q=$ $\mathrm{Cv}$, then the above equation can be expressed as

$$
q=C_{1}(V) v+C_{2}\left(V v^{2}+C_{3}(V) v^{3}+\ldots\right.
$$

where $C_{n}(V)$ is the incremental capacitance at the voltage across its terminals.

The current through the capacitor is expressed as

$$
i=\frac{d q}{d t}=q V \frac{d v}{d t}
$$

Differentiating the charge in equations (2.2) and (2.3) gives 


$$
\begin{aligned}
i & =\frac{d f_{d}(V)}{d V} \frac{d v}{d t}+\frac{d^{2} f_{d}(V)}{d V^{2}} v \frac{d v}{d t}+\frac{1}{2} \frac{d^{3} f(V)}{d V^{3}} v^{2} \frac{d v}{d t}+\ldots \\
& =C_{1}(V) \frac{d v}{d t}+C_{2}(V) \frac{\left.d v^{2}\right]}{d t}+C_{3}(V) \frac{\left.d v^{3}\right]}{d t}+\ldots
\end{aligned}
$$

The gate-to-source capacitance $\left(C_{g s}\right)$ exhibits dependence on the gate bias voltage $\mathrm{V}_{\mathrm{GS}}$ and can be expressed as a power series around its operating point

$$
C_{g S S}\left(V_{G S}\right)=C_{g S 1}+C_{g S 2} V_{G S}+C_{g s 3} V_{G S}^{2}+\ldots
$$

The coefficients $C_{g s n}$ are derived by applying the least square curve fitting of experimentally measured $\mathrm{C}_{\mathrm{gs}}$ values at several $\mathrm{V}_{\mathrm{GS}}$ values for a given $V_{D S}$ value (Appendix $A$ ) or by using the expression

$$
C_{g S O}\left(V_{G S}\right)=\frac{C_{g S O}}{\left(1-\frac{V_{G S}}{\phi}\right)^{1 / 2}}
$$

where $\mathrm{C}_{\mathrm{gs} 0}$ is the zero-bias junction capacitance and $\phi$ is the diffusion potential (generally 0.7 to 0.8 volt) [7]. Equation (2.7) is used to determine the value of $\mathrm{C}_{\mathrm{gso}}$ at the bias point. Then the coefficients $\mathrm{C}_{\mathrm{gsn}}$ can be found by using the binomial expansion of equation (2.7).

The gate-to-drain capacitance $\left(\mathrm{C}_{\mathrm{gd}}\right)$ exhibits dependence on the gate-to- 
drain bias voltage $V_{G D}$, where $V_{G D}=V_{D S}-V_{G S}$, and can be expressed as a power series around its operating point

$$
C_{g d}\left(V_{C D}\right)=C_{g d l}+C_{g d z} V_{G D}+C_{g d 3} V_{G D}^{2}+\ldots
$$

The coefficients $\mathrm{C}_{\mathrm{gdn}}$ can be derived in the same way as $\mathrm{C}_{\mathrm{gsn}}$.

Modeling of Nonlinear Conductance. The nonlinear conductance can be described by its $\mathrm{I} / \mathrm{V}$ characteristics

$$
I=R V
$$

Expanding the current in a Taylor series, the small-signal current is given as

$$
i=\frac{d f V}{d V} v+\frac{1}{2} \frac{\left.d^{2} f V\right)}{d V^{2}} v^{2}+\frac{1}{6} \frac{d^{3} f V}{d V^{3}} v^{3}+\ldots
$$

The current through the conductance is expressed as

$$
i=g(V)
$$

where $g(V)$ is the incremental conductance at $V$. Expanding equation (2.11) in a Taylor series gives 


$$
i=g_{1}(V) v+g_{2}\left(V v^{2}+g_{3}(V) v^{3}+\ldots\right.
$$

The drain-to-source conductance $\left(\mathrm{g}_{\mathrm{ds}}\right)$ exhibits dependence on the drain bias voltage $V_{D S}$ and can be expressed as a power series around its operating point

$$
g_{d s}\left(V_{D S}\right)=g_{d s 1}+g_{d s 2} V_{D S}+g_{d s 3} V_{D S}^{2}+\ldots
$$

The coefficients $g_{d s n}$ are derived by applying the least square curve fitting of experimentally measured $g_{d s}$ at several $V_{D S}$ values for a given $V_{G S}$ value (Appendix A).

Modeling of Nonlinear Controlled Current. The nonlinear controlled drain current is dependent on $V_{G S}$, and it can be expressed by Taylor series expansions of its $\mathrm{I} / \mathrm{V}$ characteristics

$$
i_{d}=\frac{d I_{d}\left(V_{G S}\right)}{d V_{G S}} v_{g}+\frac{1}{2} \frac{d^{2} I_{d}\left(V_{G S}\right)}{d V_{G S}^{2}} v_{g}^{2}+\frac{1}{6} \frac{\left.d^{3} I_{d} V_{G S}\right)}{d V_{G S}^{3}} v_{g}^{3}+\ldots
$$

where $I_{d}\left(V_{G S}\right)$ is the large-signal gate-to-drain characteristic. The current through the controlled current source is expressed as

$$
i_{d}=g_{m}\left(V_{G S}\right) v_{g}
$$


where $\mathrm{g}_{\mathrm{m}}\left(\mathrm{V}_{\mathrm{Gs}}\right)$ is the incremental transconductance at $\mathrm{V}_{\mathrm{Gs}}$. Expanding equation (2.15) in a Taylor series gives

$$
i_{d}=g_{m l}\left(V_{G S}\right) v_{g}+g_{m x}\left(V_{G S}\right) v_{g}^{2}+g_{m g}\left(V_{G S}\right) v_{g}^{3}+\ldots
$$

The coefficients $g_{m n}$ can be derived by applying the least square curve fitting of experimentally measured $g_{m}$ values at several $V_{G s}$ values for a given $V_{D S}$ value (Appendix $A$ ). Further details on the extraction of the nonlinear elements and their values are given in Chapter IV. In general, equations (2.2) and (2.10) describe nonlinear elements and can be written as

$$
\begin{aligned}
& q(t)=c_{1} v(t)+c_{2} v^{2}(t)+c_{3} v^{3}(t)+\ldots \\
& x(t)=g_{1} v(t)+g_{2} v^{2}(t)+g_{3} v^{3}(t)+\ldots
\end{aligned}
$$

When voltages at two frequencies $\left(\omega_{1}\right.$ and $\left.\omega_{2}\right)$ are present across the nonlinear elements , $\pm n \omega_{1} \pm m \omega_{2}$ components are generated. Limiting the first-order voltage term to the third-order components gives us

$$
v(t)=v_{1}(t)+v_{2}(t)+v_{3}(t)
$$

where $v_{1}(t)$ consists of voltage components at $\omega_{1}$ and $\omega_{2}$. $v_{2}(t)$ consists of 
voltage components at $\pm 2 \omega_{1}, \pm 2 \omega_{2}, \omega_{1} \pm \omega_{2}$, and $\omega_{2} \pm \omega_{1} . v_{3}(t)$ consists of voltage components at $\pm 3 \omega_{1}, \pm 3 \omega_{2}, \pm 2 \omega_{1} \pm \omega_{2}$, and $\pm \omega_{1} \pm 2 \omega_{2}$. Limiting the second-order voltage term to the third-order frequency components gives us

$$
v^{2}(t)=v_{1}^{2}(t)+2 v_{1}(t) v_{2}(t)
$$

where $v_{1}{ }^{2}(t)$ term in equation (2.20) generates only second-order mixing products, and $2 v_{1}(t) v_{2}(t)$ term, represents the third-order products. Limiting the third-order voltage term to the third-order frequency components gives us

$$
v^{3}(t)=v_{1}^{3}(t)
$$

Substituting in equation (2.17) gives

$$
q(t)=q_{1}(t)+q_{2}(t)+q_{3}(t)
$$

where

$$
\begin{gathered}
q_{1}(t)=c_{1} v(t)=c_{1}\left[v_{1}(t)+v_{2}(t)+v_{3}(t]\right] \\
q_{2}(t)=c_{2} v_{1}^{2}(t) \\
q_{3}(t)=2 c_{2} v_{1}(t) v_{2}(t)+c_{3} v_{1}^{3}(t)
\end{gathered}
$$


where $q_{1}(t)$ represents the first-order component, $q_{2}(t)$ represents the secondorder component, and $\mathrm{q}_{3}(\mathrm{t})$ represents the third-order component.

Similarly equation (2.18) gives

$$
\lambda(t)=i_{1}(t)+i_{2}(t)+i_{3}(t)
$$

where

$$
\begin{gathered}
i_{1}(t)=g_{1} v(t)=g_{1}\left[v_{1}(t)+v_{2}(t)+v_{3}(t)\right] \\
i_{2}(t)=g_{2} v_{1}^{2}(t) \\
i_{3}(t)=2 g_{2} v_{1}(t) v_{2}(t)+g_{3} v_{1}^{3}(t)
\end{gathered}
$$

where $i_{1}(t)$ represents the first-order component, $i_{2}(t)$ represents the secondorder component, and $i_{3}(t)$ represents the third-order component. 


\section{CHAPTER III}

\section{NONLINEAR ANALYSIS USING VOLTERRA SERIES REPRESENTATION}

The MESFET small-signal amplifier model shown in Figure 2.1 is analyzed using Volterra series representation. Volterra series was introduced into nonlinear circuit analysis in 1942 by Wiener [12]. It is applicable primarily to weakly driven nonlinear circuits having multiple small-signal excitations, and it is most useful for evaluating nonlinear phenomena such as intermodulation characteristics [7]. An equivalent block diagram for the weakly nonlinear circuit model based upon the functional expansion is shown in Figure 3.1, and its output response can be expressed as follows:

$$
v_{o}(t)=\sum_{n=1}^{N} a_{n} v_{s}^{n}(t)=a_{1} v_{s}(t)+a_{2} v_{s}^{2}(t)+a_{3} v_{s}^{3}(t)+\ldots
$$

where $a_{n}, n=1 \ldots N$, is the coefficient of the $n$ th-degree term in the power series that characterizes the weakly nonlinear model.

The power series expansion in equation (3.1) gives good results for memoryless circuits only. In order to analyze a circuit with memory (i.e., contains capacitor and inductor elements), a modified form of equation (3.1), 
called Volterra series expansion can be used.

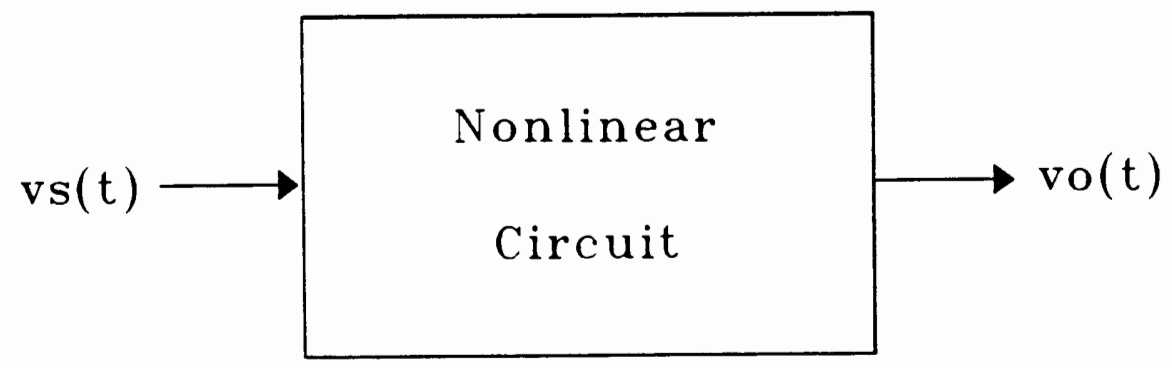

(a)

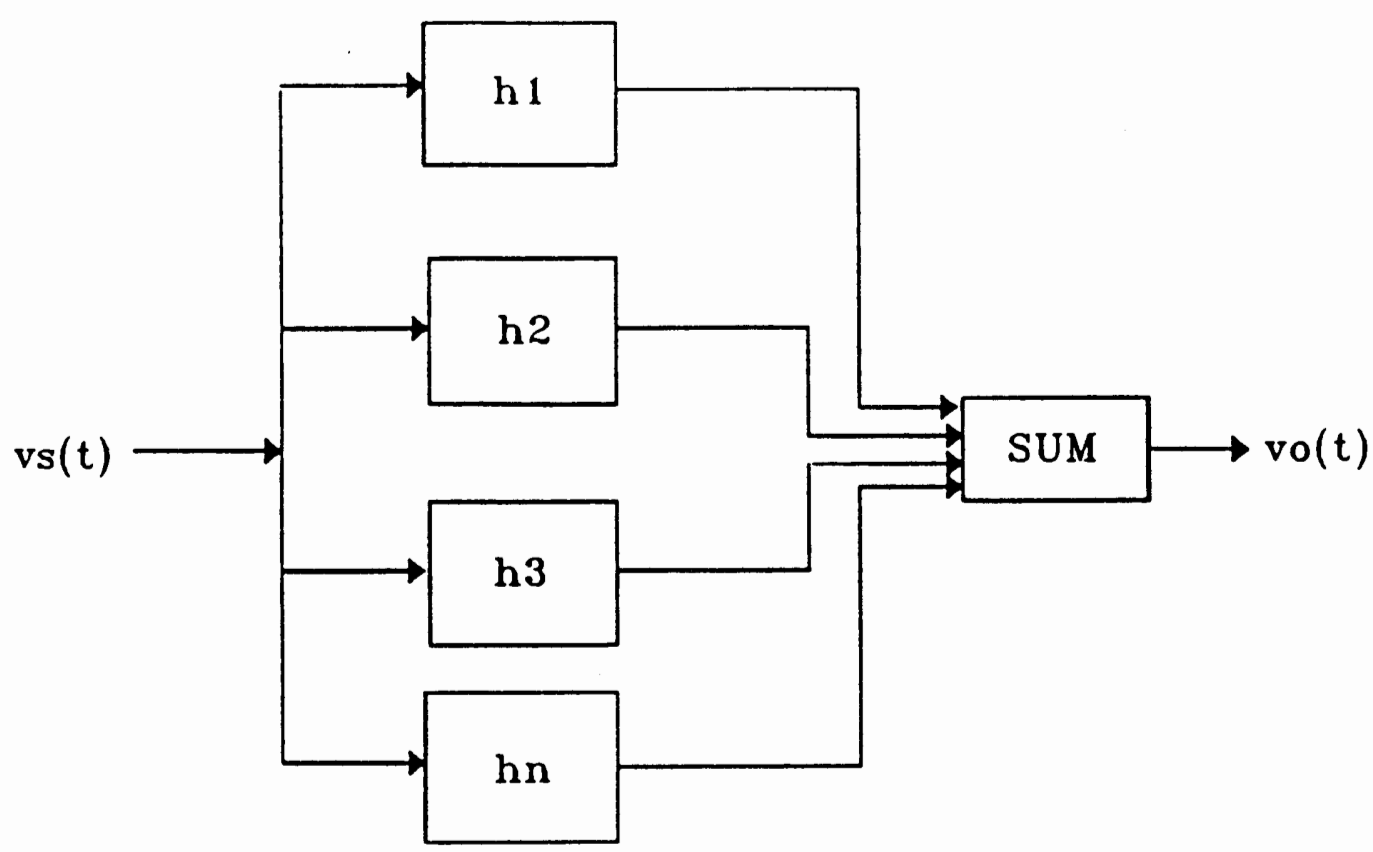

(b)

Figure 3.1. (a) Weakly nonlinear circuit model. (b) Functional expansion of the weakly nonlinear circuit model. 
The response of a weakly nonlinear circuit having small excitations $v_{s}(t)$ and nonlinear elements with memory can be expressed by the following functional series; called Volterra series expansion:

$$
\begin{aligned}
v_{o}(t) & =\int_{-\infty}^{\infty} h_{1}\left(\tau_{1}\right) v_{s}\left(t-\tau_{1}\right) d \tau_{1}+\iint_{-\infty}^{\infty} h_{2}\left(\tau_{1}, \tau_{2}\right) v_{s}\left(t-\tau_{1}\right) v_{s}\left(t-\tau_{2}\right) d \tau_{1} d \tau_{2} \\
& +\iiint_{-\infty}^{\infty} h_{3}\left(\tau_{1}, \tau_{2}, \tau_{3}\right) v_{s}\left(t-\tau_{1}\right) v_{s}\left(t-\tau_{2}\right) v_{s}\left(t-\tau_{3}\right) d \tau_{1} d \tau_{2} d \tau_{3}+\ldots
\end{aligned}
$$

where $v_{0}(t)$ is the total response of the nonlinear circuit model, and it is rewritten as

$$
v_{o}(t)=\sum_{n=1}^{N} v_{a n}(t)
$$

where

$$
v_{\alpha a}(t)=\iint \ldots \int_{-\infty}^{\infty} h_{n}\left(\tau_{1}, \tau_{2}, \ldots, \tau_{n}\right) v_{s}\left(t-\tau_{1}\right) v_{s}\left(t-\tau_{2}\right) \ldots v_{s}\left(t-\tau_{n}\right) d \tau_{1} d \tau_{2} \ldots d \tau_{n}
$$

and $h_{n}\left(\tau_{1}, \tau_{2}, \ldots, \tau_{n}\right)$ is called the nth-order Volterra kernel or the nth-order nonlinear impulse response. The nonlinear transfer function $H_{n}\left(\omega_{1}, \omega_{2}, \ldots\right.$ ,$\left.\omega_{n}\right)$ is the $n$-dimensional Fourier transform of $h_{n}\left(\tau_{1}, \tau_{2}, \ldots, \tau_{n}\right)$

$$
H_{n}\left(\omega_{1}, \omega_{2}, \ldots, \omega_{n}\right)=\iint \ldots \int_{-\infty}^{\infty} h_{n}\left(\tau_{1}, \tau_{2}, \ldots, \tau_{n}\right) e^{-\lambda\left(\omega_{1} \tau_{1}+\omega_{2} \tau_{2}+\ldots \omega_{n} \tau_{n}\right)} d t_{1} d t_{2} \ldots d t_{n}
$$

Conversely, 


$$
h_{n}\left(\tau_{1}, \tau_{2}, \ldots, \tau_{n}\right)=\frac{1}{(2 \pi)^{n}} \iint \ldots \int_{-\infty}^{\infty} H_{n}\left(\omega_{1}, \omega_{2}, \ldots, \omega_{n}\right) e^{\lambda\left(\omega_{1} \tau_{1}+\omega_{2} \tau_{2}+\ldots \omega_{n} \tau_{n}\right)} d \omega_{1} d \omega_{2} \ldots d \omega_{n}
$$

The input $v_{s}(t)$ in general contains more than one frequency, and when it has $\mathrm{Q}$ sinusoidal frequencies, it is expressed as

$$
v_{s}(t)=\frac{1}{2} \sum_{q=-Q}^{Q} V_{s q} e^{j \omega_{q} t}
$$

where $q=-Q$ to $Q$ and $q \neq 0$ is the range of the excitation frequencies.

Substituting (3.6) and (3.7) into (3.4) gives an expression for a single order of mixing products $v_{o n}(t)$ in the circuit's total response $v_{0}(t)$ :

$$
V_{\alpha a}(t)=\frac{1}{2^{n}} \sum_{q_{1}=-Q}^{Q} \sum_{\substack{q_{q^{\prime}}=-Q \\ q_{n} \neq 0}}^{Q} \ldots \sum_{q_{n}=-Q}^{Q} V_{s q_{1}} V_{s q_{2}} \ldots V_{s q_{n}} H_{n}\left(\omega_{q_{1}}, \omega_{q_{2}}, \ldots, \omega_{q_{n}}\right) e^{\lambda\left(\omega_{q_{1}}+\omega_{q_{2}}+\ldots \omega_{q_{d}} t\right.}
$$

Substituting (3.8) into (3.3) gives the total response $v_{0}(t)$ of the circuit in terms of the nonlinear transfer function:

$$
v_{o}(t)=\sum_{n=1}^{N} \frac{1}{2^{n}} \sum_{q_{1}=-Q}^{Q} \sum_{\substack{q_{2}=-Q \\ q_{n} \neq 0}}^{Q} \ldots \sum_{q_{n}=-Q}^{Q} V_{s q_{1}} V_{s q_{2}} \ldots V_{s q_{n}} H_{n}\left(\omega_{q_{1}}, \omega_{q_{2}}, \ldots, \omega_{q_{n}}\right) e^{\lambda\left(\omega_{q_{1}}+\omega_{q_{2}}+\ldots \omega_{q_{d}} t\right.}
$$

Calculation of the first-order transfer function $\mathrm{H}_{1}(\omega)$ is achieved by applying an input excitation signal ( $\mathrm{e}^{\mathrm{j} \omega t}$ ) and performing a linear analysis. 
The second-order transfer function $\mathrm{H}_{2}\left(\omega_{1}, \omega_{2}\right)$ is calculated by applying an input excitation signal $\left(\mathrm{e}^{\mathrm{j} \omega}{ }_{1} \mathrm{t}+\mathrm{e}^{\mathrm{j} \omega}{ }_{2} \mathrm{t}\right)$ and evaluating the output at frequency $\left(\omega_{1}+\omega_{2}\right)$, using the nonlinearity of the elements in the equivalent circuit. Similarly, the third-order transfer function $\mathrm{H}_{3}\left(\omega_{1}, \omega_{2}, \omega_{3}\right)$ is calculated by applying an input excitation signal $\left(\mathrm{e}^{\mathrm{j} \omega}{ }_{1} \mathrm{t}+\mathrm{e}^{\mathrm{j} \omega}{ }_{2} \mathrm{t}+\mathrm{e}^{\mathrm{j} \omega}{ }_{3} \mathrm{t}\right)$ and evaluating the output at frequency $\left(\omega_{1}+\omega_{2}+\omega_{3}\right)$, using the nonlinearity of the elements in the equivalent circuit. Now, we share the details of the method by applying it to the MESFET equivalent circuit in Figure 2.1. We begin by connecting the source impedance $\left(\mathrm{Z}_{\mathrm{s}}\right)$, load impedance $\left(\mathrm{Z}_{\mathrm{L}}\right)$, and a 2-tone input signal source (excitation source $\left.v_{s}(t)\right)$ at $\omega_{1}$ and $\omega_{2}$ to the device; the corresponding equivalent circuit is shown in Figure 3.2. First (linearized), second, and thirdorder transfer functions and intermodulation products (IM) for the amplifier model are calculated as follows:

\section{First-Order Transfer Functions}

The first-order transfer functions of the amplifier model are obtained by replacing each nonlinear element in Figure 3.2 (marked with / ) by the corresponding first-order values $\left(\mathrm{C}_{\mathrm{gs}}, \mathrm{C}_{\mathrm{gd} 1}, \mathrm{~g}_{\mathrm{m} 1}, \mathrm{~g}_{\mathrm{ds}}\right)$ and using linear circuit analysis techniques. 


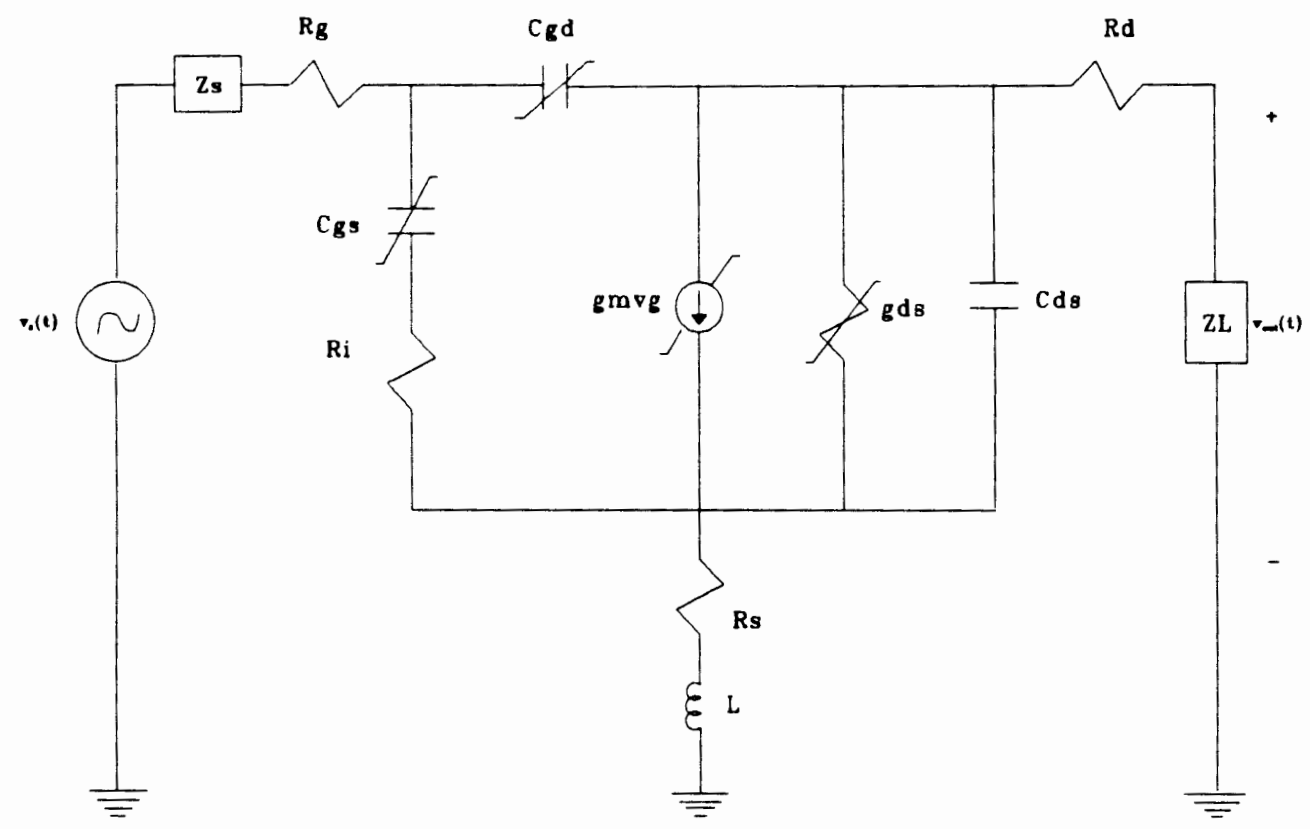

Figure 3.2. MESFET equivalent circuit.

In order to facilitate the analysis and for use in subsequent analysis, voltage transfer functions corresponding to the voltages across the nonlinear elements are introduced. These first-order transfer functions are defined below and calculated by a simple linear analysis.

Ratio of the voltage across $C_{g s}$ at $\omega$ to the excitation voltage at $\omega$ :

$$
H_{1 g}(\omega)=\frac{V_{g}}{V_{s}}=\frac{Y_{s}}{\Delta}\left(\frac{1}{1+R j \omega C_{g s I}}\right)\left(Y_{L}\left(Y_{D S}(\omega)+Y_{R L}(\omega)\right)+Y_{R L}(\omega)\left(Y_{D S}(\omega)+j \omega C_{g d l}\right)\right)
$$

Ratio of the voltage across $C_{g d}$ at $\omega$ to the excitation voltage at $\omega$ :

$$
H_{1 g d}(\omega)=\frac{V_{g d}}{V_{s}}=\frac{Y_{s}}{\Delta}\left(Y_{L}\left(j \omega C_{g e l}+g_{m e l}+Y_{D s}(\omega)+Y_{R L}(\omega)\right)+Y_{R L}(\omega)\left(Y_{D s}(\omega)+g_{m e l}\right)\right)
$$


Ratio of the voltage across $g_{d s}$ at $\omega$ to the excitation voltage at $\omega$ :

$$
H_{1 d s}(\omega)=\frac{V_{d s}}{V_{s}}=\frac{Y_{s}}{\Delta}\left(Y_{R L}(\omega)\left(j \omega C_{g d I^{\prime}} g_{m e s}\right)-Y_{L}\left(j \omega C_{g e I^{+}} g_{m e l}\right)\right)
$$

The first-order transfer function for the output $\left(v_{\text {out }}\right.$ at $\left.\omega\right)$ is derived as the ratio of the output voltage at $\omega$ to the applied excitation voltage at $\omega$ and it is calculated as

$$
H_{1}(\omega)=\frac{V_{o u t}}{V_{s}}=\frac{Y_{s}}{\Delta}\left(Y_{D S}(\omega) j \omega C_{g e l}-g_{m e l} Y_{R L}(\omega)+j \omega C_{g d}\left(j \omega C_{g e I}+g_{m e l}+Y_{D S}(\omega)+Y_{R L}(\omega)\right)\right)
$$

where

$$
\begin{aligned}
Y_{s} & =\frac{1}{Z_{s}+R_{g}} \\
Y_{L} & =\frac{1}{Z_{L}+R_{d}} \\
g_{m e} & =\frac{g_{m I}}{1+R j \omega C_{g s I}} \\
j \omega C_{g e I} & =j \omega \frac{C_{g s I}}{1+R_{j} j \omega C_{g s I}} \\
Y_{0}(\omega) & =Y_{D s}+j \omega C_{g d I}+Y_{L} \\
Y_{R L}(\omega) & =\frac{1}{R_{s}+j \omega L} \\
Y_{D S}(\omega) & =g_{d s I}+j \omega C_{d s}
\end{aligned}
$$

and

$$
\begin{aligned}
\Delta= & Y_{s}\left(Y_{D s}(\omega)\left(j \omega C_{g e l}+Y_{R L}(\omega)\right)+\left(j \omega C_{g d l}+Y_{D}\right)\left(j \omega C_{g e l}+g_{m e l}+Y_{D S}(\omega)+Y_{R L}(\omega)\right)\right) \\
& +j \omega C_{g d d}\left(\left(Y_{R L}(\omega)+Y_{D}\right)\left(Y_{D s}(\omega)+g_{m e l}\right)+Y_{L}\left(j \omega C_{g e I}+Y_{R L}\right)\right) \\
& +j \omega C_{g e d}\left(Y_{R L}(\omega)\left(Y_{D s}(\omega)+j \omega C_{g d l}\right)+Y_{L}\left(Y_{D S}(\omega)+Y_{R L}(\omega)\right)\right)
\end{aligned}
$$


$\underline{\text { Second-Order Nonlinear Transfer Functions }}$

The second-order transfer functions of the amplifier model are obtained by applying an input excitation voltage $\left(\mathrm{V}_{\mathrm{s}} \mathrm{e}^{\mathrm{j} \omega}{ }_{1}{ }_{1}+\mathrm{V}_{\mathrm{s}} \mathrm{e}^{\mathrm{j} \omega}{ }_{2}{ }^{\mathrm{t}}\right)$ to the second-order equivalent circuit (Figure 3.3). The four current sources at the frequency $\omega_{1}+\omega_{2}$, generated by the four nonlinear elements, are identified and connected across the nonlinear elements as shown in Figure 3.3. Then the output voltage at $\omega_{1}+\omega_{2}$ is calculated. The second-order transfer function $H_{2}\left(\omega_{1}, \omega_{2}\right)$ is defined as the output voltage at $\omega_{1}+\omega_{2}$ divided by the product of magnitudes of the excitation voltages at $\omega_{1}$ and $\omega_{2}$. The source voltage at $\omega_{1}+\omega_{2}$ is set to zero while calculating the responses at $\omega_{1}+\omega_{2}$. 


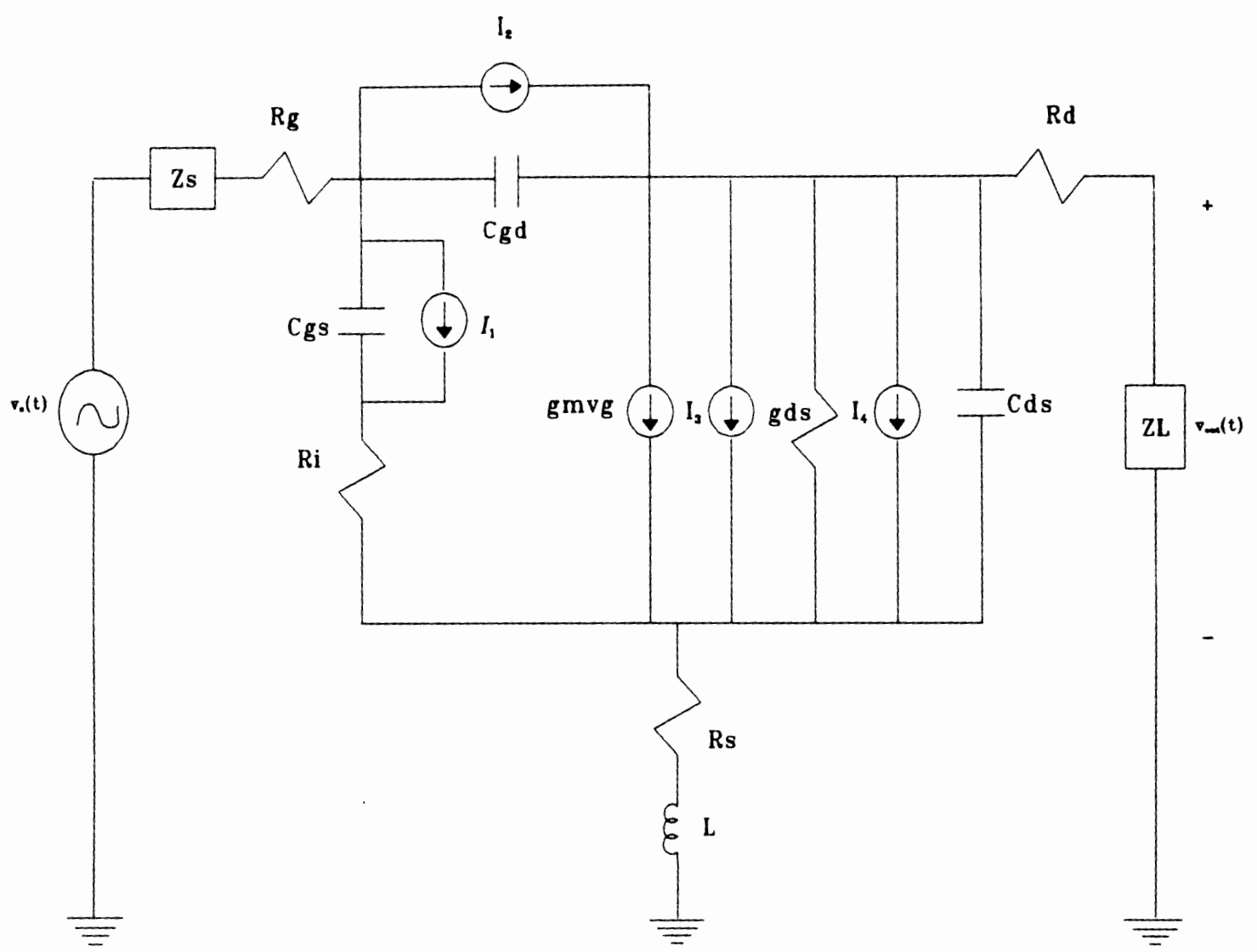

Figure 3.3. Second-order equivalent circuit.

where

$$
\begin{aligned}
v_{s}(t) & =V_{s} e^{j \omega_{1} t}+V_{s} e^{j \omega_{2} t} \\
v_{\text {our }}(t) & =V_{\text {out }} e^{\left.\lambda \omega_{1}+\omega_{2}\right) t}
\end{aligned}
$$

The second-order source currents at $\omega_{1}+\omega_{2}$ were derived by applying the second term of the incremental $\mathrm{L} / \mathrm{V}$ characteristics of the nonlinear elements given in (2.5), (2.12), and (2.16). There are four current components at the second-order mixing frequency $\omega^{\prime}=\omega_{1}+\omega_{2}$ due to the nonlinearities. The first current component $\left(I_{1}\right)$ is across the gate-to-source capacitance $\mathrm{C}_{\mathrm{gs}}$ and given by (using equation 2.24 ) 


$$
I_{1}=j \omega^{\prime} C_{g s 2} H_{1 g}\left(\omega_{1}\right) H_{1 g}\left(\omega_{2}\right) v_{s}^{2}
$$

where $\mathrm{H}_{\mathrm{lg}}\left(\omega_{1}\right) \mathrm{v}_{\mathrm{s}}$ is the first-order voltage across the gate-to-source capacitance $C_{\mathrm{gs}}$ at $\omega_{1}, \mathrm{H}_{1 \mathrm{~g}}\left(\omega_{2}\right) \mathrm{v}_{\mathrm{s}}$ is the first-order voltage across the gate-tosource capacitance $C_{g s}$ at $\omega_{2}, C_{g s 2}$ is the second-order nonlinear gate-tosource capacitance, and $\omega^{\prime}=\omega_{1}+\omega_{2} . H_{1 g}(\omega)$ is given by equation (3.10).

Similarly, the second current component $\left(\mathrm{I}_{2}\right)$ across the gate-to-drain capacitance $\mathrm{C}_{\mathrm{gd}}$ is given by (using equation (2.24))

$$
I_{2}=j \omega^{\prime} C_{g d 2} H_{1 g d}\left(\omega_{1}\right) H_{1 g d}\left(\omega_{2}\right) v_{s}^{2}
$$

where $\mathrm{H}_{1 \mathrm{gd}}\left(\omega_{1}\right) \mathrm{v}_{\mathrm{s}}$ is the first-order voltage across the gate-to-drain capacitance $C_{g d}$ at $\omega_{1}, H_{1 g d}\left(\omega_{2}\right) v_{s}$ is the first-order voltage across the gate-todrain capacitance $\mathrm{C}_{\mathrm{gd}}$ at $\omega_{2}, \mathrm{C}_{\mathrm{gd} 2}$ is the second-order nonlinear gate-to-drain capacitance, and $\omega^{\prime}=\omega_{1}+\omega_{2} . H_{1 \mathrm{gd}}(\omega)$ is given by equation (3.11).

The third current component $\left(\mathrm{I}_{3}\right)$ across the controlled current source (transconductance $g_{m}$ ) is given by (using equation (2.28))

$$
I_{3}=g_{m 2} H_{1 g}\left(\omega_{1}\right) H_{1 g}\left(\omega_{2}\right) v_{s}^{2}
$$

where $\mathrm{H}_{1 \mathrm{~g}}\left(\omega_{1}\right) \mathrm{v}_{\mathrm{s}}$ is the first-order voltage across the gate-to-source 
capacitance $\mathrm{C}_{\mathrm{gs}}$ at $\omega_{1}, \mathrm{H}_{\mathrm{lg}}\left(\omega_{2}\right) \mathrm{v}_{\mathrm{s}}$ is the first-order voltage across the gate-tosource capacitance $C_{g s}$ at $\omega_{2}, g_{m 2}$ is the second-order nonlinear transconductance, and $\omega^{\prime}=\omega_{1}+\omega_{2} . H_{1 g}(\omega)$ is given by equation (3.10).

Finally, the fourth current component $\left(\mathrm{I}_{4}\right)$ across the drain-to-source conductance $\mathrm{g}_{\mathrm{ds}}$ is given by (using equation (2.28))

$$
I_{4}=g_{d s 2} H_{1 d s}\left(\omega_{1}\right) H_{1 s s}\left(\omega_{2}\right) v_{s}^{2}
$$

where $\mathrm{H}_{1 \mathrm{ds}}\left(\omega_{1}\right) v_{\mathrm{s}}$ is the first-order voltage across the drain-to-source conductance $g_{d s}$ at $\omega_{1}, H_{1 d s}\left(\omega_{2}\right) v_{s}$ is the first-order voltage across the drainto-source conductance $g_{\mathrm{ds}}$ at $\omega_{2}, \mathrm{~g}_{\mathrm{ds} 2}$ is the second-order nonlinear drain-tosource conductance, and $\omega^{\prime}=\omega_{1}+\omega_{2} . H_{1 d s}(\omega)$ is given by equation (3.12).

These four second-order current sources at $\omega^{\prime}=\omega_{1}+\omega_{2}$ are shown in Figure 3.3 and a linear analysis of the equivalent circuit has been performed to obtain the second-order transfer functions in terms of the firstorder transfer functions.

Ratio of the voltage across $C_{g s}$ at $\omega_{1}+\omega_{2}$ to the product of the excitation voltages at $\omega_{1}$ and $\omega_{2}$ : 


$$
\begin{aligned}
& H_{2 \delta}\left(\omega_{1}, \omega_{2}\right)=\frac{V_{g}}{V_{s}^{2}}=\frac{1}{\Delta^{\prime}}\left[H _ { 1 g } ( \omega _ { 1 } ) H _ { 1 g } ( \omega _ { 2 } ) \left[-g_{m} f\left(\omega^{\prime} C_{g d d}\left(Y_{R L}\left(\omega^{\prime}\right)+Y_{s}^{\prime}\right)+Y_{L}^{\prime}\left(Y_{s}^{\prime}+j \omega^{\prime} C_{g d l}\right)\right)\right.\right. \\
& -j \omega^{\prime} C_{g S t}\left(Y_{R L}(\omega)\left(Y_{D S}(\omega)+\dot{j} \omega^{\prime} C_{g d L}\right)+Y_{L}^{\prime}\left(Y_{D S}(\omega)+Y_{R L}(\omega)\right)\right] \\
& -H_{1 g d}\left(\omega_{1}\right) H_{1 g d}\left(\omega_{2}\right) j \omega^{\prime} C_{g d d}\left(Y_{L}^{\prime}\left(Y_{D S}(\omega)+Y_{R L}(\omega)\right)+Y_{D s}(\omega)\left(Y_{R L}(\omega)+Y_{s}^{\prime}\right)\right) \\
& \left.-H_{1 \omega \sigma}\left(\omega_{1}\right) H_{10 s}\left(\omega_{2}\right) g_{d d s}\left(j \omega^{\prime} C_{g d l}\left(Y_{R L}(\omega)+Y_{s}^{\prime}\right)+Y_{L}^{\prime}\left(Y_{s}^{\prime}+j \omega^{\prime} C_{g d l}\right)\right)\right]\left(\frac{1}{1+R j \omega^{\prime} C_{g s l}}\right)
\end{aligned}
$$

Ratio of the voltage across $C_{g d}$ at $\omega_{1}+\omega_{2}$ to the product of the excitation voltages at $\omega_{1}$ and $\omega_{2}$ :

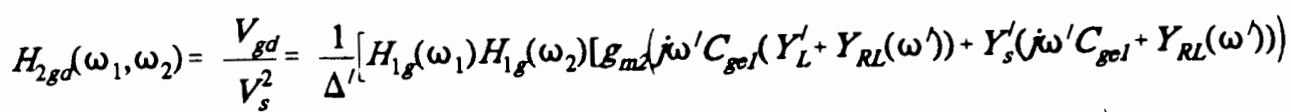

$$
\begin{aligned}
& \left.-j \omega^{\prime} C_{g s L}\left(\left(Y_{R L}(\omega)+Y_{D}^{\prime}\right)\left(g_{\text {mel }}^{\prime}+Y_{D S}(\omega)\right)+Y_{L}\left(Y_{R L}(\omega)+j \omega^{\prime} C_{g s t}\right)\right)\right] \\
& \left.-H_{1 g d}\left(\omega_{1}\right) H_{1 g d}\left(\omega_{2}\right) j \omega^{\prime} C_{g d t}\left(Y_{s}^{\prime}+Y_{L}^{\prime}+Y_{R L}(\omega)\right)\left(\omega^{\prime} C_{g e l}+g_{m e l}^{\prime}+Y_{R L}(\omega)\right)+Y_{D s}^{\prime}\left(Y_{s}^{\prime}+Y_{D}^{\prime}\right)\right\}
\end{aligned}
$$

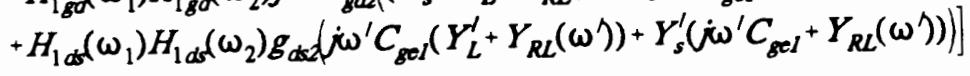

Ratio of the voltage across $g_{d s}$ at $\omega_{1}+\omega_{2}$ to the product of the excitation voltages at $\omega_{1}$ and $\omega_{2}$ :

$$
\begin{aligned}
& H_{2 d s}\left(\omega_{1}, \omega_{2}\right)=\frac{V_{d s}}{V_{s}^{2}}=\frac{1}{\Delta^{\prime}}\left[H _ { 1 g } ( \omega _ { 1 } ) H _ { 1 g } ( \omega _ { 2 } ) \left[\dot{\omega}^{\prime} C_{g c t}\left(Y_{R L}(\omega)\left(-j \omega^{\prime} C_{g d I}+g_{m e l}^{\prime}\right)+Y_{L}^{\prime}\left(\dot{\omega}^{\prime} C_{g e l}+g_{m e l}^{\prime}\right)\right)\right.\right. \\
& -g_{m 2}\left(\left(Y_{s}^{\prime}+Y_{L}^{\prime}+Y_{R L}(\omega)\right)\left(\omega^{\prime} C_{g d I^{\prime}}+\dot{\omega}^{\prime} C_{g o l}\right)+Y_{s}^{\prime}\left(Y_{R L}(\omega)-Y_{D}^{\prime}\right)\right] \\
& \left.+H_{1 g d}\left(\omega_{1}\right) H_{1 g d}\left(\omega_{2}\right) j \omega^{\prime} C_{g d t}\left(Y_{s}^{\prime}+Y_{L}^{\prime}+Y_{R L}(\omega)\right)\left(\dot{\omega}^{\prime} C_{g e I^{\prime}}+g_{\text {atel }}^{\prime}\right)+Y_{s}^{\prime} Y_{R L}(\omega)\right) \\
& \left.\left.-H_{1 \omega s}\left(\omega_{1}\right) H_{1 \omega s}\left(\omega_{2}\right) g_{d d l}\left(Y_{s}^{\prime}+Y_{L}^{\prime}+Y_{R L}(\omega)\right)\left(j \omega^{\prime} C_{g d l}+j \omega^{\prime} C_{g e l}\right)+Y_{s}^{\prime}\left(Y_{R L}(\omega)+Y_{L}^{\prime}\right)\right)\right]
\end{aligned}
$$

The second-order nonlinear transfer function for the output $\left(v_{\text {out }}\right.$ at $\left.\omega_{1}+\omega_{2}\right)$ is

$$
\begin{aligned}
& H_{2}\left(\omega_{1}, \omega_{2}\right)=\frac{V_{o u t}}{V_{s}^{2}}=\frac{1}{\Delta^{\prime}}\left[H_{1 g}\left(\omega_{1}\right) H_{1 g}\left(\omega_{2}\right)\left[-g_{m d} d Y_{s}^{\prime}\left(\omega^{\prime} C_{g e l}+Y_{R L}(\omega)\right)+Y_{R L}(\omega)\left(j \omega^{\prime} C_{g d l}+j \omega^{\prime} C_{g e l}\right)\right)\right] \\
& \left.+j \omega^{\prime} C_{g d d}\left(-j \omega^{\prime} C_{g d d}\left(j \omega^{\prime} C_{g e l}+g_{m e l}^{\prime}+Y_{D S}\left(\omega^{\prime}\right)+Y_{R L}\left(\omega^{\prime}\right)\right)+g_{\operatorname{mel}}^{\prime} Y_{R L}\left(\omega^{\prime}\right)-Y_{D S}\left(\omega^{\prime}\right) j \omega^{\prime} C_{g e t I}\right)\right] \\
& +H_{1 g d}\left(\omega_{1}\right) H_{1 g d}\left(\omega_{2}\right) j \omega^{\prime} C_{g d t}\left(Y_{s}^{\prime}\left(Y_{D s}(\omega)+Y_{R L}(\omega)\right)+\left(Y_{s}^{\prime}+Y_{R L}\left(\omega^{\prime}\right)\right)\left(\dot{\omega}^{\prime} C_{g e l}+g_{m e l}^{\prime}\right)\right)
\end{aligned}
$$

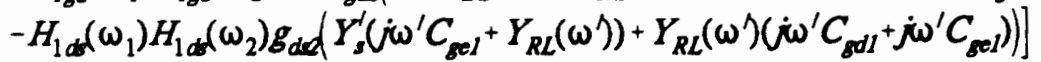




\section{Third-Order Nonlinear Transfer Function}

The third-order transfer functions of the amplifier model are obtained by applying an input excitation source $\left(\mathrm{V}_{\mathrm{s}} \mathrm{e}^{\mathrm{j} \omega_{1}}{ }_{1}+\mathrm{V}_{\mathrm{S}} \mathrm{e}^{\mathrm{j} \omega_{2}}{ }_{2}+\mathrm{V}_{\mathrm{s}} \mathrm{e}^{\left.\mathrm{j} \omega_{3}{ }^{\mathrm{t}}\right)}\right.$ to the thirdorder equivalent circuit (Figure 3.4) and calculating the currents at frequency $\omega_{1}+\omega_{2}+\omega_{3}$ generated by the four nonlinear elements. Then the output voltage at frequency $\omega_{1}+\omega_{2}+\omega_{3}$ due to these current sources is calculated.

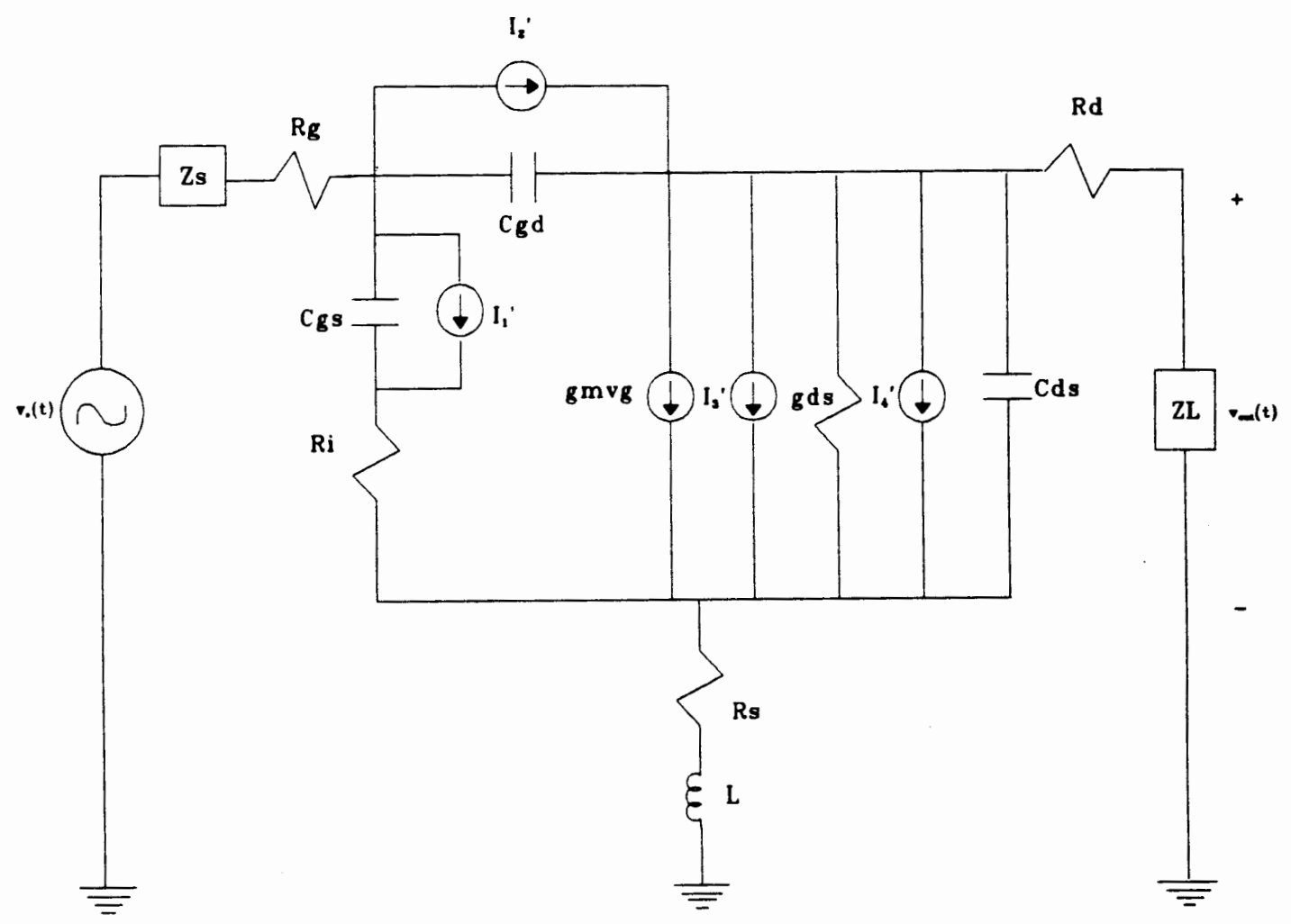

Figure 3.4. Third-order equivalent circuit.

where

$$
\begin{aligned}
V_{s}(t) & =V_{s} e^{j \omega_{1} t}+V_{s} e^{j \omega_{2} t}+V_{s} e^{j \omega_{s} t} \\
V_{\text {out }}(t) & =V_{\text {out }} e^{j\left(\omega_{1}+\omega_{2}+\omega_{s}\right) t}
\end{aligned}
$$


The third-order source currents were derived from the third term of the incremental $\mathrm{I} / \mathrm{V}$ characteristics of the nonlinear elements given in (2.5), (2.12), and (2.16). There are four current components at the third-order mixing frequency $\omega^{\prime \prime}=\omega_{1}+\omega_{2}+\omega_{3}$. The first current component $\left(\mathrm{I}_{1}{ }^{\prime}\right)$ is across the gate-to-source capacitance $\mathrm{C}_{\mathrm{gs}}$ and given by (using equation (2.25) and collecting components at $\left.\omega^{\prime \prime}=\omega_{1}+\omega_{2}+\omega_{3}\right)$

$$
I_{1}^{\prime}=2 j \omega^{\prime \prime} C_{g s 2} \overline{H_{1 g}\left(\omega_{1}\right) H_{2 g}\left(\omega_{2}, \omega_{3}\right)} v_{s}^{3}+j \omega^{\prime \prime} C_{g s s^{3}} H_{1 g}\left(\omega_{1}\right) H_{1 g}\left(\omega_{2}\right) H_{1 g}\left(\omega_{3}\right) v_{s}^{3}
$$

where $C_{g s 3}$ is the third-order gate-to-source capacitance, $\omega^{\prime \prime}=\omega_{1}+\omega_{2}+\omega_{3}$, $\mathrm{H}_{1 \mathrm{~g}}\left(\omega_{1}\right) \mathrm{v}_{\mathrm{s}}, \mathrm{H}_{1 \mathrm{~g}}\left(\omega_{2}\right) \mathrm{v}_{\mathrm{s}}$, and $\mathrm{H}_{1 \mathrm{~g}}\left(\omega_{3}\right) \mathrm{v}_{\mathrm{s}}$ are the first-order voltages across the gate-to-source capacitance $C_{g s}$ at $\omega_{1}, \omega_{2}$, and $\omega_{3}$ respectively, and $\mathrm{H}_{2 \mathrm{~g}}\left(\omega_{2}, \omega_{3}\right) \mathrm{V}_{\mathrm{s}}{ }^{2}$ is the second-order voltage across the gate-to-source capacitance $C_{g s}$ at $\omega_{2}+\omega_{3}$. The third-order current in equation (3.24) consists of two terms which represent the third-order products. The first term can be derived as the sum of the three terms where each term is a product of the first-order voltage at one of the frequencies and the second-order voltage at the sum of the other two frequencies. Both voltages are across the secondorder nonlinear gate-to-source capacitance $\mathrm{C}_{\mathrm{gs} 2}$. These generate a current $2 \mathrm{j}\left(\omega_{1}+\omega_{2}+\omega_{3}\right) \mathrm{C}_{\mathrm{gs} 2} \mathrm{~V}_{\mathrm{g}}\left(\omega_{1}\right) \mathrm{V}_{\mathrm{g}}\left(\omega_{2}, \omega_{3}\right)$ as given in the first term of equation 
(3.24), where the overbar indicates symmetrization over the frequencies. The second term can be derived as the product of the three first-order voltages across the third-order nonlinear gate-to-source capacitance $C_{g s 3}$ at $\omega_{1}, \omega_{2}$, and $\omega_{3}$. These generate a current $j\left(\omega_{1}+\omega_{2}+\omega_{3}\right) C_{g s 3} V_{g}\left(\omega_{1}\right) V_{g}\left(\omega_{2}\right) V_{g}\left(\omega_{3}\right)$ as given in the second term of equation (3.24).

Similarly, the second current component $\left(\mathrm{I}_{2}{ }^{\prime}\right)$ across the gate-to-drain capacitance $\mathrm{C}_{\mathrm{gd}}$ is given by (using equation (2.25) and collecting components at $\left.\omega^{\prime \prime}=\omega_{1}+\omega_{2}+\omega_{3}\right)$

$$
I_{2}^{\prime}=2 j \omega^{\prime \prime} C_{g d d^{d}} \overline{H_{18 d}\left(\omega_{1}\right) H_{28 d}\left(\omega_{2}, \omega_{3}\right)} v_{s}^{3}+j \omega^{\prime \prime} C_{g d s} H_{1 g d}\left(\omega_{1}\right) H_{18 d}\left(\omega_{2}\right) H_{18 d}\left(\omega_{3}\right) v_{s}^{3}
$$

where $C_{g d 3}$ is the third-order gate-to-drain capacitance, $\omega^{\prime \prime}=\omega_{1}+\omega_{2}+\omega_{3}$, $\mathrm{H}_{\mathrm{lgd}}\left(\omega_{1}\right) v_{\mathrm{s}}, \mathrm{H}_{\mathrm{lgd}}\left(\omega_{2}\right) \mathrm{v}_{\mathrm{s}}$, and $\mathrm{H}_{\mathrm{lgd}}\left(\omega_{3}\right) \mathrm{v}_{\mathrm{s}}$ are the first-order voltages across the gate-to-drain capacitance $C_{g d}$ at $\omega_{1}, \omega_{2}$, and $\omega_{3}$ respectively, and $\mathrm{H}_{2 \mathrm{gd}}\left(\omega_{2}, \omega_{3}\right) \mathrm{v}_{\mathrm{s}}{ }^{2}$ is the second-order voltage across the gate-to-drain capacitance $C_{g d}$ at $\omega_{2}$ and $\omega_{3}$. The third-order current in equation (3.25) consists of two terms which represent the third-order products. The first term can be derived as the sum of the three terms where each term is a product of the first-order voltage at one of the frequencies and the second-order voltage at the sum of the other two frequencies. Both voltages are across the 
second-order nonlinear gate-to-drain capacitance $\mathrm{C}_{\mathrm{gd} 2}$. These generate a current $2 \mathrm{j}\left(\omega_{1}+\omega_{2}+\omega_{3}\right) \mathrm{C}_{\mathrm{gd} 2} \mathrm{~V}_{\mathrm{gd}}\left(\omega_{1}\right) \mathrm{V}_{\mathrm{gd}}\left(\omega_{2}, \omega_{3}\right)$ as given in the first term of equation (3.25), where the overbar indicates symmetrization over the frequencies. The second term can be derived as the product of the three firstorder voltages across the third-order nonlinear gate-to-source capacitance $\mathrm{C}_{\mathrm{gd} 3}$ at $\omega_{1}, \omega_{2}$, and $\omega_{3}$. These generate a current $j\left(\omega_{1}+\omega_{2}+\omega_{3}\right) C_{g d 3}$ $\mathrm{V}_{\mathrm{gd}}\left(\omega_{1}\right) \mathrm{V}_{\mathrm{gd}}\left(\omega_{2}\right) \mathrm{V}_{\mathrm{gd}}\left(\omega_{3}\right)$ as given in the second term of equation (3.25).

The third current component $\left(\mathrm{I}_{3}\right)$ across the controlled current source (transconductance $g_{m}$ ) is given by (using equation (2.29) and collecting components at $\left.\omega^{\prime \prime}=\omega_{1}+\omega_{2}+\omega_{3}\right)$

$$
I_{3}^{\prime}=2 g_{m 2} \overline{H_{1 g}\left(\omega_{1}\right) H_{2 g}\left(\omega_{2}, \omega_{3}\right)} v_{s}^{3}+g_{m 3} H_{1 g}\left(\omega_{1}\right) H_{1 g}\left(\omega_{2}\right) H_{1 g}\left(\omega_{3}\right) v_{s}^{3}
$$

where $g_{\mathrm{m} 3}$ is the third-order transconductance, $\omega^{\prime \prime}=\omega_{1}+\omega_{2}+\omega_{3}, H_{1 g}\left(\omega_{1}\right) v_{s}$, $\mathrm{H}_{\mathrm{lg}}\left(\omega_{2}\right) \mathrm{v}_{\mathrm{s}}$, and $\mathrm{H}_{1 \mathrm{~g}}\left(\omega_{3}\right) \mathrm{v}_{\mathrm{s}}$ are the first-order voltages across the gate-to-source capacitance $C_{g s}$ at $\omega_{1}, \omega_{2}$, and $\omega_{3}$ respectively, and $H_{2 g}\left(\omega_{2}, \omega_{3}\right) v_{s}{ }^{2}$ is the second-order voltage across the gate-to-source capacitance $C_{g s}$ at $\omega_{2}$ and $\omega_{3}$. The third-order current in equation (3.26) consists of two terms which represent the third-order products. The first term can be derived as the sum of the three terms where each term is a product of the first-order voltage at 
one of the frequencies and the second-order voltage at the sum of the other two frequencies. Both voltages are across the second-order nonlinear transconductance $g_{m 2}$. These generate a current $2 g_{m 2} V_{g}\left(\omega_{1}\right) V_{g}\left(\omega_{2}, \omega_{3}\right)$ as given in the first term of equation (3.26), where the overbar indicates symmetrization over the frequencies. The second term can be derived as the product of the three first-order voltages across the third-order nonlinear controlled current $g_{m 3}$ at $\omega_{1}, \omega_{2}$, and $\omega_{3}$. These generate a current $g_{m 3}$ $\mathrm{V}_{\mathrm{g}}\left(\omega_{1}\right) \mathrm{V}_{\mathrm{g}}\left(\omega_{2}\right) \mathrm{V}_{\mathrm{g}}\left(\omega_{3}\right)$ as given in the second term of equation (3.26).

Finally, the fourth current component $\left(\mathrm{I}_{4}\right)$ across the drain-to-source capacitance $g_{d s}$ is given by (using equation (2.29) and collecting components at $\left.\omega^{\prime \prime}=\omega_{1}+\omega_{2}+\omega_{3}\right)$

$$
I_{4}^{\prime}=2 g_{d s 2} \overline{H_{10 s}\left(\omega_{1}\right) H_{2 \omega s}\left(\omega_{2}, \omega_{3}\right)} v_{s}^{3}+g_{d s} H_{1 \omega s}\left(\omega_{1}\right) H_{1 \alpha s}\left(\omega_{2}\right) H_{1 \alpha s}\left(\omega_{3}\right) v_{s}^{3}
$$

where $g_{d s 3}$ is the third-order drain-to-source conductance, $\omega^{\prime \prime}=\omega_{1}+\omega_{2}+\omega_{3}$, $H_{1 d s}\left(\omega_{1}\right) v_{s}, H_{1 d s}\left(\omega_{2}\right) v_{s}$, and $H_{1 d s}\left(\omega_{3}\right) v_{s}$ are the first-order voltages across the drain-to-source conductance $g_{d s}$ at $\omega_{1}, \omega_{2}$, and $\omega_{3}$ respectively, and $\mathrm{H}_{2 \mathrm{ds}}\left(\omega_{2}, \omega_{3}\right) \mathrm{v}_{\mathrm{s}}^{2}$ is the second-order voltage across the drain-to-source conductance $g_{d s}$ at $\omega_{2}$ and $\omega_{3}$. The third-order current in equation (3.27) consists of two terms which represent the third-order products. The first term 
can be derived as the sum of the three terms where each term is a product of the first-order voltage at one of the frequencies and the second-order voltage at the sum of the other two frequencies. Both voltages are across the second-order nonlinear drain-to-source conductance $\mathbf{g}_{\mathrm{ds} 2}$. These generate a current $2 \mathrm{~g}_{\mathrm{ds} 2} \mathrm{~V}_{\mathrm{ds}}\left(\omega_{1}\right) \mathrm{V}_{\mathrm{ds}}\left(\omega_{2}, \omega_{3}\right)$ as given in the first term of equation (3.27), where the overbar indicates symmetrization over the frequencies. The second term can be derived as the product of the three first-order voltages across the third-order nonlinear drain-to-source conductance $g_{d s 3}$ at $\omega_{1}, \omega_{2}$, and $\omega_{3}$. These generate a current $g_{d s 3} V_{d s}\left(\omega_{1}\right) V_{d s}\left(\omega_{2}\right) V_{d s}\left(\omega_{3}\right)$ as given in the second term of equation (3.27).

These four current sources are shown in Figure 3.4 and a linear analysis of the equivalent circuit has been performed to obtain the third-order nonlinear transfer function at the output $\left(v_{\text {out }}\right.$ at $\left.\omega_{1}+\omega_{2}+\omega_{3}\right)$

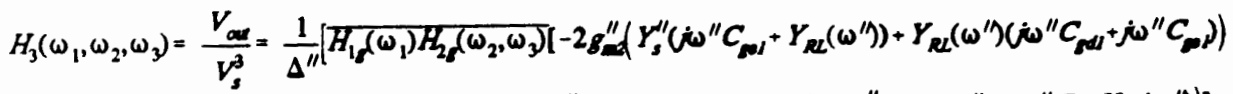

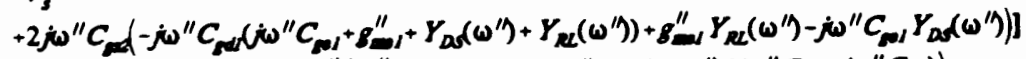

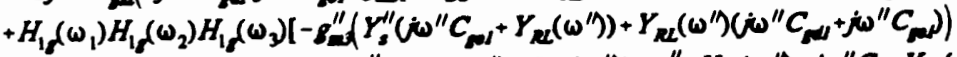

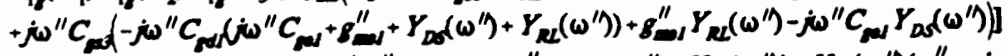

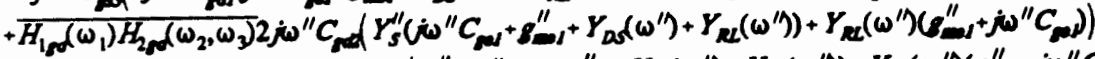

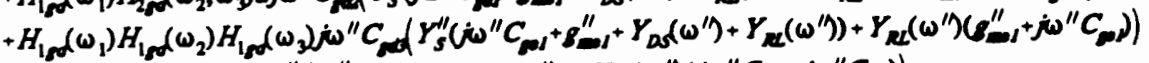

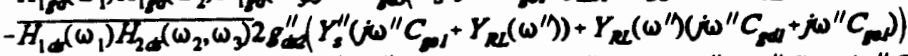

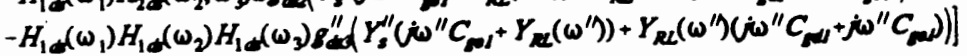

where the overbar indicates symmetrization over the frequencies $\omega_{1}, \omega_{2}$, and $\omega_{3}$ 
These nonlinear transfer functions will be used to calculate the thirdorder intermodulation distortion output power and intercept point in the next section.

\section{Computation of Intermodulation Distortion}

Intermodulation distortion products occur when more than one excitation frequency is applied to the nonlinear circuit model. Third-order intermodulation distortion products which occur at $2 \omega_{1}-\omega_{2}$ and $2 \omega_{2}-\omega_{1}$ are the greatest concern in this analysis because they are very close to signals that generate them and fall within the receiver's passband which produces distortion in the output. For example, if $f_{1}=729.75 \mathrm{MHz}$ and $f_{2}=730.25 \mathrm{MHz}$, then $2 f_{1}-f_{2}=729.25 \mathrm{MHz}$ and $2 f_{2}-f_{1}=730.75 \mathrm{MHz}$. Figure 3.5 shows the spectrum of intermodulation frequencies.
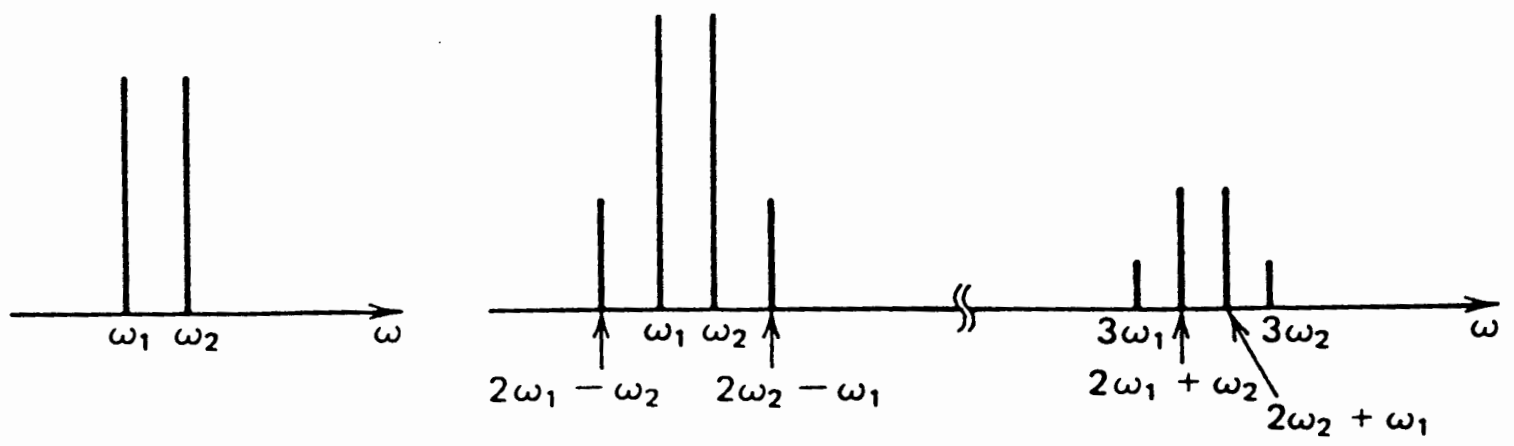

Figure 3.5. Intermodulation frequencies spectrum.

Assume the input signal $v_{s}(t)$ applied to the MESFET circuit model contains two frequencies $\omega_{1}$ and $\omega_{2}$ is given by 


$$
v_{s}(t)=V_{s} \cos \omega_{1} t+V_{s} \cos \omega_{2} t
$$

Then the linear output voltage at the fundamental frequency $\omega_{1}$ (the first-order output voltage) is given by

$$
V_{o l}=V_{s}\left|H_{1}\left(\omega_{1}\right)\right| \cos \left(\omega_{1} t+\angle H_{1}\left(\omega_{1}\right)\right)
$$

where $H_{1}\left(\omega_{1}\right)$ is given by equation (3.13).

The output voltages at the mixing frequencies $\omega_{1}-\omega_{2}$ and $2 \omega_{1}$ (the second-order output voltages) are given respectively by

$$
\begin{gathered}
V_{o 2}=\frac{V_{s}^{2}}{2}\left|H_{2}\left(\omega_{1},-\omega_{2}\right)\right| \cos \left(\left(\omega_{1}-\omega_{2}\right) t+\angle H_{2}\left(\omega_{1},-\omega_{2}\right)\right) \\
V_{o 2}=\frac{V_{s}^{2}}{2}\left|H_{2}\left(\omega_{1}, \omega_{1}\right)\right| \cos \left(2 \omega_{1} t+\angle H_{2}\left(\omega_{1}, \omega_{1}\right)\right)
\end{gathered}
$$

where $H_{2}\left(\omega_{1},-\omega_{2}\right)$ and $H_{2}\left(\omega_{1}, \omega_{1}\right)$ are given by equation (3.23).

The intermodulation output voltage at $2 \omega_{1}-\omega_{2}$ (the third-order output voltage) is given by

$$
V_{o 3}=\frac{3}{4} V_{s}^{3}\left|H_{3}\left(\omega_{1}, \omega_{1},-\omega_{2}\right)\right| \cos \left(\left(2 \omega_{1}-\omega_{2}\right) t+\angle H_{3}\left(\omega_{1}, \omega_{1},-\omega_{2}\right)\right)
$$

where $H_{3}\left(\omega_{1}, \omega_{1},-\omega_{2}\right)$ is given by equation (3.28). 
The first, second, and third-order powers delivered to the load impedance can be evaluated by substituting equations (3.30) through (3.33) into the general expression

$$
p_{a a^{\prime}}=10 \log \left[\operatorname{Re}\left(v_{a x} \frac{v_{a b}^{*}}{Z_{L}^{*}}\right)\right]
$$

where $n=1,2$, and 3 .

The third-order intermodulation distortion $\left(\mathrm{IM}_{3}\right)$ is defined as the ratio of the third-order intermodulation power at $2 \omega_{1}-\omega_{2}$ to the first-order power at $\omega_{1}$ and it is expressed in terms of the amplifier transfer functions [3]

$$
I M_{3}=20 \log \left(\frac{3}{4} V_{s}^{2} \frac{\left|H_{3}\left(\omega_{1}, \omega_{1},-\omega_{2}\right)\right|}{\left|H_{1}\left(\omega_{1}\right)\right|}\right)
$$

The third-order intercept point $\left(\mathrm{IP}_{3}\right)$ is defined as the output power at which the intermodulation distortion component equals the fundamental frequency output power. It is used to normalize the distortion performance of the device for the purpose of comparison and it is expressed as

$$
I P_{3}=\frac{3 p_{o 1}-p_{o 3}}{2}
$$


where $p_{01}$ is the linear output power at $\omega_{1}$ and $p_{03}$ is the intermodulation output power at $2 \omega_{1}-\omega_{2}$.

These analytical expressions will be used in the next Chapter to calculate MESFET intermodulation distortion performance and for comparison with experimental data. 


\section{CHAPTER IV}

\section{RESULTS \& COMPARISONS}

DC Experimental Measurements of the Device

Measurements were made on a E1718515 MESFET device with $0.5 \mu \mathrm{m}$ gate length at TriQuint Semiconductor and Figure 4.1 shows its smoothed DC I/V data.

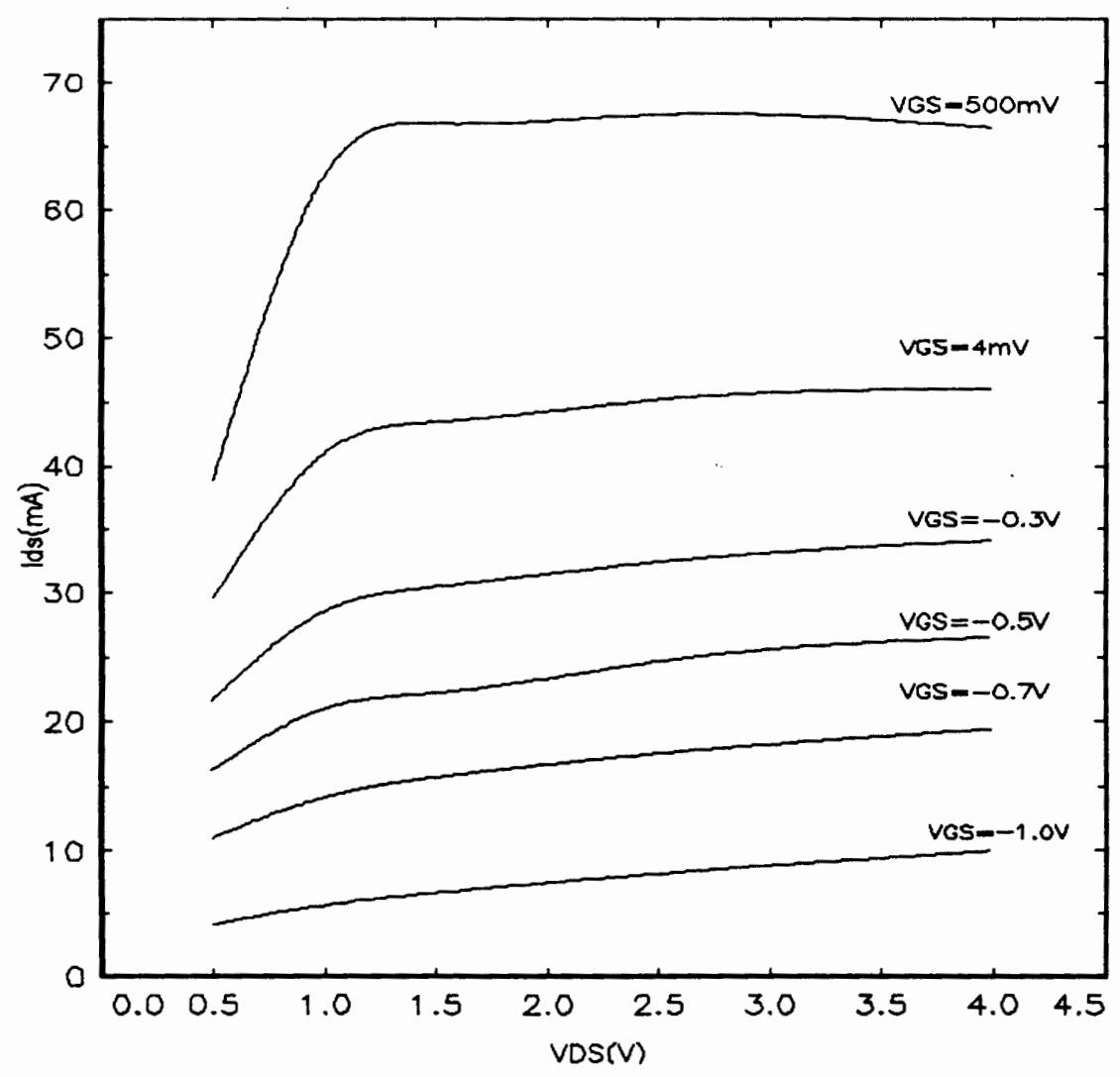

Figure 4.1. I/V characteristics of $0.5 \mu \mathrm{m}$ MESFET model. 
S-parameters of the MESFET device were measured at several bias points over the frequency ranges between 0.1 to $26.1 \mathrm{GHz}$ to extract the linear equivalent circuit shown in Figure 2.1. Table I shows a typical Sparameter data set $\left(\mathrm{V}_{\mathrm{DS}}=1.5 \mathrm{~V}\right.$ and $\left.\mathrm{V}_{\mathrm{GS}}=-0.5 \mathrm{~V}\right)$ and Table II shows values of the linear equivalent circuit elements at that bias point extracted through FetFitter.

TABLE I

S-PARAMETERS DATA SET AT $\mathrm{V}_{\mathrm{DS}}=1.5 \mathrm{~V}$ AND $\mathrm{V}_{\mathrm{GS}}=-0.5 \mathrm{~V}$

\begin{tabular}{|c|c|c|c|c|}
\hline $\begin{array}{c}\text { Frequency } \\
\text { (GHz) }\end{array}$ & $\mathrm{S} 11$ & $\mathrm{~S} 21$ & $\mathrm{~S} 12$ & $\mathrm{~S} 22$ \\
\hline 0.10 & $0.9998-\mathrm{j} 0.0270$ & $2.9575+\mathrm{j} 0.0620$ & $0.0003+\mathrm{j} 0.0033$ & $0.6178-\mathrm{j} 0.0116$ \\
2.10 & $0.8362-\mathrm{j} 0.4996$ & $-2.5596+\mathrm{j} 1.1567$ & $0.0215+\mathrm{j} 0.0590$ & $0.5628-\mathrm{j} 0.1989$ \\
4.10 & $0.5047-\mathrm{j} 0.7696$ & $-1.7677+\mathrm{j} 1.7680$ & $0.0647+\mathrm{j} 0.0856$ & $0.4502-\mathrm{j} 0.3191$ \\
6.10 & $0.1899-\mathrm{j} 0.8483$ & $-1.0261+\mathrm{j} 1.9051$ & $0.1043+\mathrm{j} 0.0896$ & $0.3435-\mathrm{j} 0.3807$ \\
8.10 & $-0.0507-\mathrm{j} 0.8231$ & $-0.4576+\mathrm{j} 1.7981$ & $0.1327+\mathrm{j} 0.0793$ & $0.2565-\mathrm{j} 0.4074$ \\
10.10 & $-0.2253-\mathrm{j} 0.7612$ & $-0.0662+\mathrm{j} 1.6149$ & $0.1517+\mathrm{j} 0.0639$ & $0.1870-\mathrm{j} 0.4202$ \\
12.10 & $-0.3457-\mathrm{j} 0.6905$ & $0.1935+\mathrm{j} 1.3997$ & $0.1642+\mathrm{j} 0.0492$ & $0.1340-\mathrm{j} 0.4319$ \\
14.10 & $-0.4346-\mathrm{j} 0.6217$ & $0.3737+\mathrm{j} 1.2032$ & $0.1715+\mathrm{j} 0.0340$ & $0.0857-\mathrm{j} 0.4403$ \\
16.10 & $-0.4965-\mathrm{j} 0.5585$ & $0.4856+\mathrm{j} 1.0238$ & $0.1757+\mathrm{j} 0.0206$ & $0.0458-\mathrm{j} 0.4447$ \\
18.10 & $-0.5461-\mathrm{j} 0.5012$ & $0.5627+\mathrm{j} 0.8625$ & $0.1775+\mathrm{j} 0.0084$ & $0.0058-\mathrm{j} 0.4550$ \\
20.10 & $-0.5671-\mathrm{j} 0.4433$ & $0.5844+\mathrm{j} 0.7279$ & $0.1626-\mathrm{j} 0.0047$ & $-0.0036-\mathrm{j} 0.4480$ \\
22.10 & $-0.6052-\mathrm{j} 0.4126$ & $0.6385+\mathrm{j} 0.5988$ & $0.1778-\mathrm{j} 0.0046$ & $-0.0629-\mathrm{j} 0.4825$ \\
24.10 & $-0.6383-\mathrm{j} 0.3714$ & $0.6525+\mathrm{j} 0.4915$ & $0.1735-\mathrm{j} 0.0129$ & $-0.1000-\mathrm{j} 0.4837$ \\
26.10 & $-0.6664-\mathrm{j} 0.3322$ & $0.6729+\mathrm{j} 0.4437$ & $0.1792-\mathrm{j} 0.0129$ & $-0.1476-\mathrm{j} 0.4875$ \\
\hline
\end{tabular}




\section{TABLE II}

LINEAR EQUIVALENT CIRCUIT ELEMENT VALUES AT $\mathrm{V}_{\mathrm{DS}}=1.5 \mathrm{~V}$ AND $\mathrm{V}_{\mathrm{GS}}=-0.5 \mathrm{~V}$

\begin{tabular}{|c|c|c|c|c|c|c|c|c|c|}
\hline $\begin{array}{c}\mathrm{C}_{\mathrm{gsl}} \\
\mathrm{pf}\end{array}$ & $\begin{array}{c}\mathrm{C}_{\mathrm{gdl}} \\
\mathrm{pf}\end{array}$ & $\begin{array}{c}\mathrm{C}_{\mathrm{ds}} \\
\mathrm{pf}\end{array}$ & $\begin{array}{c}\mathrm{g}_{\mathrm{ml}} \\
\mathrm{ms}\end{array}$ & $\begin{array}{c}\mathrm{g}_{\mathrm{dsl}} \\
\mathrm{ms}\end{array}$ & $\begin{array}{c}\mathrm{R}_{\mathrm{g}} \\
\text { ohms }\end{array}$ & $\begin{array}{c}\mathrm{R}_{\mathrm{d}} \\
\text { ohms }\end{array}$ & $\begin{array}{c}\mathrm{R}_{\mathrm{i}} \\
\text { ohms }\end{array}$ & $\begin{array}{c}\mathrm{R}_{\mathrm{s}} \\
\text { ohms }\end{array}$ & $\begin{array}{c}\mathrm{L} \\
\mathrm{pH}\end{array}$ \\
\hline 0.272 & 0.061 & 0.088 & 40.17 & 5.17 & 1.0 & 5.59 & 3.57 & 1.44 & 1.18 \\
\hline
\end{tabular}

The above procedure was repeated at several bias points, and at each bias point the equivalent circuit element values were obtained for use in developing a nonlinear model. Table III shows the nonlinear element values at several bias points.

The $\mathrm{C} / \mathrm{V}$ characteristic curves of $\mathrm{C}_{\mathrm{gs}}$ and $\mathrm{C}_{\mathrm{gd}}$ are shown in Figure 4.2 and Figure 4.3. The $\mathrm{G} / \mathrm{V}$ characteristic curves of $\mathrm{g}_{\mathrm{m}}$ and $\mathrm{g}_{\mathrm{ds}}$ are shown in Figure 4.4 and Figure 4.5. Also, the I/V characteristic curve of the controlled current source is shown in Figure 4.6. The nature of these characteristics agrees with that of similar data reported in the literature [7]. For example, $\mathrm{C}_{\mathrm{gs}}$ decreases for larger negative bias voltage $\mathrm{V}_{\mathrm{GS}}$ and curves do not cross over each other (Figure 4.2). Similarly, $\mathrm{C}_{\mathrm{gd}}$ decreases for larger bias voltage $V_{G D}$ and curves do not cross over each other (Figure 4.3). In Figure 4.4, $g_{m}$ curves are highly nonlinear but $I_{d s}$ versus $V_{G S}$ in Figure 4.6 shows a slightly cubic trend but not a high degree of nonlinearity. This is expected from 
MESFET's. In general, not much data are reported on $g_{d s}$ (Figure 4.5) in the literature. Our goal is not trying to probe device physics in detail but rather to build a good nonlinear model for the device at a chosen bias point.

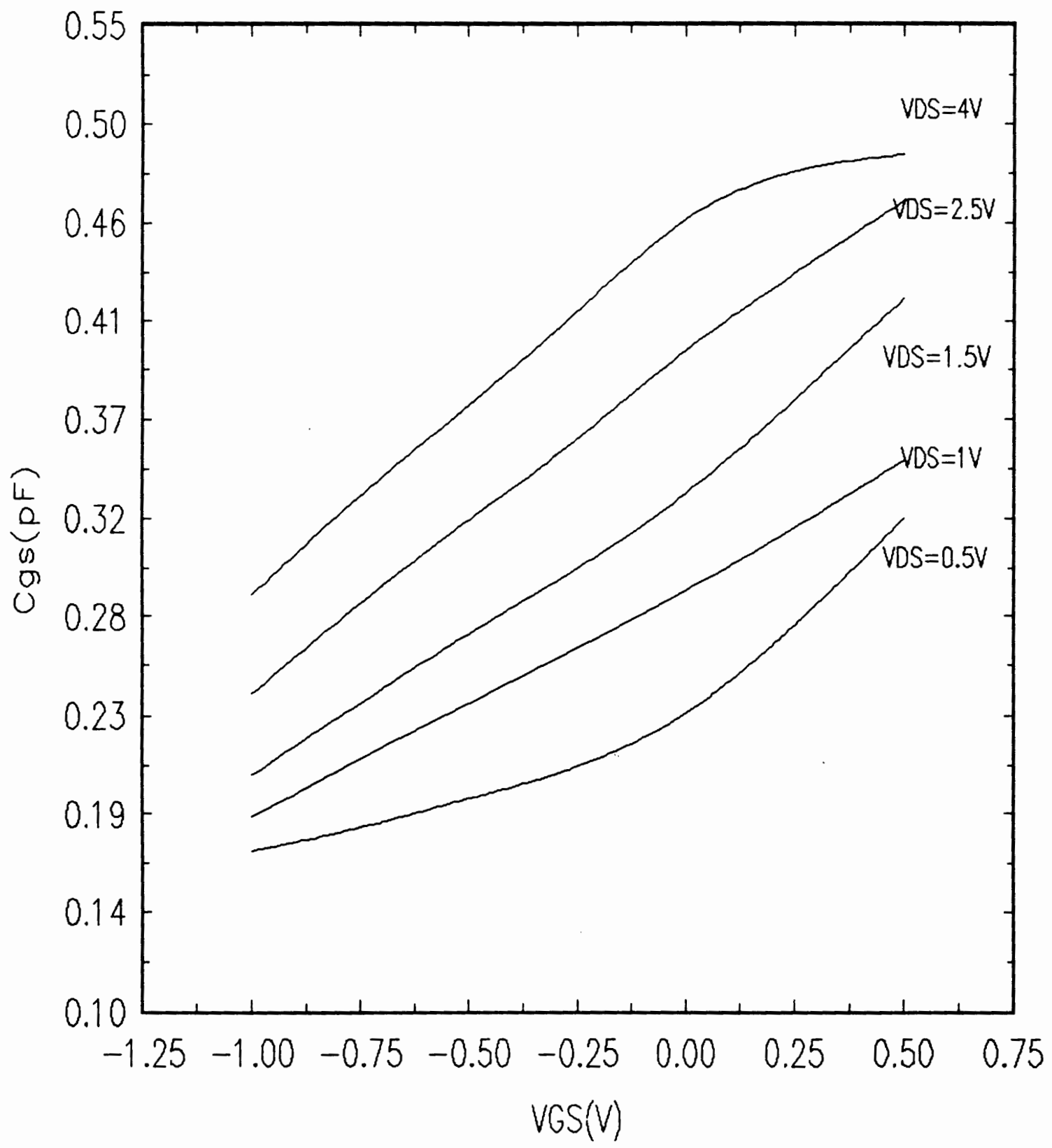

Figure 4.2. Measured $\mathrm{C}_{\mathrm{gs}}\left(\mathrm{V}_{\mathrm{GS}}\right)$ characteristics of MESFET model. 
TABLE III

NONLINEAR EQUIVALENT CIRCUIT ELEMENT VALUES AT SEVERAL BIAS POINTS

\begin{tabular}{|c|c|c|c|c|c|c|c|c|}
\hline $\begin{array}{c}\mathrm{V}_{\mathrm{DS}} \\
\mathrm{V}\end{array}$ & $\begin{array}{c}\mathrm{V}_{\mathrm{GS}} \\
\mathrm{V}\end{array}$ & $\begin{array}{c}\mathrm{V}_{\mathrm{GD}} \\
\mathrm{V}\end{array}$ & $\begin{array}{c}\mathrm{I}_{\mathrm{DS}} \\
\mathrm{mA}\end{array}$ & $\begin{array}{c}\mathrm{I}_{\mathrm{DSs}} \\
\%\end{array}$ & $\begin{array}{c}\mathrm{C}_{\mathrm{gs}} \\
\mathrm{pf}\end{array}$ & $\begin{array}{c}\mathrm{C}_{\mathrm{gd}} \\
\mathrm{pf}\end{array}$ & $\begin{array}{c}\mathrm{g}_{\mathrm{m}} \\
\mathrm{ms}\end{array}$ & $\begin{array}{c}\mathrm{g}_{\mathrm{ds}} \\
\mathrm{ms}\end{array}$ \\
\hline 0.5 & -1 & 1.5 & 4.1 & 13.85 & 0.173 & 0.103 & 19.06 & 6.06 \\
& -0.7 & 1.2 & 11.0 & 37.16 & 0.186 & 0.120 & 27.98 & 13.62 \\
& -0.5 & 1.0 & 16.3 & 55.06 & 0.197 & 0.135 & 31.56 & 22.48 \\
& -0.3 & 0.8 & 21.6 & 72.97 & 0.208 & 0.154 & 34.47 & 38.55 \\
& 0.0 & 0.5 & 29.6 & 100.00 & 0.236 & 0.179 & 35.15 & 71.73 \\
& 0.5 & 0.0 & 38.9 & 131.41 & 0.325 & 0.219 & 29.76 & 126.42 \\
\hline 1.0 & -1 & 2.0 & 5.6 & 13.69 & 0.188 & 0.080 & 23.88 & 4.39 \\
& -0.7 & 1.7 & 14.1 & 34.47 & 0.220 & 0.081 & 34.31 & 6.64 \\
& -0.5 & 1.5 & 20.9 & 51.10 & 0.240 & 0.081 & 39.13 & 8.04 \\
& -0.3 & 1.3 & 28.4 & 69.43 & 0.260 & 0.082 & 42.99 & 9.50 \\
& 0.0 & 1.0 & 40.9 & 100.00 & 0.292 & 0.089 & 47.65 & 13.08 \\
& 0.5 & 0.5 & 62.7 & 153.30 & 0.351 & 0.123 & 50.03 & 26.74 \\
\hline 1.5 & -1 & 2.5 & 6.6 & 15.20 & 0.208 & 0.067 & 25.95 & 3.71 \\
& -0.7 & 2.2 & 15.6 & 35.94 & 0.245 & 0.064 & 35.06 & 4.90 \\
& -0.5 & 2.0 & 22.7 & 52.30 & 0.272 & 0.061 & 40.17 & 5.17 \\
& -0.3 & 1.8 & 30.4 & 70.04 & 0.296 & 0.059 & 43.71 & 5.50 \\
& 0.0 & 1.5 & 43.4 & 100.00 & 0.337 & 0.055 & 48.94 & 5.84 \\
& 0.5 & 1.0 & 66.7 & 153.68 & 0.426 & 0.047 & 57.98 & 6.46 \\
\hline 2.5 & -1 & 3.5 & 8.1 & 17.92 & 0.245 & 0.049 & 27.41 & 2.99 \\
& -0.7 & 3.2 & 17.5 & 38.71 & 0.294 & 0.044 & 35.91 & 3.28 \\
& -0.5 & 3.0 & 24.6 & 54.42 & 0.324 & 0.039 & 39.40 & 3.31 \\
& -0.3 & 2.8 & 32.4 & 71.68 & 0.353 & 0.037 & 42.48 & 3.23 \\
& 0.0 & 2.5 & 45.2 & 100.00 & 0.402 & 0.031 & 45.99 & 2.98 \\
& 0.5 & 2.0 & 67.4 & 149.11 & 0.470 & 0.018 & 51.65 & 1.76 \\
\hline 4.0 & -1 & 5.0 & 10.0 & 21.73 & 0.290 & 0.035 & 27.72 & 2.44 \\
& -0.7 & 4.7 & 19.4 & 42.17 & 0.344 & 0.031 & 34.90 & 2.46 \\
& -0.5 & 4.5 & 26.5 & 57.60 & 0.376 & 0.029 & 38.05 & 2.38 \\
& -0.3 & 4.3 & 34.1 & 74.13 & 0.410 & 0.026 & 40.17 & 2.23 \\
& 0.0 & 4.0 & 46.0 & 100.00 & 0.462 & 0.020 & 41.74 & 1.86 \\
& 0.5 & 3.5 & 66.4 & 144.34 & 0.491 & 0.016 & 47.19 & 1.51 \\
\hline
\end{tabular}




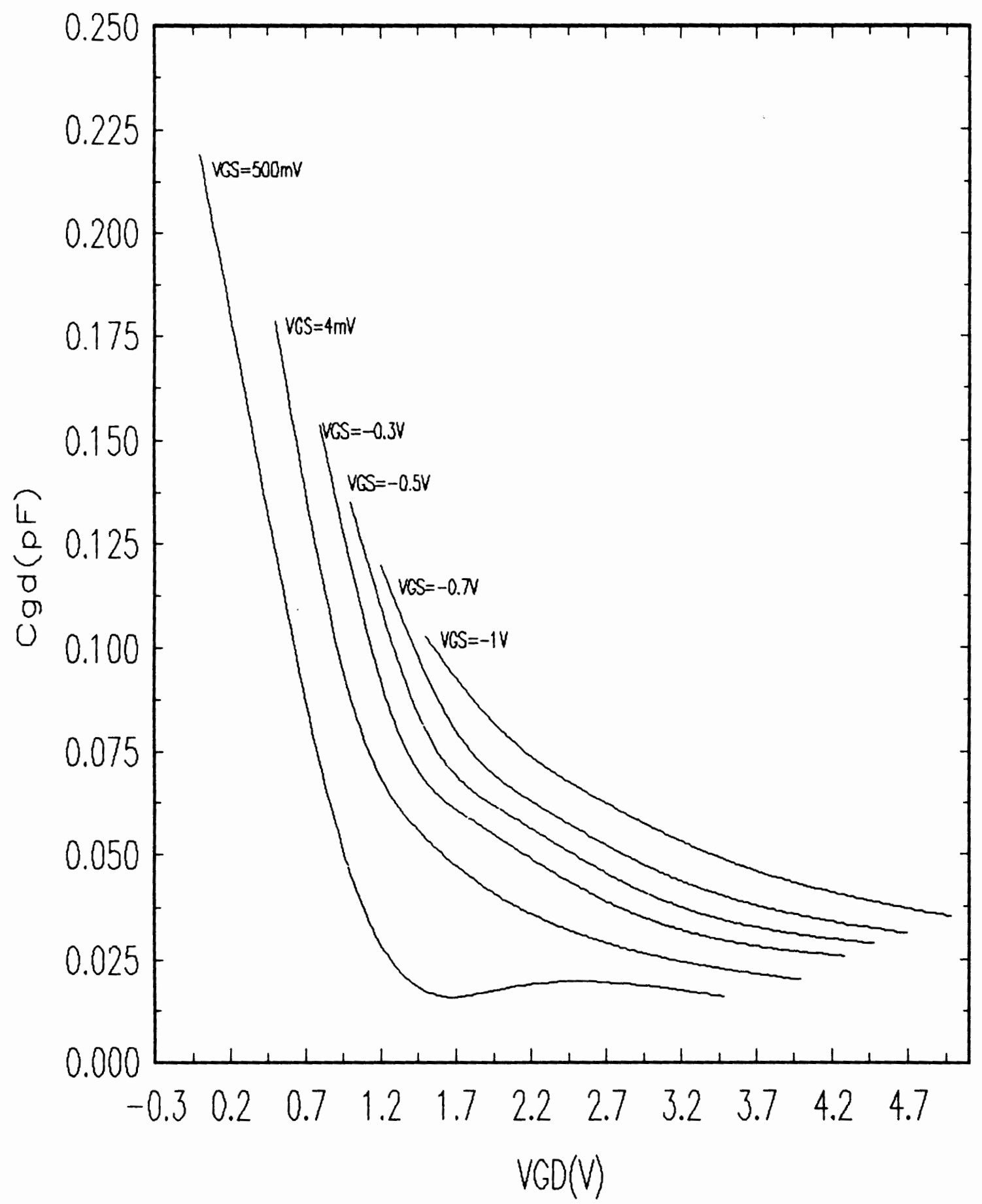

Figure 4.3. Measured $\mathrm{C}_{\mathrm{gd}}\left(\mathrm{V}_{\mathrm{GD}}\right)$ characteristics of MESFET model. 


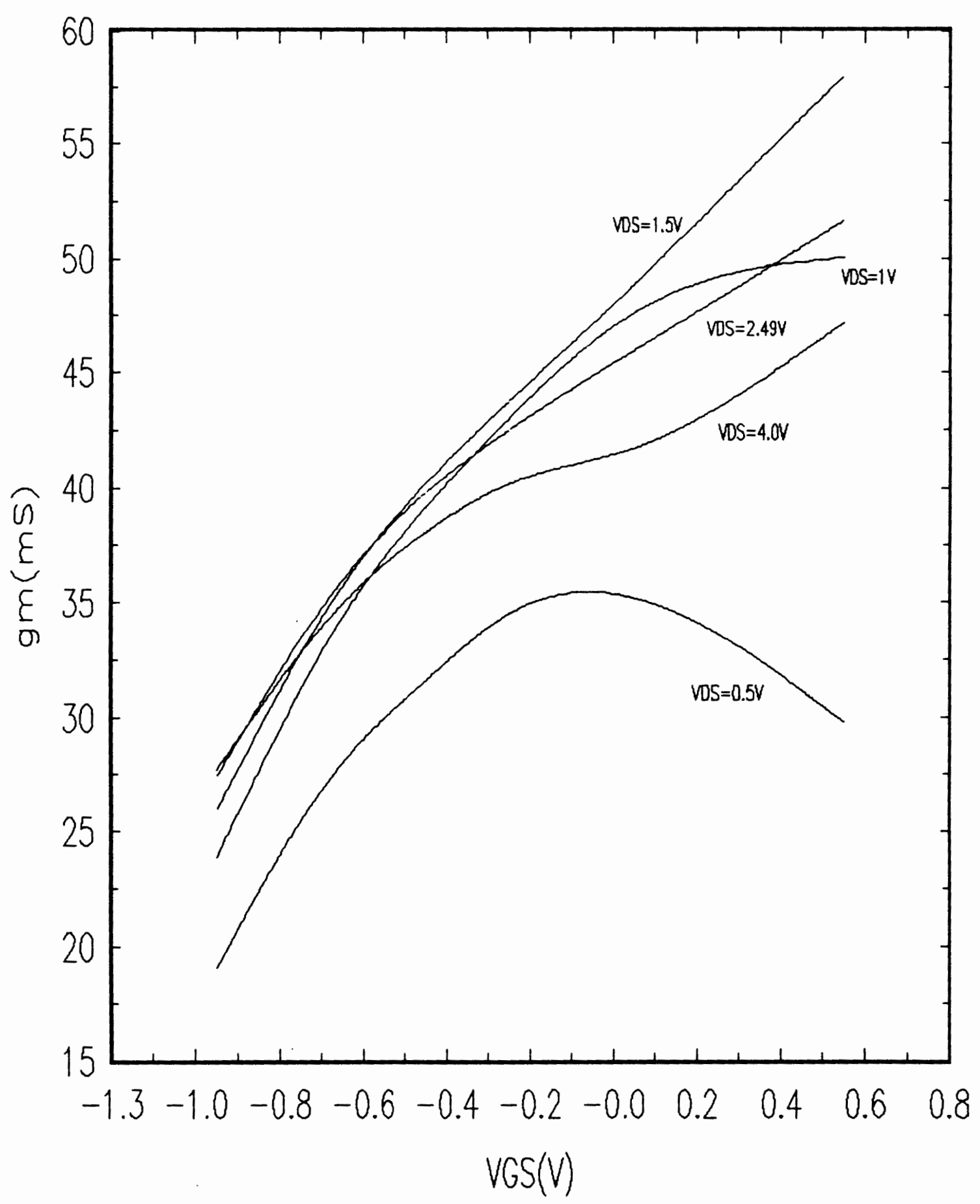

Figure 4.4. Measured $\mathrm{g}_{\mathrm{m}}\left(\mathrm{V}_{\mathrm{GS}}\right)$ characteristics of MESFET model. 


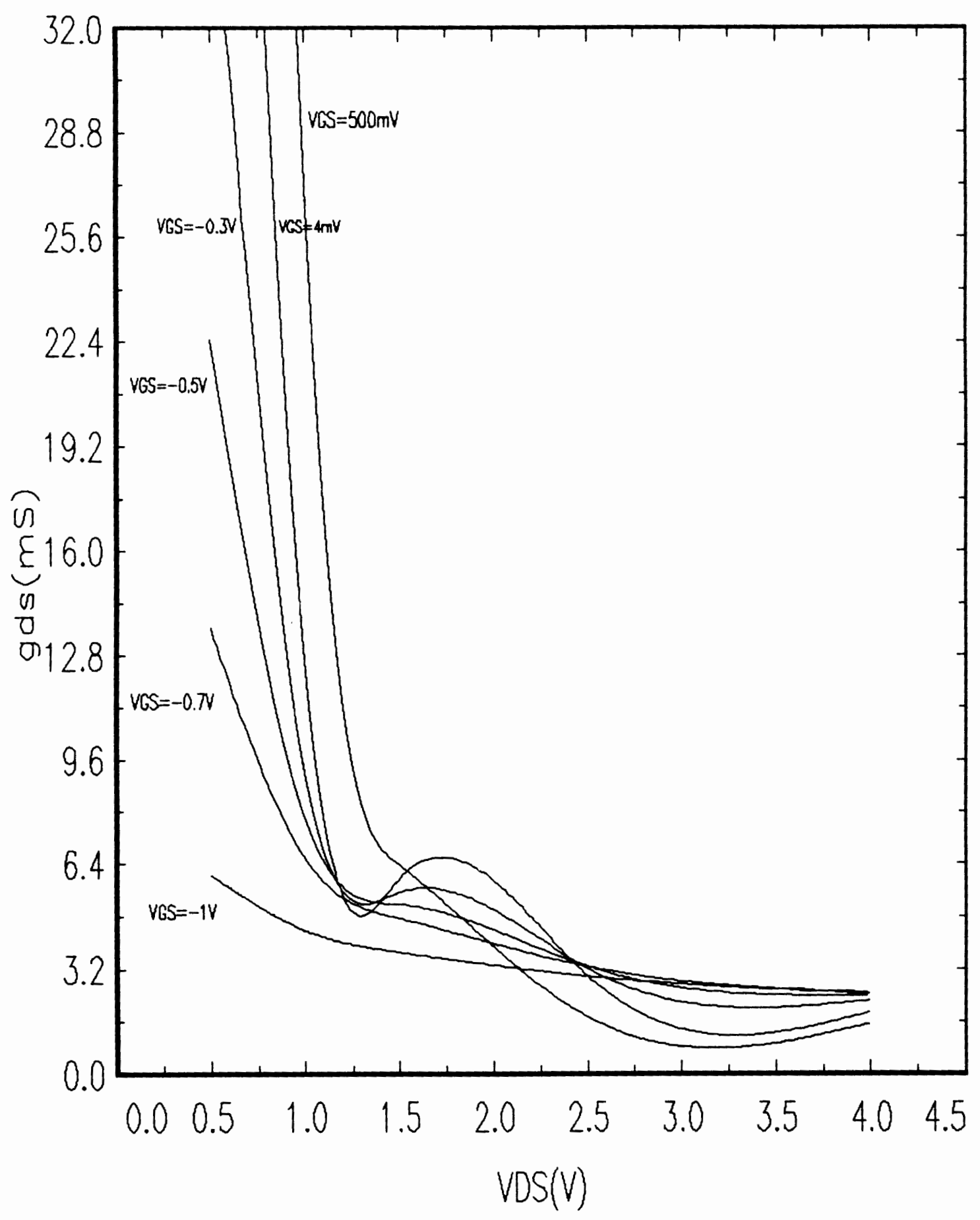

Figure 4.5. Measured $g_{d s}\left(V_{D S}\right)$ characteristics of MESFET model. 


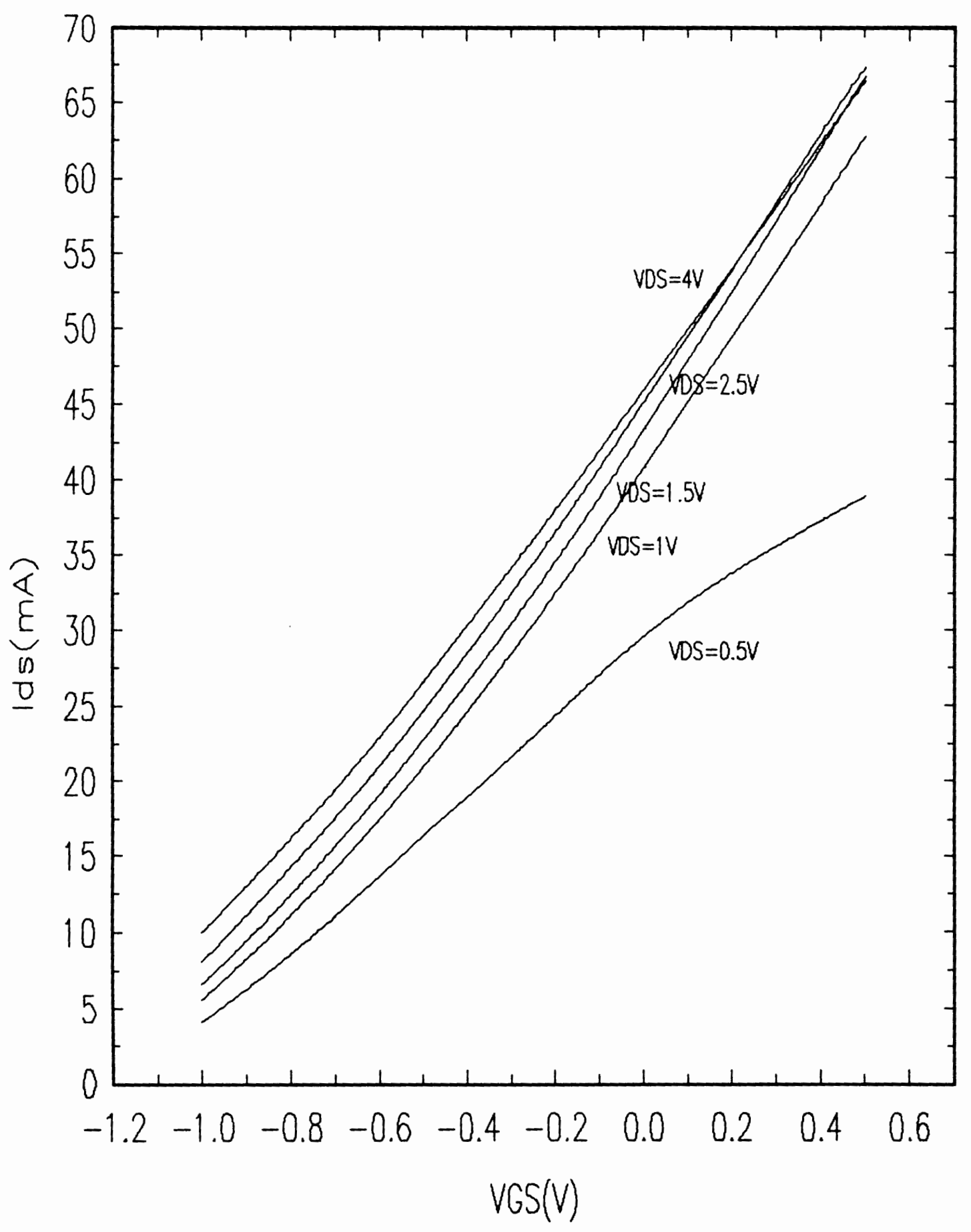

Figure 4.6. Measured $i_{d}\left(V_{G S}\right)$ characteristics of MESFET model. 
Table III and Figure 4.2 through Figure 4.6 were used along with the least square curve fitting program (Appendix A) to extract the Taylor series coefficients of the nonlinear elements described in Chapter II. No largesignal AC measurements were made but the values at several DC bias points were used. This is because around the tested bias points, most of the data showed a cubic or less than cubic behavior. The corresponding coefficients at $\mathrm{V}_{\mathrm{DS}}=1.5 \mathrm{~V}$ and $\mathrm{V}_{\mathrm{GS}}=-0.5 \mathrm{~V}$ are given in Table IV. This is a good bias point for an amplifier design.

\section{TABLE IV}

TAYLOR SERIES COEFFICIENTS OF THE NONLINEAR ELEMENTS AT $\mathrm{V}_{\mathrm{DS}}=1.5 \mathrm{~V}$ AND $\mathrm{V}_{\mathrm{GS}}=-0.5 \mathrm{~V}$

\begin{tabular}{|c|c|c|c|c|c|c|c|c|c|}
\hline & & & $\mathrm{C}_{\mathrm{gdm}}$ & & $g_{m n}$ & & & $g_{d s n}$ & \\
\hline$C_{g s 1}$ & $\underset{\times 10^{-12}}{C_{\mathrm{gs2}}} \mathrm{C}_{\mathrm{gs3}}$ & & $\begin{array}{r}\mathrm{C}_{\mathrm{gd} 2} \\
\times 10^{-12}\end{array}$ & $g_{m l}$ & $\begin{array}{c}\mathrm{g}_{\mathrm{m} 2} \\
\times 10^{-3}\end{array}$ & $\mathbf{g}_{\mathrm{m} 3}$ & $\mathbf{g}_{d s 1}$ & $\begin{array}{r}g_{d s 2} \\
\times 10^{-3}\end{array}$ & $\mathbf{g}_{\mathrm{ds} 3}$ \\
\hline 0.27 & 0.130 .0038 & 0.061 & $-0.040 \quad 0.013$ & 40.1 & 21.62 & -10.79 & 5.17 & -9.62 & 3.34 \\
\hline
\end{tabular}

These values will be used in the next section for the intermodulation distortion analysis.

\section{Intermodulation Distortion Measurements}

Figure 4.7 shows the intermodulation experimental setup used for 
making measurements at $f_{1}=729.75 \mathrm{MHz}$ and $f_{2}=730.25 \mathrm{MHz}$. Measurements were made at the input powers of -18 and $-15 \mathrm{dBm}$ using different bias points and these are shown in Table $V$. The output power $\left(p_{o l}\right)$ is measured at $f_{1}$, the intermodulation distortion power $\left(\mathrm{p}_{\mathrm{o} 3}\right)$ is measured at $2 \mathrm{f}_{1}-\mathrm{f}_{2}$, and the intercept point $\left(\mathrm{IP}_{3}\right)$ is calculated using Equation (3.36).

Initially, the device is disconnected at the input and the input power $\left(\mathrm{p}_{\text {in }}\right)$ measured into a $50 \Omega$ termination. Then the device is connected and at proper bias voltage. The output power at fundamental and intermodulation frequencies are measured by the spectrum analyzer. The power divider is used as a power combiner and a $3 \mathrm{~dB}$ attenuator is used to reduce reflections. 


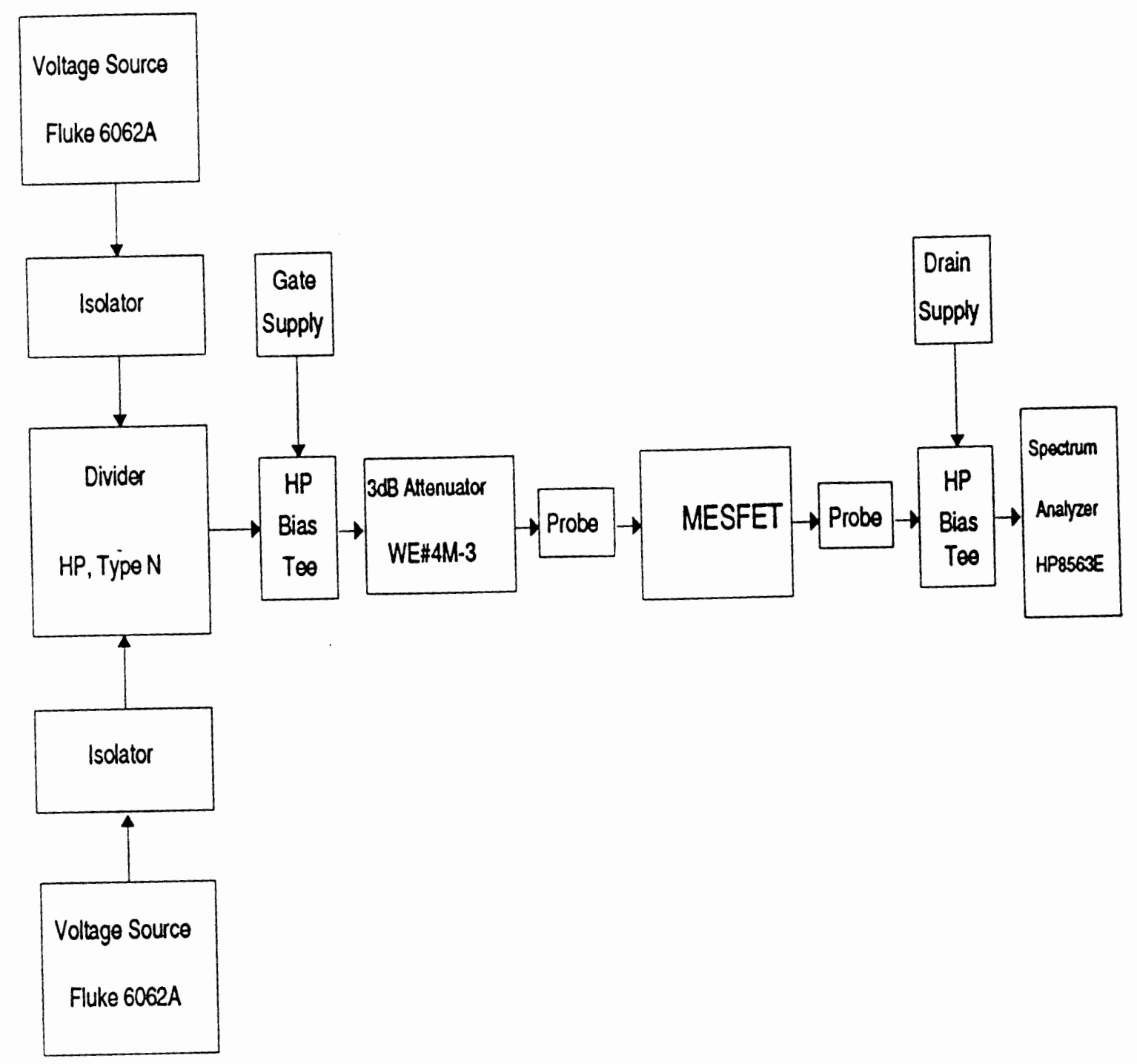

Figure 4.7. Intermodulation distortion experimental setup. 


\section{TABLE V}

INTERMODULATION DISTORTION MEASUREMENTS AT $\mathrm{f}_{1}=729.75 \mathrm{MHz}, \mathrm{f}_{2}=730.25 \mathrm{MHz}$, AND $\mathrm{p}_{\text {in }}=-18 \mathrm{dBm}$ AND $-15 \mathrm{dBm}$

\begin{tabular}{|c|c|c|c|c|c|c|c|}
\hline \multirow[b]{2}{*}{$\begin{array}{c}V_{D S} \\
V\end{array}$} & \multirow[b]{2}{*}{$\begin{array}{c}\mathrm{V}_{\mathrm{GS}} \\
\mathrm{V}\end{array}$} & \multicolumn{3}{|c|}{$\mathrm{p}_{\text {in }}=-18 \mathrm{dBm}$} & \multicolumn{3}{|c|}{$\mathrm{p}_{\mathrm{in}}=-15 \mathrm{dBm}$} \\
\hline & & $\begin{array}{c}\mathrm{p}_{\mathrm{ol}} \\
\mathrm{dBm}\end{array}$ & $\begin{array}{c}\mathrm{p}_{\mathrm{o} 3} \\
\mathrm{dBm}\end{array}$ & $\begin{array}{c}\mathrm{IP}_{3} \\
\mathrm{dBm}\end{array}$ & $\begin{array}{c}\mathrm{P}_{\mathrm{ol}} \\
\mathrm{dBm}\end{array}$ & $\begin{array}{c}\mathrm{P}_{03} \\
\mathrm{dBm}\end{array}$ & $\begin{array}{c}\mathrm{IP}_{3} \\
\mathrm{dBm}\end{array}$ \\
\hline 1.5 & $\begin{array}{c}-1.2 \\
-1.1 \\
-1.0 \\
-0.9 \\
-0.7 \\
-0.5 \\
-0.3 \\
0.0\end{array}$ & $\begin{array}{l}-15.23 \\
-12.81 \\
-11.48 \\
-10.57 \\
-9.31 \\
-8.57 \\
-7.98 \\
-7.48\end{array}$ & $\begin{array}{l}-66.91 \\
-64.13 \\
-64.72 \\
-65.57 \\
-66.97 \\
-66.91 \\
-64.48 \\
-56.88\end{array}$ & $\begin{array}{l}10.61 \\
12.85 \\
15.14 \\
16.93 \\
19.52 \\
20.60 \\
20.27 \\
17.22\end{array}$ & $\begin{array}{c}-12.00 \\
-10.00 \\
-8.66 \\
-7.66 \\
-6.41 \\
-5.58 \\
-5.08 \\
-4.50\end{array}$ & $\begin{array}{r}-58.42 \\
-55.58 \\
-55.82 \\
-56.74 \\
-58.07 \\
-57.74 \\
-54.98 \\
-47.42\end{array}$ & $\begin{array}{l}11.21 \\
12.79 \\
14.92 \\
16.88 \\
19.42 \\
20.50 \\
19.87 \\
16.96\end{array}$ \\
\hline 1.7 & $\begin{array}{l}-1.2 \\
-1.1 \\
-1.0 \\
-0.9 \\
-0.7 \\
-0.5 \\
-0.3 \\
0.0\end{array}$ & $\begin{array}{l}-14.48 \\
-12.57 \\
-11.23 \\
-10.40 \\
-9.15 \\
-8.31 \\
-7.73 \\
-7.07\end{array}$ & $\begin{array}{l}-66.06 \\
-64.91 \\
-65.65 \\
-66.66 \\
-68.41 \\
-69.47 \\
-68.91 \\
-63.23\end{array}$ & $\begin{array}{l}11.31 \\
13.60 \\
15.98 \\
17.73 \\
20.48 \\
22.27 \\
22.86 \\
21.01\end{array}$ & $\begin{array}{c}-11.66 \\
-9.74 \\
-8.41 \\
-7.41 \\
-6.24 \\
-5.41 \\
-4.83 \\
-4.08\end{array}$ & $\begin{array}{l}-58.24 \\
-56.24 \\
-56.81 \\
-57.81 \\
-59.58 \\
-60.57 \\
-59.67 \\
-53.40\end{array}$ & $\begin{array}{l}11.63 \\
13.51 \\
15.79 \\
17.79 \\
20.43 \\
22.17 \\
22.59 \\
20.58\end{array}$ \\
\hline 2.0 & $\begin{array}{l}-1.2 \\
-1.1 \\
-1.0 \\
-0.9 \\
-0.7 \\
-0.5 \\
-0.3 \\
0.0\end{array}$ & $\begin{array}{l}-14.07 \\
-12.23 \\
-11.07 \\
-10.15 \\
-8.90 \\
-8.07 \\
-7.57 \\
-6.73\end{array}$ & $\begin{array}{l}-66.23 \\
-65.91 \\
-66.91 \\
-68.07 \\
-69.98 \\
-72.07 \\
-73.81 \\
-73.23\end{array}$ & $\begin{array}{l}12.01 \\
14.61 \\
16.85 \\
18.81 \\
21.64 \\
23.93 \\
25.55 \\
26.52\end{array}$ & $\begin{array}{l}-11.24 \\
-9.41 \\
-8.16 \\
-7.24 \\
-6.00 \\
-5.16 \\
-4.58 \\
-3.74\end{array}$ & $\begin{array}{l}-58.08 \\
-57.23 \\
-58.08 \\
-59.24 \\
-61.08 \\
-63.16 \\
-64.90 \\
-63.58\end{array}$ & $\begin{array}{l}12.18 \\
14.50 \\
16.80 \\
18.76 \\
21.54 \\
23.84 \\
25.58 \\
26.18\end{array}$ \\
\hline 2.5 & $\begin{array}{l}-1.2 \\
-1.1 \\
-1.0 \\
-0.9 \\
-0.7 \\
-0.5 \\
-0.3 \\
0.0\end{array}$ & $\begin{array}{c}-13.48 \\
-11.90 \\
-10.81 \\
-9.98 \\
-8.73 \\
-7.9 \\
-7.4 \\
-6.65\end{array}$ & $\begin{array}{l}-66.80 \\
-67.48 \\
-68.71 \\
-69.72 \\
-71.41 \\
-73.82 \\
-77.74 \\
-81.49\end{array}$ & $\begin{array}{l}13.18 \\
15.89 \\
18.14 \\
19.89 \\
22.61 \\
25.06 \\
27.77 \\
30.77\end{array}$ & $\begin{array}{c}-10.66 \\
-9.08 \\
-7.91 \\
-7.08 \\
-5.83 \\
-5.00 \\
-4.41 \\
-3.58\end{array}$ & $\begin{array}{l}-58.48 \\
-58.74 \\
-59.91 \\
-60.90 \\
-62.75 \\
-65.24 \\
-69.15 \\
-73.06\end{array}$ & $\begin{array}{l}13.25 \\
15.75 \\
18.09 \\
19.83 \\
22.63 \\
25.12 \\
27.96 \\
31.16\end{array}$ \\
\hline
\end{tabular}




\section{TABLE V}

INTERMODULATION DISTORTION MEASUREMENTS AT $\mathrm{f}_{1}=729.75 \mathrm{MHz}, \mathrm{f}_{2}=730.25 \mathrm{MHz}$, AND $\mathrm{p}_{\text {in }}=-18 \mathrm{dBm}$ AND $-15 \mathrm{dBm}$ (continued)

\begin{tabular}{|c|c||ccc||ccc|}
\hline & & \multicolumn{3}{|c||}{$\mathrm{p}_{\text {in }}=-18 \mathrm{dBm}$} & \multicolumn{3}{c|}{$\mathrm{p}_{\mathrm{in}}=-15 \mathrm{dBm}$} \\
\hline $\mathrm{V} \mathrm{V}_{\mathrm{DS}}$ & $\mathrm{V}_{\mathrm{GS}}$ & $\mathrm{p}_{\mathrm{ol}}$ & $\mathrm{p}_{\mathrm{o} 3}$ & $\mathrm{IP}_{3}$ & $\mathrm{p}_{\mathrm{ol}}$ & $\mathrm{p}_{\mathrm{o} 3}$ & $\mathrm{IP}_{3}$ \\
$\mathrm{~V}$ & $\mathrm{~V}$ & $\mathrm{dBm}$ & $\mathrm{dBm}$ & $\mathrm{dBm}$ & $\mathrm{dBm}$ & $\mathrm{dBm}$ & $\mathrm{dBm}$ \\
\hline 4.0 & -1.2 & -12.73 & -70.41 & 16.11 & -9.83 & -61.59 & 16.05 \\
& -1.1 & -11.57 & -71.81 & 18.55 & -8.58 & -62.98 & 18.62 \\
& -1.0 & -10.57 & -72.65 & 20.47 & -7.66 & -63.90 & 20.46 \\
& -0.9 & -9.90 & -72.90 & 21.60 & -6.91 & -64.07 & 21.67 \\
& -0.7 & -8.73 & -72.99 & 23.40 & -5.74 & -64.24 & 23.51 \\
& -0.5 & -7.98 & -73.64 & 24.85 & -5.08 & -65.08 & 24.92 \\
& -0.3 & -7.48 & -76.38 & 26.97 & -4.50 & -67.92 & 27.21 \\
& 0.0 & -6.90 & -77.48 & 28.39 & -3.91 & -68.23 & 28.25 \\
\hline 5.0 & -1.2 & -12.48 & -73.38 & 17.97 & -9.58 & -64.48 & 17.87 \\
& -1.1 & -11.40 & -74.48 & 20.14 & -8.50 & -65.66 & 20.08 \\
& -1.0 & -10.57 & -74.91 & 21.60 & -7.66 & -65.98 & 21.50 \\
& -0.9 & -9.90 & -74.40 & 22.35 & -7.00 & -65.58 & 22.29 \\
& -0.7 & -8.81 & -73.47 & 23.52 & -5.91 & -64.81 & 23.54 \\
& -0.5 & -8.07 & -73.65 & 24.72 & -5.16 & -65.16 & 24.84 \\
& -0.3 & -7.73 & -76.65 & 26.73 & -4.66 & -68.24 & 27.13 \\
& 0.0 & -7.23 & -77.31 & 27.81 & -4.16 & -68.40 & 27.96 \\
\hline
\end{tabular}

\section{Comparison of Computed Distortion with Experimental Results}

In this section, we apply the analytical expressions described in Chapter III to compute the output power, intermodulation distortion power, and intercept point for an $0.5 \mu \mathrm{m}$ MESFET amplifier having parameters listed in Table II and Table IV. For $\mathrm{V}_{\mathrm{DS}}=1.5 \mathrm{~V}$ and $\mathrm{V}_{\mathrm{GS}}=-0.5 \mathrm{~V}$, the analytical results give a linear output power $\left(\mathrm{p}_{\mathrm{ol}}\right)$ of $-8.14 \mathrm{dBm}$, intermodulation distortion 
power $\left(\mathrm{p}_{\mathrm{o}}\right)$ of $-66.14 \mathrm{dBm}$, and intercept point $\left(\mathrm{IP}_{3}\right)$ of $20.86 \mathrm{dBm}$ for an input power $\left(p_{\text {in }}\right)$ of $-18 \mathrm{dBm}$ at frequencies of $f_{1}=729.75 \mathrm{MHz}$ and $f_{2}=730.25 \mathrm{MHz}$. The corresponding experimental values from Table $V$ are $p_{o 1}=-8.57 \mathrm{dBm}$, $p_{03}=-66.91 \mathrm{dBm}$, and $\mathrm{IP}_{3}=20.60 \mathrm{dBm}$ at $\mathrm{p}_{\mathrm{in}}=-18 \mathrm{dBm}$, and $\mathrm{f}_{1}=729.75 \mathrm{MHz}$ and $\mathrm{f}_{2}=730.25 \mathrm{MHz}$. Thus, good agreement is obtained. Comparison were also made at three other bias points and once more, good agreements are obtained. The results are summarized in Table VI.

\section{TABLE VI}

COMPARISON OF THE COMPUTED VALUES WITH EXPERIMENTAL RESULTS AT $\mathrm{p}_{\text {in }}=-18 \mathrm{dBm}$, $\mathrm{f}_{1}=729.75 \mathrm{MHz}$, AND $\mathrm{f}_{2}=730.25 \mathrm{MHz}$

\begin{tabular}{|c|c|c|c|c|c|c|c|}
\hline \multirow[b]{2}{*}{$\begin{array}{c}V_{D s} \\
V\end{array}$} & \multirow[b]{2}{*}{$\begin{array}{c}V_{G S} \\
V\end{array}$} & \multicolumn{3}{|c|}{ Computed Values } & \multicolumn{3}{|c|}{ Experimental Results } \\
\hline & & $\begin{array}{c}\mathrm{p}_{\mathrm{ol}} \\
\mathrm{dBm}\end{array}$ & $\begin{array}{c}\mathrm{p}_{\mathrm{o} 3} \\
\mathrm{dBm}\end{array}$ & $\begin{array}{c}\mathrm{IP}_{\mathbf{3}} \\
\mathrm{dBm}\end{array}$ & $\begin{array}{c}\mathrm{p}_{\mathrm{ol}} \\
\mathrm{dBm}\end{array}$ & $\begin{array}{c}\mathrm{p}_{\mathrm{o} 3} \\
\mathrm{dBm}\end{array}$ & $\begin{array}{c}\mathrm{IP}_{\mathbf{3}} \\
\mathrm{dBm}\end{array}$ \\
\hline \multirow[t]{2}{*}{1.50} & -0.50 & -8.14 & -66.14 & 20.86 & -8.57 & -66.91 & 20.60 \\
\hline & -0.70 & -9.12 & -61.27 & 16.96 & -9.31 & -66.97 & 19.52 \\
\hline \multirow[t]{2}{*}{2.50} & -0.50 & -7.67 & -69.54 & 23.27 & -7.90 & -73.82 & 25.06 \\
\hline & -0.70 & -8.39 & -65.16 & 20.00 & -8.73 & -71.41 & 22.61 \\
\hline
\end{tabular}

Comparison of Computed Distortion with Minasian's Amplifier Results

To check the validity of the analytical expressions in Chapter III, we used the results for similar problems published by others. For example, 
Minasian [3] analyzed a Plessey $2 \times 360-\mu \mathrm{m}$ gate MESFET amplifier operated at high gain bias condition of $\mathrm{V}_{\mathrm{GS}}=0 \mathrm{~V}$ and $\mathrm{V}_{\mathrm{DS}}=3.5 \mathrm{~V}$. The amplifier parameters are (taken from Minasian's results)

$\mathrm{C}_{\mathrm{ds}}=0.067 \mathrm{pF}$

$R_{i}=45 \Omega$

$\mathrm{C}_{\mathrm{gd}}=0.088 \mathrm{pF}$

$\mathrm{g}_{\mathrm{m} 1}=0.012 ; \mathrm{g}_{\mathrm{m} 2}=0.0024 ; \mathrm{g}_{\mathrm{m} 3}=-0.0016$

$\mathrm{C}_{\mathrm{gs} 1}=0.364 \times 10^{-12} ; \mathrm{C}_{\mathrm{gs} 2}=0.082 \times 10^{-12} ; \mathrm{C}_{\mathrm{gs} 3} \approx 0$

$\mathrm{g}_{\mathrm{ds}}: \mathrm{a}=0.004 ; \mathrm{b}=0.0 ; \mathrm{c}=0.94$

where

$g_{d s}\left(V_{d d}\right)=\frac{a}{\left(V_{d s}+b\right)^{c}}$

These amplifier parameters are used in the analytical expressions described in Chapter III. The results are compared in Figure 4.8 through Figure 4.10 with Minasian's results, and excellent agreement was obtained.

Comparison of the two results for the frequency dependency of the third-order intermodulation distortion power for the amplifier terminated in $50 \Omega$ is shown in Figure 4.8. It was measured by varying the center frequency of the two tone input source (with $\mathrm{p}_{\mathrm{in}}=-7 \mathrm{dBm}$ ) while maintaining 
frequency separation at $2 \mathrm{MHz}$.

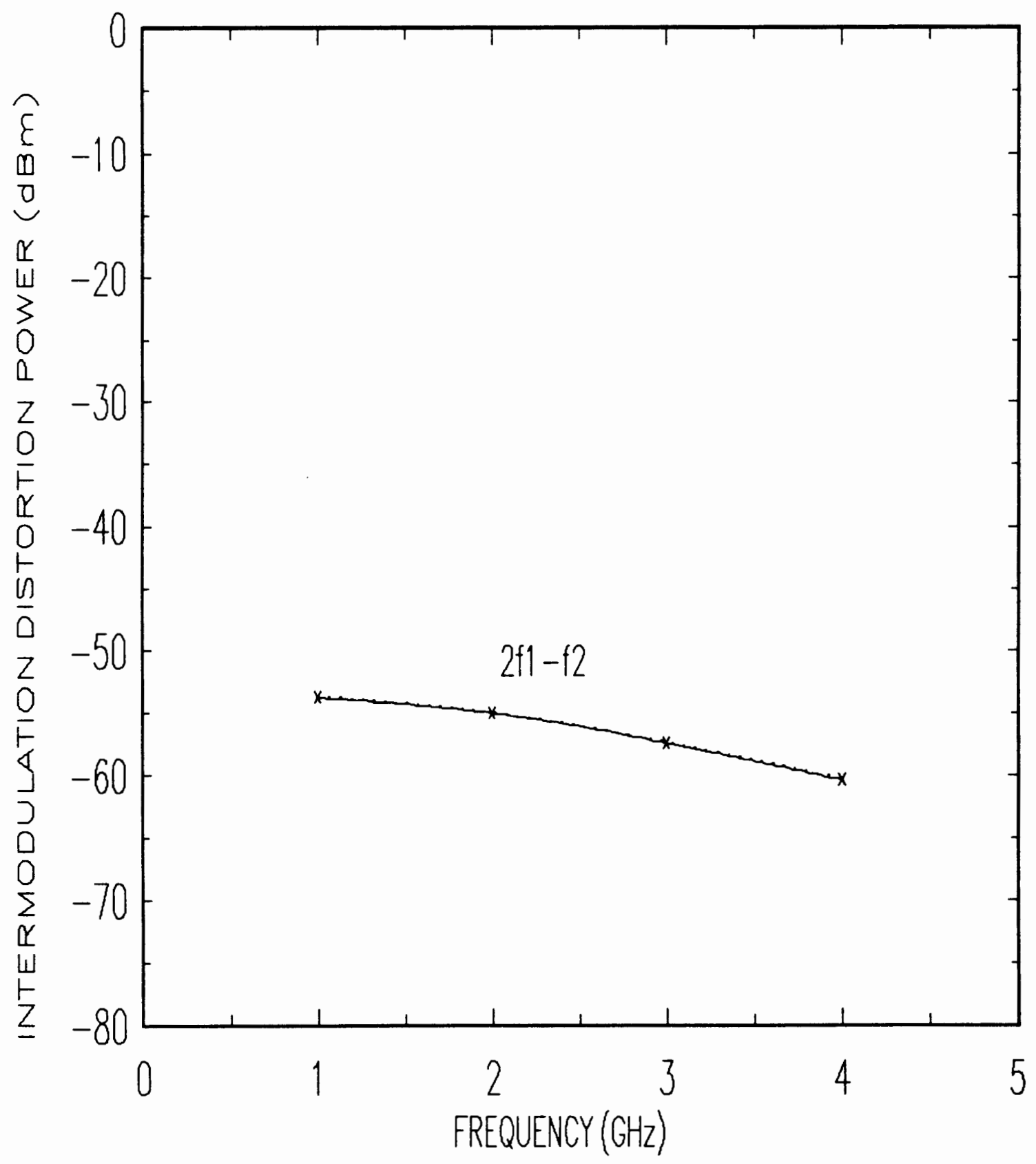

Figure 4.8. Comparison of Minasian's and predicted theory for frequency dependency of intermodulation distortion. $\mathbf{x}$ indicates Minasian's data. 
Comparison of the linear output power and third-order intermodulation distortion power as a function of input available power per tone at $2.4 \mathrm{GHz}$ is shown for the maximum gain load condition $\left(Z_{L}=165+j 110\right)$ in Figure 4.9, and for the maximum power load $\left(Z_{L}=138+j 38.3\right)$ in Figure 4.10.

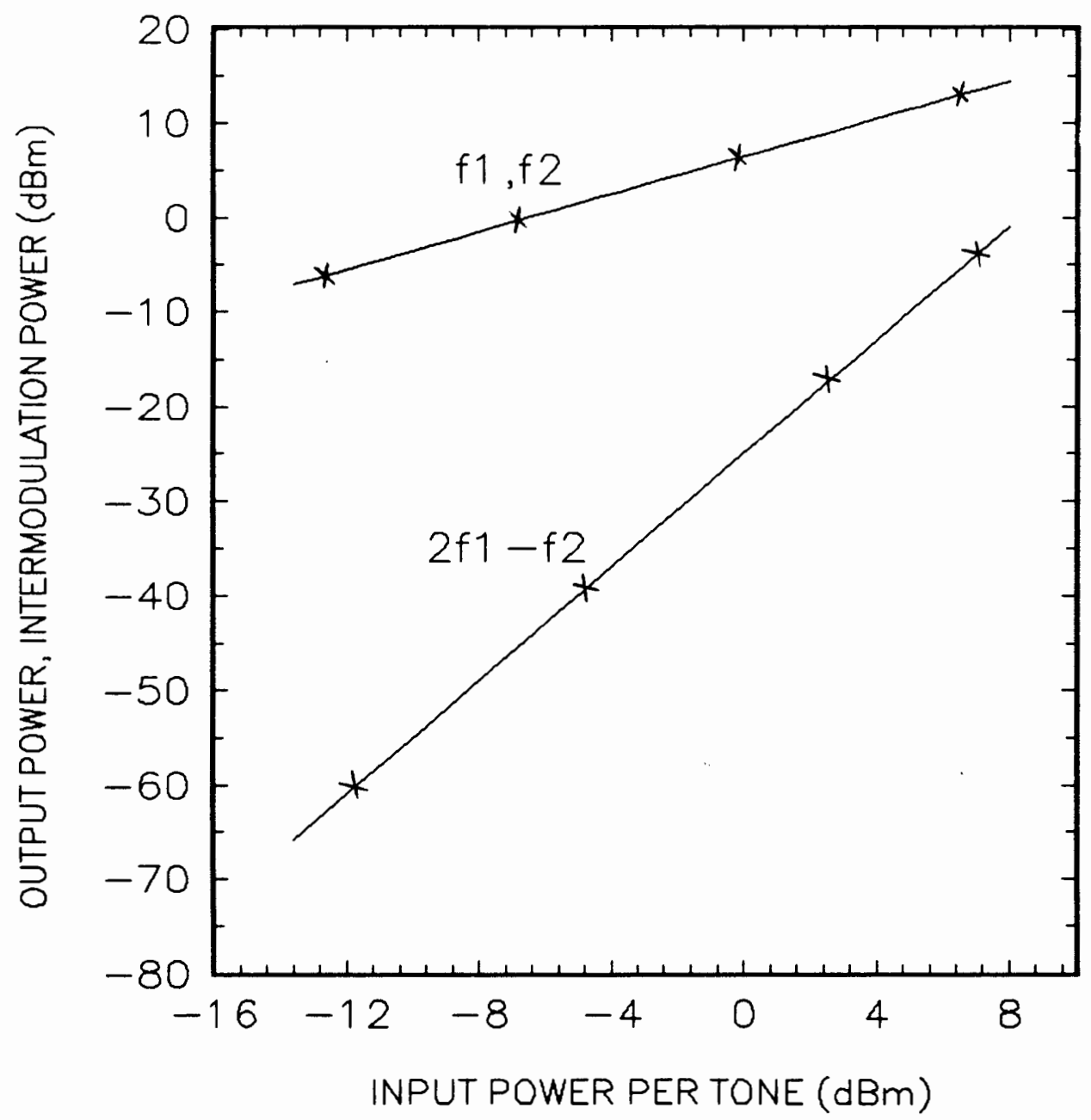

Figure 4.9. Comparison of Minasian's and predicted theory for the linear and intermodulation output power responses for the maximum gain load condition. $x$ indicates Minasian's data. 


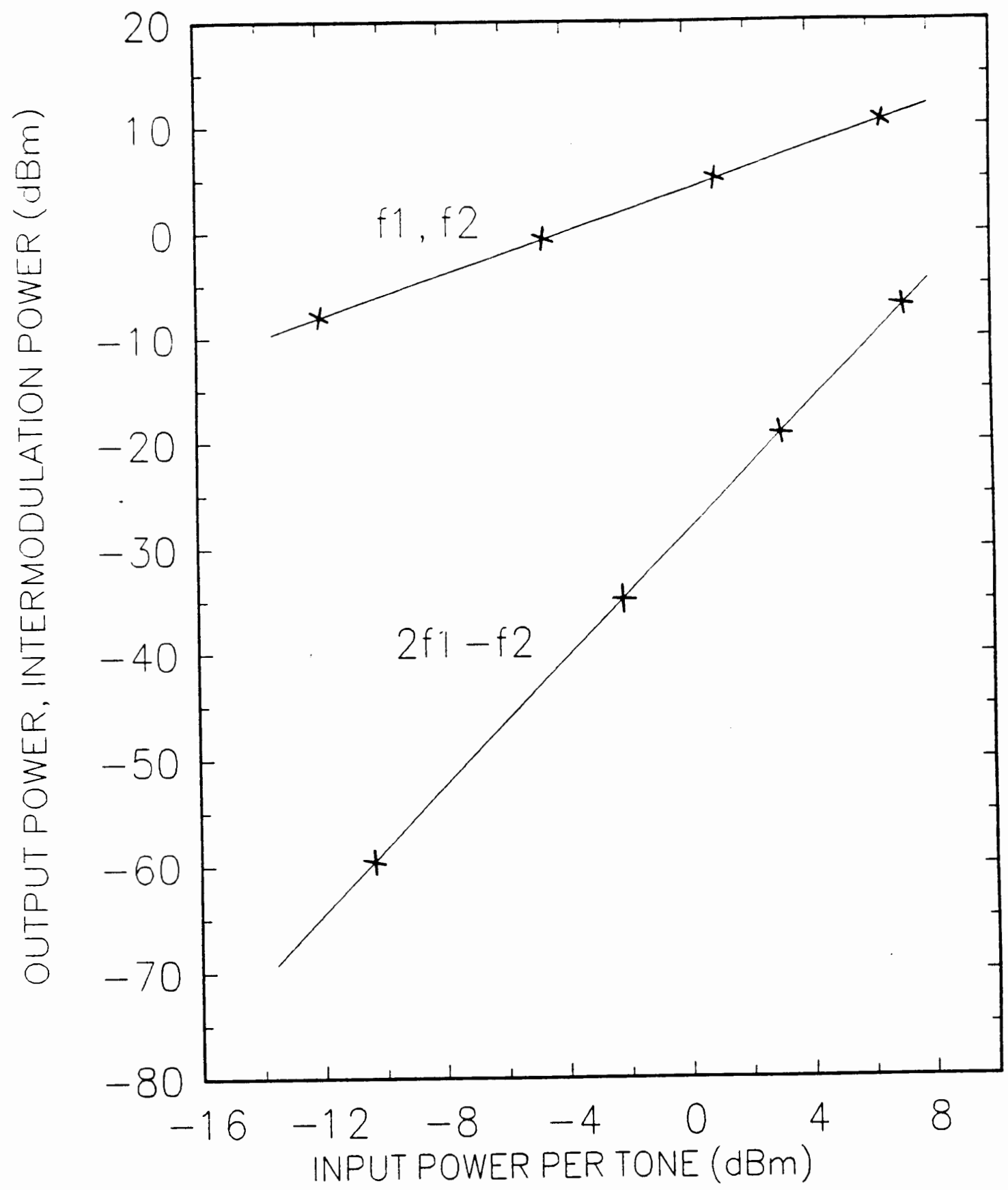

Figure 4.10. Comparison of Minasian's and predicted results for the linear and intermodulation output power responses for the maximum power load. $\mathbf{x}$ indicates Minasian's data. 
Variation of Intermodulation Distortion with Frequency and Input Power

Variation of intermodulation distortion with center frequency and input power was studied to check if the analytical expressions predict acceptable performance.

The frequency dependency of the intermodulation distortion power for the MESFET amplifier terminated in $50 \Omega$ is calculated using the analytical expressions in Chapter III and it is shown in Figure 4.11. It was determined by varying the center frequency of the two tone input while maintaining a frequency separation of $0.5 \mathrm{MHz}\left(\mathrm{f}_{2}=\mathrm{f}_{1}+0.5 \mathrm{MHz}\right)$. No detailed data on intermodulation distortion power variation with frequency have been published in the literature. The performance shown in Figure 4.11 appears reasonable at higher frequencies. 


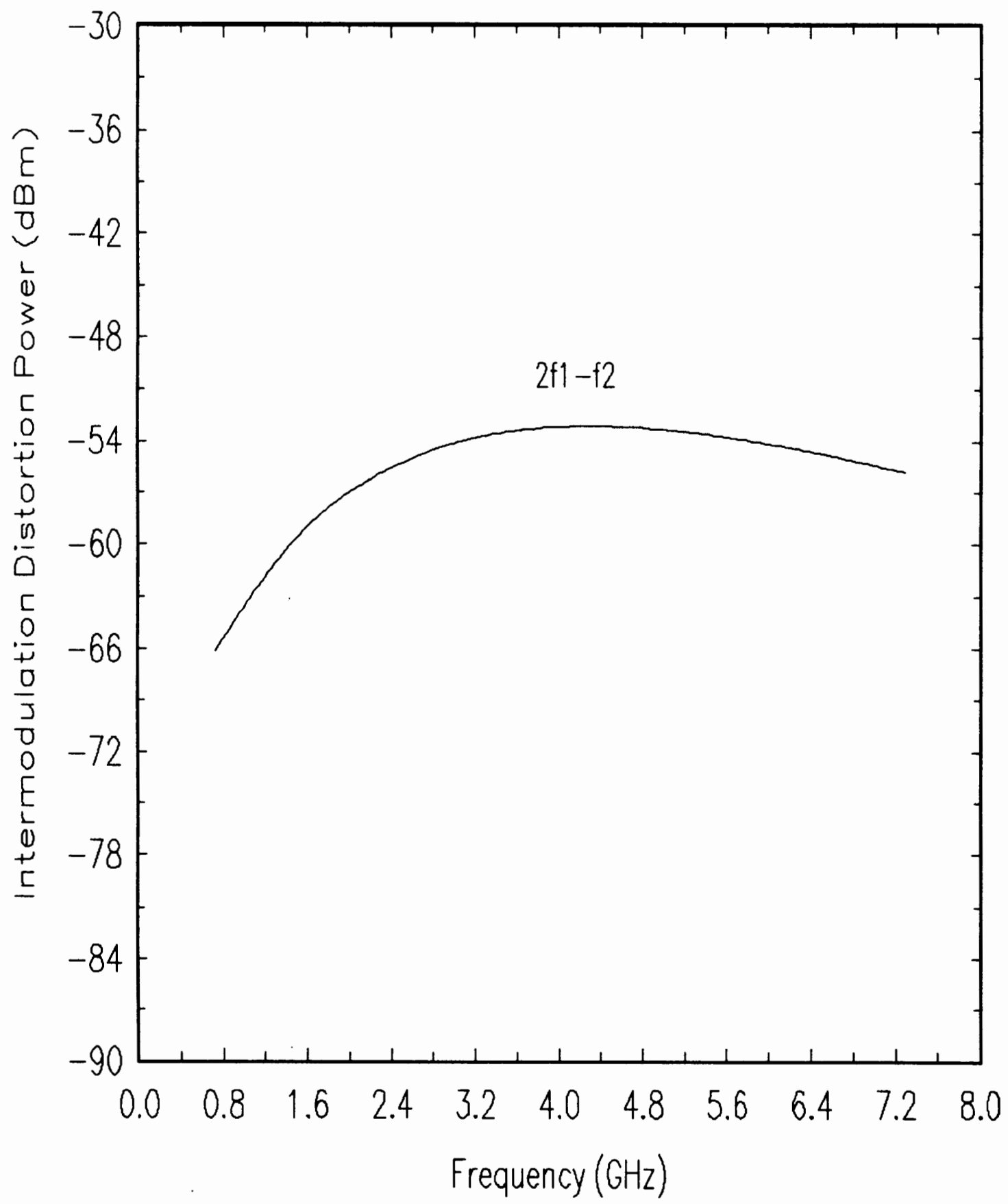

Figure 4.11. Frequency dependency of intermodulation distortion for an input of $-18 \mathrm{dBm}$. 
The linear output power and the intermodulation distortion power as a function of input power per tone at $730 \mathrm{MHz}$ is shown for a $50 \Omega$ amplifier termination in Figure 4.12. As the input power $\left(\mathrm{p}_{\text {in }}\right)$ increases, the linear output power $\left(\mathrm{p}_{\mathrm{ol}}\right)$ increases with a slope of 1 and the intermodulation power $\left(p_{03}\right)$ increases with a slope of 3 . This is expected from the theory of microwave amplifiers. Thus, the analytical expressions appear to be valid.

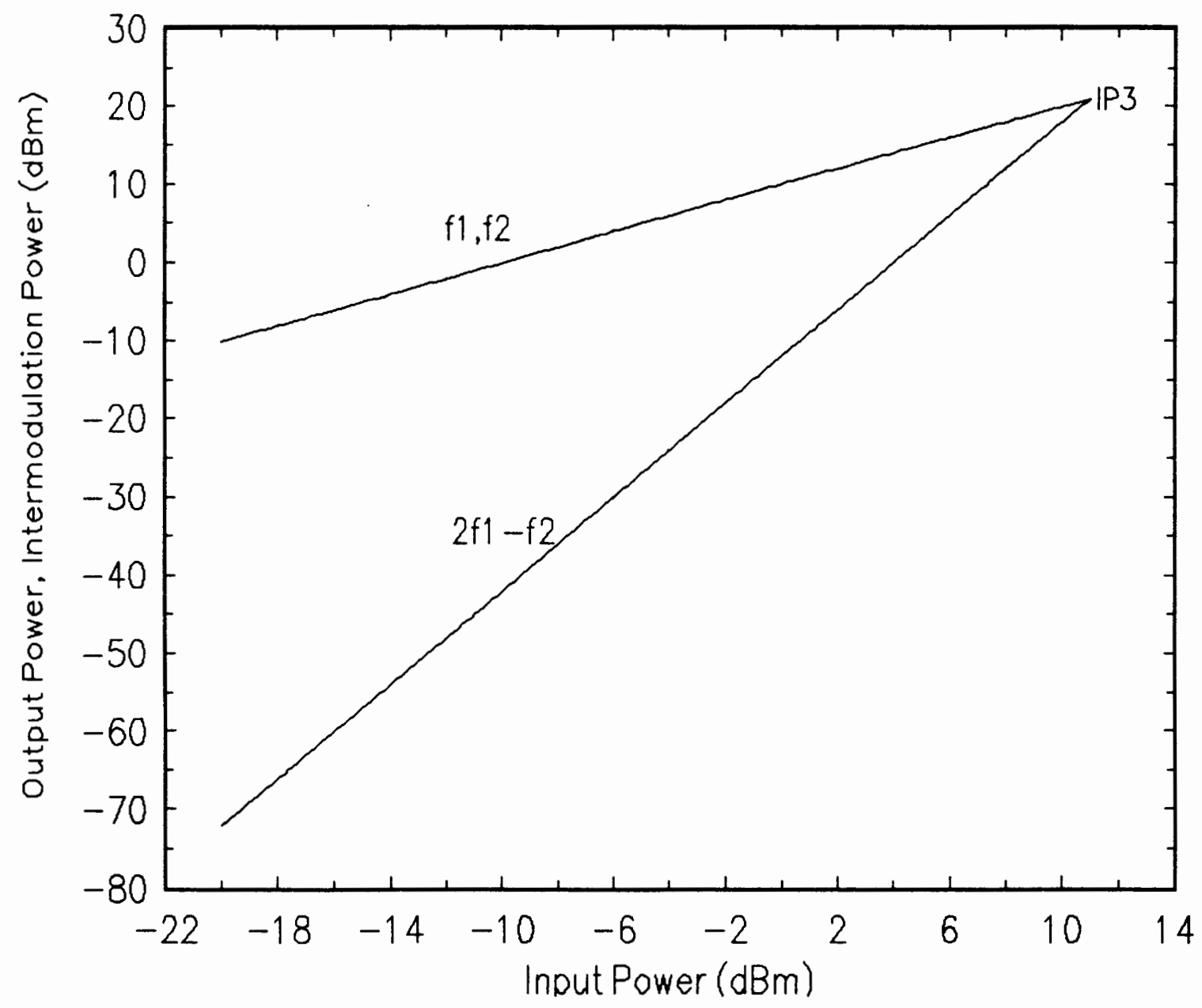

Figure 4.12. Linear and intermodulation output power responses at $730 \mathrm{MHz}, \mathrm{V}_{\mathrm{DS}}=1.5 \mathrm{~V}$, and $\mathrm{V}_{\mathrm{GS}}=-0.5 \mathrm{~V}$. 
Effect of Source and Load Impedances

The effect of source and load impedances on the amplifier's output intercept point are shown in Figure 4.13 and Figure 4.14. Developing such figures helps us draw load-pull contours on the Smith chart, and is very valuable in power amplifier designs. Development of such figures could take long amount of time using the standard method of intermodulation analysis (a typical calculation procedure is shown in (Appendix C), but the analytical expressions developed in Chapter III lead to quick and simplified calculations.

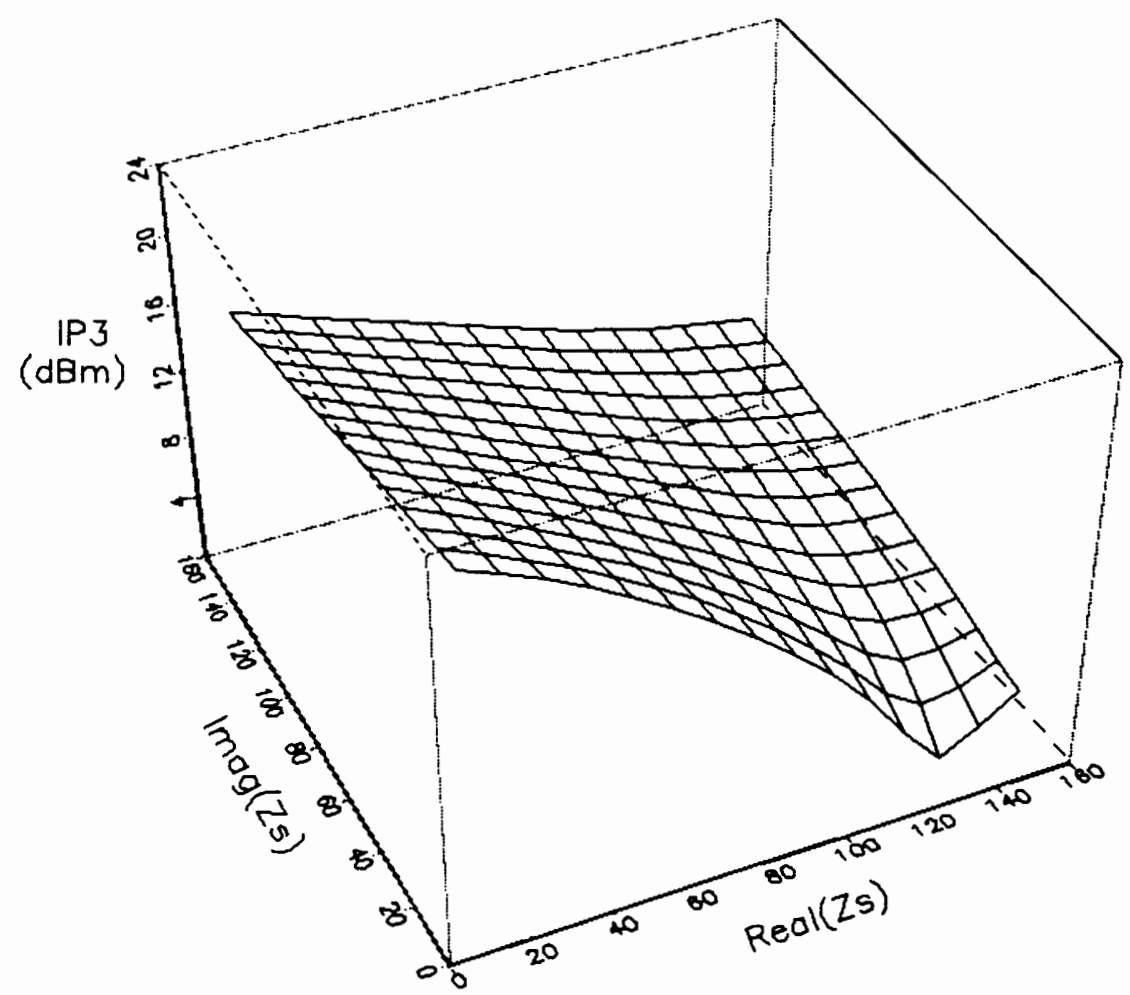

Figure 4.13. Intercept point as a function of the real and imaginary parts of the source impedance. 


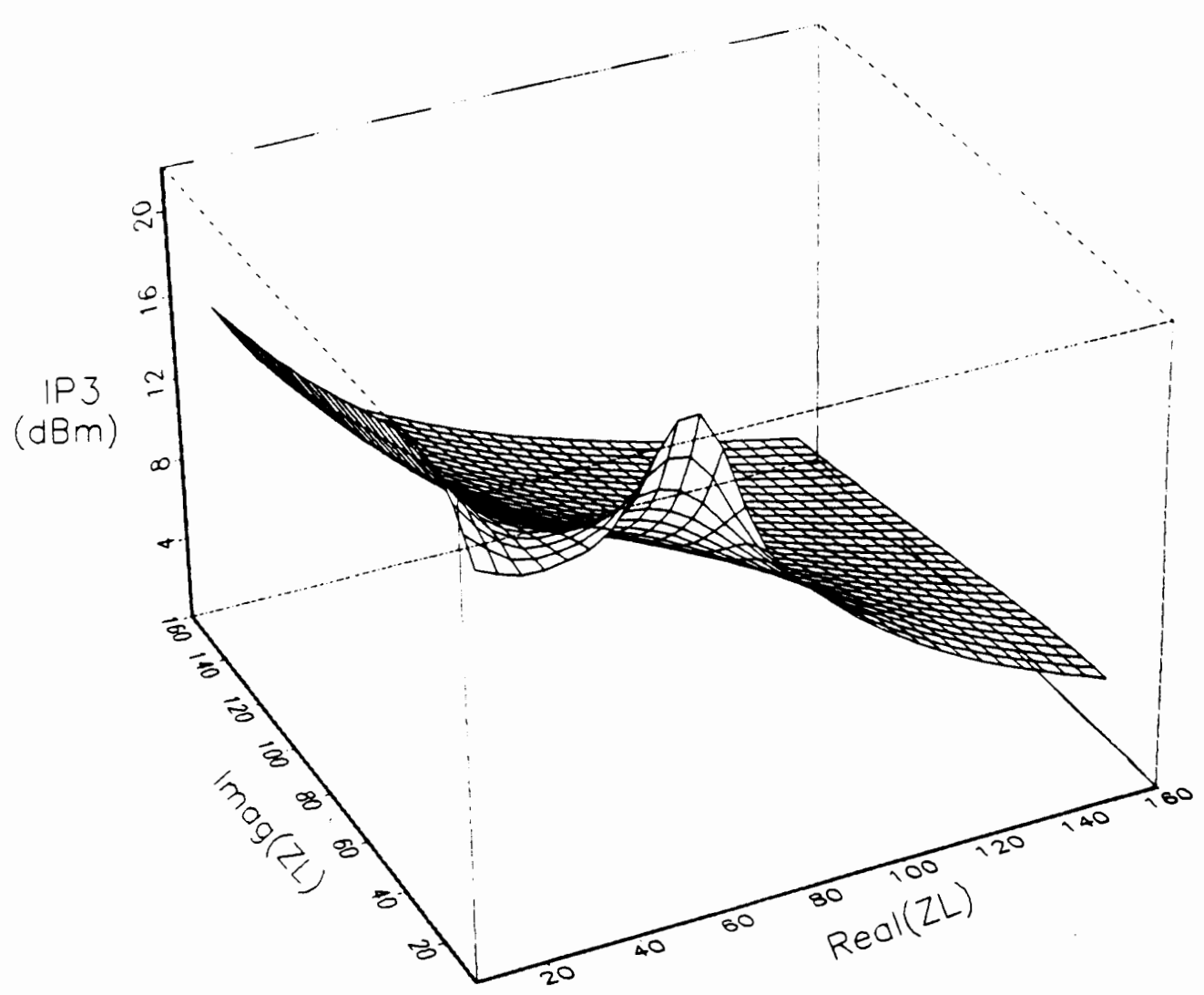

Figure 4.14. Intercept point as a function of the real and imaginary parts of the load impedance.

Effect of Feedback Capacitance and Other Nonlinear Elements of MESFET

Table VII shows the changes in the intermodulation distortion power $\left(\Delta \mathrm{P}_{\mathrm{o} 3}\right)$ and intercept point $\left(\Delta \mathrm{IP}_{3}\right)$ when nonlinearity and the role of $\mathrm{C}_{\mathrm{gd}}$ are ignored in the calculations. The first column is the reference column where $\mathrm{C}_{\mathrm{gd}}$ treated as a nonlinear element. The second column gives the intermodulation distortion power and intercept point when the nonlinear element $C_{g d}$ is replaced with a linear one $\left(C_{g d 2}=0\right.$ and $\left.C_{g d 3}=0\right)$, and the third 
column, when $\mathrm{C}_{\mathrm{gd}}$ is eliminated $\left(\mathrm{C}_{\mathrm{gd} 1}=0, \mathrm{C}_{\mathrm{gd} 2}=0\right.$, and $\left.\mathrm{C}_{\mathrm{gd} d}=0\right)$. The table emphasizes the important role of both $\mathrm{C}_{\mathrm{gd}}$ and it's nonlinearity. The calculations were performed at $p_{\text {in }}=-18 \mathrm{dBm}, f_{1}=729.75 \mathrm{MHz}, \mathrm{f}_{2}=730.25 \mathrm{MHz}$, $\mathrm{V}_{\mathrm{DS}}=1.5 \mathrm{~V}$, and $\mathrm{V}_{\mathrm{GS}}=-0.5 \mathrm{~V}$

\section{TABLE VII}

\section{CHANGE IN THE INTERMODULATION DISTORTION DUE TO THE EFFECT OF $C_{g d}$ ON MESFET AMPLIFIER}

\begin{tabular}{|c|c|c|c|}
\hline $\mathrm{C}_{\mathrm{gd}}$ & Nonlinear & Linear & Ignored \\
\hline$\Delta \mathrm{P}_{\mathrm{o} 3}(\mathrm{~dB})$ & 0.0 & -4.10 & -7.24 \\
\hline$\Delta \mathrm{IP}_{3}(\mathrm{~dB})$ & 0.0 & 2.05 & 3.67 \\
\hline
\end{tabular}

Similarly, Table VIII shows the changes in the intermodulation distortion power $\left(\Delta \mathrm{P}_{03}\right)$ when replacing each of the nonlinear elements with a linear one in the MESFET's equivalent circuit at $p_{\text {in }}=-18 \mathrm{dBm}$, $\mathrm{f}_{1}=729.75 \mathrm{MHz}, \mathrm{f}_{2}=730.25 \mathrm{MHz}, \mathrm{V}_{D S}=1.5 \mathrm{~V}$, and $\mathrm{V}_{G S}=-0.5 \mathrm{~V}$. NL means the first three terms given in equations (2.6), (2.8), (2.13), and (2.16) are used. $L$ indicates that only the first term in those expansions is used.

Table VIII shows that $g_{m}$ is the most important contributor to the intermodulation distortion. This agrees with the conclusion previously reported in the literature. In general, Table VIII shows that as the number of 
nonlinear elements increases, the intermodulation distortion also increases and in most cases the controlled current source is singularly the most important nonlinear element. The contribution of $g_{d s}$ may depend on the load impedance. In this case, $\mathrm{g}_{\mathrm{ds}}$ corresponds to the an impedance of $300 \Omega$, which is comparable to $50 \Omega$ of load impedance.

TABLE VIII

CHANGE IN THE INTERMODULATION DISTORTION POWER DUE TO LINEARIZING OF MESFET ELEMENTS

\begin{tabular}{|c|c|c|c|c|c|}
\hline Case No. & $\mathrm{C}_{\mathrm{gd}}$ & $\mathrm{C}_{\mathrm{gs}}$ & $\mathrm{g}_{\mathrm{ds}}$ & $\mathrm{g}_{\mathrm{m}}$ & $\Delta \mathrm{P}_{\mathrm{o3}}$ \\
\hline 1 & $\mathrm{NL}$ & $\mathrm{NL}$ & $\mathrm{NL}$ & $\mathrm{NL}$ & 0 \\
\hline 2 & $\mathrm{NL}$ & $\mathrm{NL}$ & $\mathrm{NL}$ & $\mathrm{L}$ & 12.29 \\
\hline 3 & $\mathrm{NL}$ & $\mathrm{NL}$ & $\mathrm{L}$ & $\mathrm{NL}$ & 0.53 \\
\hline 4 & $\mathrm{NL}$ & $\mathrm{L}$ & $\mathrm{NL}$ & $\mathrm{NL}$ & 0.31 \\
\hline 5 & $\mathrm{~L}$ & $\mathrm{NL}$ & $\mathrm{NL}$ & $\mathrm{NL}$ & -4.10 \\
\hline 6 & $\mathrm{~L}$ & $\mathrm{NL}$ & $\mathrm{NL}$ & $\mathrm{L}$ & 13.03 \\
\hline 7 & $\mathrm{~L}$ & $\mathrm{NL}$ & $\mathrm{L}$ & $\mathrm{NL}$ & -4.42 \\
\hline 8 & $\mathrm{~L}$ & $\mathrm{~L}$ & $\mathrm{NL}$ & $\mathrm{NL}$ & -3.71 \\
\hline 9 & $\mathrm{NL}$ & $\mathrm{NL}$ & $\mathrm{L}$ & $\mathrm{L}$ & -5.80 \\
\hline 10 & $\mathrm{NL}$ & $\mathrm{L}$ & $\mathrm{L}$ & $\mathrm{NL}$ & 0.94 \\
\hline 11 & $\mathrm{NL}$ & $\mathrm{L}$ & $\mathrm{NL}$ & $\mathrm{L}$ & 12.31 \\
\hline 12 & $\mathrm{NL}$ & $\mathrm{L}$ & $\mathrm{L}$ & $\mathrm{L}$ & -5.37 \\
\hline 13 & $\mathrm{~L}$ & $\mathrm{NL}$ & $\mathrm{L}$ & $\mathrm{L}$ & -45.76 \\
\hline 14 & $\mathrm{~L}$ & $\mathrm{~L}$ & $\mathrm{~L}$ & $\mathrm{NL}$ & -4.924 \\
\hline 15 & $\mathrm{~L}$ & $\mathrm{~L}$ & $\mathrm{NL}$ & $\mathrm{L}$ & 13.04 \\
\hline
\end{tabular}




\section{CHAPTER V \\ CONCLUSIONS}

In this thesis, new analytical expressions involving the nonlinearity of $\mathrm{C}_{\mathrm{gd}}$ have been developed to calculate the intermodulation distortion of MESFET. These are the first analytical expressions that incorporated the nonlinearity of $\mathrm{C}_{\mathrm{gd}}$ in the intermodulation distortion expressions explicitly. In the past, nonlinearity of this element was incorporated as a part of gate-tosource and drain-to-source capacitances $\left(\mathrm{C}_{\mathrm{gs}}\right.$ and $\left.\mathrm{C}_{\mathrm{ds}}\right)$ so that it led to a unilateral equivalent circuit. Experimental measurements were made for the output power, intermodulation power, and intercept point. Excellent agreement was obtained between analytical expressions and experimental data. The analytical expressions were also used to study the variation of intermodulation distortion with input power, frequency, and source and load impedance.

Our analytical expressions for intermodulation power and intercept point can be studied for special cases of frequency ranges and device parameter ranges and then they can be further simplified for rapid analysis of intermodulation. 


\section{REFERENCES}

[1] R. S. Tucker and C. Rauscher, "Modelling the 3rd-order intermodulation-distortion properties of a GaAs FET," Electron. Lett., vol. 13, pp. 508-510, Aug. 8, 1977.

[2] R. S. Tucker, "Third-order Intermodulation distortion and gain compression in GaAs FET's," IEEE Trans. Microwave Theory Tech., vol. MTT-27, pp. 400-408, May 1979.

[3] R. A. Minasian, "Intermodulation distortion analysis of MESFET amplifiers using the Volterra series representation," IEEE Trans. Microwave Theory Tech., vol. MTT-28, pp. 1-8, Jan. 1980.

[4] A. M. Khadr and R. H. Johnston, "Distortion in high-frequency FET amplifiers," IEEE J. Solid-State Circuit, vol. SC-9, pp. 180-189, Aug. 1974.

[5] G. M. Lambrianou and C. S. Aitchison, "Optimization of third-order intermodulation product and output power from an $\mathrm{x}$-band MESFET amplifier using Volterra series analysis," IEEE Trans. Microwave Theory Tech., vol. MTT-33, pp. 1395-1403, Dec. 1985.

[6] J. Bussgang, L. Ehrman, and J. Graham, "Analysis of nonlinear systems with multiple inputs," Proc. IEEE, vol. 62, pp. 1089-1119, Aug. 1974.

[7] S. A. Maas, Nonlinear Microwave Circuits. Norwood, MA: Artech House, 1988.

[8] A. M. Crosmun and S. A. Maas, "Minimization of intermodulation distortion in GaAs MESFET small-signal amplifiers," IEEE Trans. Microwave Theory Tech., vol. 37, pp. 1411-1417, Sep. 1989.

[9] J. C. Pedro and J. Perez, "Accurate simulation of GaAs MESFET's intermodulation distortion using a new drain-source current model," 
IEEE Trans. Microwave Theory Tech., vol. 42, pp. 25-33, Jan. 1994.

[10] R. E. Williams and D. W. Show, "Graded channel FET's: improved linearity and noise figure," IEEE Trans. Electron Devices, vol. ED-25, pp. 600-605, June 1978.

[11] J. A. Higgins and R. L. Kuvas, "Analysis and improvement of intermodulation distortion in GaAs power FET's," IEEE Trans. Microwave Theory Tech., vol. MTT-28, pp. 9-17, Jan. 1980.

[12] N. Wiener, Nonlinear Problems in Random Theory, Technology Press, New York, 1958. 
APPENDIX A

CURVE FITTING MATLAB PROGRAM 
\% Curve fitting matlab program.

\% Calculating $n$ coefficients at VGS $=-0.5$ and VDS $=1.5$

vgs $=\left[\begin{array}{lllll}-1 & -.7 & -.5 & -.3 & 0\end{array}\right]$

vgsnew $=\left[\begin{array}{lllll}-.5 & -.2 & 0 & .2 & .5\end{array}\right]$;

$v g d=\left[\begin{array}{lllll}0.995 & 1.484 & 1.99 & 2.98 & 4.48\end{array}\right]$;

vgdnew $=\left[\begin{array}{lllll}-0.995 & -0.506 & 0 & 0.99 & 2.49\end{array}\right]$;

$v d s=\left[\begin{array}{llllll}0.49455 & 0.98377 & 1.49 & 2.48 & 3.98\end{array}\right]$;

vdsnew $=\left[\begin{array}{lllll}-0.995 & -0.506 & 0 & 0.99 & 2.48\end{array}\right]$;

cgs $=\left[\begin{array}{lllll}.20780 & .24693 & .27179 & .29573 & .33700\end{array}\right]$;

$\operatorname{cgd}=\left[\begin{array}{lllll}.13513 & .08116 & .06098 & 04053 & .02867\end{array}\right]$;

$\mathrm{gm}=\left[\begin{array}{lllll}.02595 & .03567 & .04017 & 04371 & .04894\end{array}\right]$;

gds=[0.022477 0.008039 .0051677.0033096 0.0023804];

p1 =polyfit $($ vgsnew,cgs,3)

vgs $1=-0.5: .001: 0.5$;

cgs1 = polyval(p1,vgs1);

p11=polyfit(vgs1,cgs1,2)

p2=polyfit(vgdnew,cgd,3)

$\operatorname{vgd} 1=-1: .01: 2.5$;

$\operatorname{cgd} 1$ = polyval(p2,vgd1);

p22=polyfit (vgd1,cgd1,2)

p3=polyfit(vgsnew,gm,3)

vgs1=-0.5:.001:0.5;

gm1 =polyval(p3,vgs1);

p33=polyfit(vgs1,gm1,2)

p4=polyfit(vdsnew,gds,2)

vds $1=-1: .01: 2.5$;

gds1 = polyval(p4,vds1);

p44=polyfit(vds1,gds1,2)

save fitting0 p11 p22 p33 p44/ascii

save fiting00 p1 p2 p3 p4 /ascii 
APPENDIX B

INTERMODULATION DISTORTION CALCULATION USING

MATLAB PROGRAM 
$\%$ E1718515 MESFET device with $0.5 \mu \mathrm{m}$ gate length.

\%Matlab program to calculate the intermodulation distortion at $\mathrm{V}_{\mathrm{Gs}}=-0.5 \mathrm{~V}$ $\%$ and $\mathrm{V}_{\mathrm{DS}}=1.5 \mathrm{~V}$.

$\mathrm{VGS}=-0.50$

$\mathrm{VDS}=1.5$;

I=sqrt(-1);

$\mathrm{pi}=4^{\star} \operatorname{atan}(1)$;

Cds $=0.08846^{\star} 10^{\wedge}(-12)$;

$\mathrm{Ri}=3.57$;

Cgd $1=0.06098 * 10^{\wedge}(-12)$

$\mathrm{Cgd} 2=-0.0396^{*} 10^{\wedge}(-12)$;

$\mathrm{Cgd} 3=0.012708^{\star} 10^{\wedge}(-12)$;

gm $1=0.04017$;

gm2 $=0.021617935$;

gm3=-0.0107902;

Cgs $1=0.27179 * 10^{\wedge}(-12)$;

Cgs2 $=0.125782 * 10^{\wedge}(-12)$;

Cgs $3=0.00383 * 10^{\wedge}(-12)$;

gds $1=0.0051677$;

gds $2=-0.009619$;

gds $3=0.0033389$;

Rs=1.44;

$\mathrm{L}=1.18$ * $10^{\wedge}(-12)$;

$\mathrm{ZG}=51$;

$Z \mathrm{~L}=55.59+\left(9 * 10^{\wedge}(-12)\right) * \mathrm{I}$;

$Y S=1 / Z G$;

$Y L=1 / Z L$;

$Y L 2=1 /(\operatorname{real}(Z L)+I * i m a g(Z L) * 2)$; 
$\mathrm{Vs}=0.0563$

pindbm $=10 * \log 10\left(\left(\mathrm{Vs}^{\wedge} 2 /(4 * 50)\right) / 10^{\wedge}(-3)\right)$;

for $k=1: 3$,

$\mathrm{f} 1(\mathrm{k})=\mathrm{k}^{\star} 0.72975^{\star} 10^{\wedge} 9$;

$w 1(k)=2 * p^{\star} f 1(k)$;

$w(k)=w 1(k)$;

$\mathrm{f} 2(\mathrm{k})=\mathrm{f} 1(\mathrm{k})+0.50 * 10^{\wedge} 6$

$f 12(k)=f 1(k)-f 2(k)$

$w d(k)=2 * p{ }^{*} f 12(k)$;

gme1(k)=gm1/(1+(Ri*Cgs1* $w 1(k) \star I)) ;$

$\operatorname{cge} 1(\mathrm{k})=\mathrm{Cgs} 1^{\star} \mathrm{w} 1(\mathrm{k}){ }^{\star} \mathrm{I} /\left(1+\left(\mathrm{Ri}^{\star} \mathrm{Cgs} 1^{\star} \mathrm{w} 1(\mathrm{k})^{\star} \mathrm{I}\right)\right)$;

gme2(k)= gm1/(1+(Ri*Cgs $1 * 2 * w 1(k) * I)) ;$

$\operatorname{cge} 2(\mathrm{k})=\operatorname{Cgs} 1{ }^{*} 2{ }^{*} \mathrm{w} 1(\mathrm{k}){ }^{\star} \mathrm{I} /\left(1+\left(\mathrm{Ri}^{\star} \mathrm{Cgs} 1{ }^{*}{ }^{*} \mathrm{w} 1(\mathrm{k}){ }^{\star} \mathrm{I}\right)\right)$;

$\operatorname{gmewd}(\mathrm{k})=\operatorname{gm} 1 /\left(1+\left(\mathrm{Ri}^{\star} \mathrm{Cgs} 1^{*} \mathrm{wd}(\mathrm{k}) \star \mathrm{I}\right)\right)$;

cgewd(k)= Cgs $1{ }^{*} w d(k) \star I /\left(1+\left(\operatorname{Ri}^{*} \operatorname{Cgs} 1^{*} w d(k) \star I\right)\right)$;

$\mathrm{YLwd}(\mathrm{k})=1 /\left(\operatorname{real}(\mathrm{ZL})+\left(I^{*} \operatorname{imag}(\mathrm{ZL}) *(\mathrm{wd}(\mathrm{k}) / \mathrm{w} 1(\mathrm{k}))\right)\right)$

YDS1 $1(k)=\operatorname{gds} 1+(w 1(k) * C d s * I)$

YDS2 $(k)=\operatorname{gds} 1+\left(2 * w 1(k){ }^{\star} \mathrm{Cds}^{\star} \mathrm{I}\right)$;

YDSwd $(k)=\operatorname{gds} 1+(w d(k) \star C d s * I)$;

Yo1 $(k)=$ YDS1 $(k)+\left(w 1(k){ }^{\star} \mathrm{Cgd} 1{ }^{*} \mathrm{I}\right)+\mathrm{YL}$;

Yo2(k) $=$ YDS2 $(k)+(2 * w 1(k) \star C g d 1 * I)+Y L 2$;

Yowd(k) $=$ YDSwd(k)+(wd(k)*Cgd1*I) + YLwd(k);

YRL1(k)= $1 /(R s+(w 1(k) * L * I))$

$Y R L 2(k)=1 /\left(R s+\left(2 * w 1(k){ }^{\star}{ }^{\star} I\right)\right)$;

YRLwd(k) $=1 /\left(\operatorname{Rs}+\left(w d(k){ }^{\star}{ }^{\star} I\right)\right)$;

$Y 11(k)=Y S+(w 1(k) * C g d 1 * I)+\operatorname{cge} 1(k) ;$

$\mathrm{Y} 12(\mathrm{k})=-\mathrm{w} 1(\mathrm{k}){ }^{*} \mathrm{Cgd} 1 * \mathrm{I}$;

$\mathrm{Y} 13(\mathrm{k})=-\operatorname{cge} 1(\mathrm{k})$;

$Y 21(k)=-(w 1(k) \star C g d 1 * I)+\operatorname{gme} 1(k)$; 
$\mathrm{Y} 22(\mathrm{k})=\mathrm{Yol}(\mathrm{k})$

$\mathrm{Y} 23(\mathrm{k})=-(\mathrm{YDS} 1(\mathrm{k})+\mathrm{gme} 1(\mathrm{k}))$;

$\mathrm{Y} 31(\mathrm{k})=-(\operatorname{cge} 1(\mathrm{k})+\operatorname{gme} 1(\mathrm{k}))$;

$\mathrm{Y} 32(\mathrm{k})=-\mathrm{YDS} 1(\mathrm{k})$;

$\mathrm{Y} 33(\mathrm{k})=\operatorname{cge} 1(\mathrm{k})+\mathrm{gme} 1(\mathrm{k})+\mathrm{YDS} 1(\mathrm{k})+\mathrm{YRL} 1(\mathrm{k})$;

$A=[Y 11(k)$ Y12(k) Y13(k); Y21(k) Y22(k) Y23(k); Y31(k) Y32(k)

Y33(k)];

$\operatorname{delta} 1(\mathrm{k})=\operatorname{det}(\mathrm{A})$;

term $11(\mathrm{k})=1 /\left(1+\left(\mathrm{Ri}^{\star}\left(\mathrm{w} 1(\mathrm{k}) * \mathrm{Cgs} 1^{\star} \mathrm{I}\right)\right)\right)$;

term 12(k) $=\mathrm{YL}^{\star}(\mathrm{YDS} 1(\mathrm{k})+\mathrm{YRL} 1(\mathrm{k}))$;

term13(k) $=$ YRL1(k)* $\left(\mathrm{YDS} 1(\mathrm{k})+\left(\mathrm{w} 1(\mathrm{k}){ }^{\star} \mathrm{Cgd} 1{ }^{*} \mathrm{I}\right)\right)$;

H1cw1(k) $=(\mathrm{YS} / \operatorname{delta} 1(\mathrm{k}))^{\star}$ term11(k)*(term 12(k)+term13(k));

termaa $(k)=\left(I^{\star} w 1(k){ }^{\star} \mathrm{Cgd} 1+Y L\right) \star(\operatorname{cge} 1(k)+\operatorname{gme} 1(k)+Y D S 1(k)+Y R L 1(k))$;

termab $(k)=Y D S 1(k) \star(\operatorname{cge} 1(k)+Y R L 1(k))$;

H1vlw1(k)=(YS/delta1(k))* (termaa $(k)+\operatorname{termab}(k))$;

term 14(k) $=Y^{*}(\operatorname{cge} 1(k)+g m e 1(k)+Y D S 1(k)+Y R L 1(k))$;

term 15(k)=YRL1(k)*(YDS1(k)+gme1(k));

H1gdw1(k)=(YS/delta1 (k))*(term14(k)+term15(k));

term 16(k)= YRL1(k)*((w1(k)*Cgd1*I)-gme1(k));

term 17(k)= YL* $(\operatorname{cgel}(\mathrm{k})+\mathrm{gme} 1(\mathrm{k}))$;

H1dsw1 $(k)=(Y S / \operatorname{delta1}(k))^{\star}($ term 16(k)-term 17(k));

term 18(k) $=\left(\mathrm{w} 1(\mathrm{k}){ }^{\star} \mathrm{Cgd1}{ }^{\star} \mathrm{I}\right)^{\star}(\operatorname{cge} 1(\mathrm{k})+\mathrm{gme1}(\mathrm{k})+\mathrm{YDS} 1(\mathrm{k})+\mathrm{YRL1}(\mathrm{k}))$;

H1w1(k) $=\left(Y S /\right.$ delta1(k) ${ }^{*}\left(\mathrm{YDS} 1(\mathrm{k}){ }^{*} \operatorname{cge} 1(\mathrm{k})+\right.$ term18(k)-gme1(k)*YRL1(k)

) ;

$\operatorname{vol}(\mathrm{k})=\mathrm{Vs} \mathrm{abs}^{\mathrm{a}}(\mathrm{H} 1 \mathrm{w} 1(\mathrm{k}))$;

iol $(k)=\operatorname{vol}(k) / Z L$;

$\operatorname{pol}(\mathrm{k})=\operatorname{real}(\operatorname{vol}(\mathrm{k}) * \operatorname{conj}(\mathrm{iol}(\mathrm{k})))$;

poldb(k)=10* $\log 10($ po $1(\mathrm{k}))$;

$\operatorname{po} 1 \mathrm{dbm}(\mathrm{k})=10^{*} \log 10\left(\operatorname{pol}(\mathrm{k}) / 10^{\wedge}(-3)\right)$;

$\mathrm{Y} 112 \mathrm{w}(\mathrm{k})=\mathrm{YS}+\left(2{ }^{*} \mathrm{w} 1(\mathrm{k}){ }^{\star} \mathrm{Cgd1}{ }^{*} \mathrm{I}\right)+\mathrm{cge} 2(\mathrm{k})$ 
$Y 122 w(k)=-2^{*} w 1(k) * \operatorname{Cgd1}{ }^{\star} I$

$\mathrm{Y} 132 \mathrm{w}(\mathrm{k})=-\mathrm{cge} 2(\mathrm{k})$;

$\mathrm{Y} 212 \mathrm{w}(\mathrm{k})=-\left(2^{\star} \mathrm{w} 1(\mathrm{k}){ }^{\star} \mathrm{Cgd} 1{ }^{\star} \mathrm{I}\right)+\mathrm{gme} 2(\mathrm{k})$;

$\mathrm{Y} 222 \mathrm{w}(\mathrm{k})=\mathrm{Yo2}(\mathrm{k})$

$\mathrm{Y} 232 \mathrm{w}(\mathrm{k})=-(\mathrm{YDS} 2(\mathrm{k})+\mathrm{gme} 2(\mathrm{k}))$;

$\mathrm{Y} 312 \mathrm{w}(\mathrm{k})=-(\mathrm{cge} 2(\mathrm{k})+\mathrm{gme} 2(\mathrm{k}))$;

$\mathrm{Y} 322 \mathrm{w}(\mathrm{k})=-\mathrm{YDS} 2(\mathrm{k})$;

$Y 332 w(k)=\operatorname{cge} 2(k)+g m e 2(k)+Y D S 2(k)+Y R L 2(k)$;

$B=[Y 112 w(k) Y 122 w(k) Y 132 w(k) ; Y 212 w(k) Y 222 w(k) Y 232 w(k) ;$

$\mathrm{Y} 312 \mathrm{w}(\mathrm{k}) \mathrm{Y} 322 \mathrm{w}(\mathrm{k}) \mathrm{Y} 332 \mathrm{w}(\mathrm{k})]$;

$\operatorname{delta2}(k)=\operatorname{det}(B)$;

term $21(\mathrm{k})=1 /\left(1+\left(\mathrm{Ri}^{\star}\left(2^{\star} \mathrm{w} 1(\mathrm{k}){ }^{\star} \mathrm{Cgs} 1^{\star} \mathrm{I}\right)\right)\right)$

term22(k) $=$ YL2 $*(Y D S 2(k)+Y R L 2(k))$;

term23(k) $=$ YRL2(k)*(YDS2(k)+(2* $\left.\left.1(k){ }^{\star} \mathrm{Cgd} 1 * \mathrm{I}\right)\right)$;

term24(k)= $\left(2^{\star} \mathrm{w} 1(\mathrm{k})^{\star} \mathrm{Cgd} 1^{\star} \mathrm{I}\right)^{\star}(\mathrm{YRL} 2(\mathrm{k})+\mathrm{YS})$;

term25(k) $=\mathrm{YL} 2 *\left(\mathrm{YS}+\left(2{ }^{\star} \mathrm{w} 1(\mathrm{k}){ }^{\star} \mathrm{Cgd} 11^{\star} \mathrm{I}\right)\right)$;

term26(k) $=$ YDS2 $(k) *(Y R L 2(k)+Y S)$;

$\mathrm{H} 2 \mathrm{c} 2 \mathrm{w}(\mathrm{k})=(1 / \mathrm{delta} 2(\mathrm{k}))^{\star} \operatorname{term} 21(\mathrm{k})^{\star}\left(\mathrm{H} 1 \mathrm{cw} 1(\mathrm{k}){ }^{\wedge} 2^{\star}\left(-2{ }^{*} \mathrm{w} 1(\mathrm{k}){ }^{\star} \mathrm{Cgs} 2^{\star} \mathrm{I}^{\star}(\right.\right.$ term $22(k)+$ term $23(k))-g m 2 *(\operatorname{term} 24(k)+$ term $25(k)))-H 1 g d w 1(k) \wedge 2^{\star}\left(2^{\star} w 1(k){ }^{\star} C\right.$ $\left.\left.\mathrm{gd} 2{ }^{\star} \mathrm{I}\right) *(\operatorname{term} 22(\mathrm{k})+\operatorname{term} 26(\mathrm{k}))-\mathrm{H} 1 \mathrm{dsw} 1(\mathrm{k}){ }^{\wedge}{ }^{\star} \mathrm{gds} 2 *(\operatorname{term} 24(\mathrm{k})+\operatorname{term} 25(\mathrm{k}))\right)$ ;

term27(k)= cge2(k)*(YL2+YRL2(k));

term28(k)=YS ${ }^{\star}(\operatorname{cge} 2(k)+Y R L 2(k))$;

term29(k)=(YRL2(k)+YL2)*(gme2(k)+YDS2 $(k))$;

term210(k)=YL2*(YRL2(k)+cge2(k));

term211(k) $=(Y S+Y L 2+Y R L 2(k)) *(\operatorname{cge} 2(k)+g m e 2(k)+Y R L 2(k))$;

term212(k) $=$ YDS2 $(k) *(Y S+Y L 2)$

$\mathrm{H} 2 \mathrm{gd} 2 \mathrm{w}(\mathrm{k})=(1 / \mathrm{delta} 2(\mathrm{k}))^{\star}(\mathrm{H} 1 \mathrm{cw} 1(\mathrm{k}) \wedge 2 *(\mathrm{gm} 2 *(\operatorname{term} 27(\mathrm{k})+\operatorname{term} 28(\mathrm{k}))-(2$ *

w $\left.\left.1(\mathrm{k}){ }^{\star} \mathrm{Cgs} 2{ }^{\star} \mathrm{I}\right){ }^{\star}(\operatorname{term} 29(\mathrm{k})+\operatorname{term} 210(\mathrm{k}))\right)-\mathrm{H} 1 \mathrm{gdw} 1(\mathrm{k}){ }^{\wedge} 2{ }^{\star}\left(2{ }^{*} \mathrm{w} 1(\mathrm{k}){ }^{\star} \mathrm{Cgd} 2{ }^{\star} \mathrm{I}\right)$

*(term211(k)+term212(k))+H1dsw1(k)^ $\left.2{ }^{\star} \operatorname{gds} 2 *(\operatorname{term} 27(\mathrm{k})+\operatorname{term} 28(\mathrm{k}))\right)$;

term213(k)=YRL2(k)*((-2* w1(k)*Cgd1*I)+gme2(k));

term214(k)=YL2*(cge2(k)+gme2(k));

term215(k) $=(\mathrm{YS}+\mathrm{YL} 2+\mathrm{YRL} 2(\mathrm{k}))^{\star}\left(2^{*} \mathrm{~W} 1(\mathrm{k})^{\star} \mathrm{Cgd} 1{ }^{\star} \mathrm{I}+\mathrm{cge} 2(\mathrm{k})\right)$;

term216(k)=YS* $(Y R L 2(k)+Y L 2)$; 
term217(k) $=(Y S+Y L 2+Y R L 2(k)) *(\operatorname{cge} 2(k)+g m e 2(k)) ;$

term 218(k)=YS*YRL2(k);

$\mathrm{H} 2 \mathrm{ds} 2 \mathrm{w}(\mathrm{k})=(1 / \mathrm{delta} 2(\mathrm{k}))^{\star}\left(\mathrm{H} 1 \mathrm{cw} 1(\mathrm{k}){ }^{\wedge}{ }^{*}\left(2^{\star}{ }^{*} \mathrm{w} 1(\mathrm{k}){ }^{\star} \mathrm{Cgs} 2{ }^{\star} \mathrm{I}^{\star}(\operatorname{term} 213(\mathrm{k})+\right.\right.$ ter $\mathrm{m} 214(\mathrm{k}))-\mathrm{gm} 2 *(\mathrm{term} 215(\mathrm{k})+\operatorname{term} 216(\mathrm{k})))+\mathrm{H} 1 \mathrm{gdw} 1(\mathrm{k}){ }^{\wedge}{ }^{*}\left(2{ }^{\star} \mathrm{w} 1(\mathrm{k}){ }^{\star} \mathrm{Cgd} 2\right.$ * I)*(term217(k)+term218(k))-H1dsw1(k)^2*gds2*(term215(k)+term216(k))) ;

term 219(k)=YS* (cge2(k)+YRL2(k));

term $220(\mathrm{k})=\mathrm{YRL} 2(\mathrm{k}){ }^{\star}\left(2 * \mathrm{w} 1(\mathrm{k}){ }^{\star} \mathrm{Cgd} 1+\mathrm{cge} 2(\mathrm{k})\right)$;

term 221 $(\mathrm{k})=\left(-2^{\star} \mathrm{w} 1(\mathrm{k}) \star \mathrm{Cgd} 1\right)^{\star}(\mathrm{cge} 2(\mathrm{k})+\mathrm{gme} 2(\mathrm{k})+\mathrm{YDS} 2(\mathrm{k})+\mathrm{YRL} 2(\mathrm{k}))$;

term222(k)=gme2(k)*YRL2(k) - YDS2(k)*cge2(k);

term223(k)=YS*(YDS2(k)+YRL2(k));

term224(k) $=(\mathrm{YS}+\mathrm{YRL} 2(\mathrm{k}))^{\star}(\mathrm{cge} 2(\mathrm{k})+\mathrm{gme} 2(\mathrm{k}))$;

$\mathrm{H} 22 \mathrm{w}(\mathrm{k})=(1 / \text { delta2 }(\mathrm{k}))^{\star}\left(\mathrm{H} 1 \mathrm{cw} 1(\mathrm{k}){ }^{\wedge}{ }^{\star}(-\mathrm{gm} 2 *(\operatorname{term} 219(\mathrm{k})+\right.$ term $220(\mathrm{k}))+2$ *

w $\left.1(\mathrm{k}){ }^{\star} \mathrm{Cgs} 2{ }^{\star} \mathrm{I}^{\star}(\operatorname{term} 221(\mathrm{k})+\operatorname{term} 222(\mathrm{k}))\right)+\mathrm{H} 1 \mathrm{gdw} 1(\mathrm{k})^{\wedge} 2{ }^{\star}{ }^{\star} \mathrm{w} 1(\mathrm{k}){ }^{\star} \mathrm{Cgd} 2$

${ }^{\star} I^{\star}\left(\operatorname{term} 223(\mathrm{k})+\right.$ term224(k))-H1 dsw $1(\mathrm{k}) \wedge{ }^{\star}{ }^{\star} \mathrm{gds} 2 *(\operatorname{term} 219(\mathrm{k})+\operatorname{term} 220(\mathrm{k}))$ );

$Y 11 w d(k)=Y S+(w d(k) * C g d 1 * I)+$ cgewd(k);

$\mathrm{Y} 12 \mathrm{wd}(\mathrm{k})=-\mathrm{wd}(\mathrm{k}){ }^{\star} \mathrm{Cgd1}{ }^{\star} \mathrm{I}$;

$Y 13 w d(k)=-$ cgewd $(k)$;

$Y 21 w d(k)=-(w d(k) * C g d 1 * I)+\operatorname{gmewd}(k)$;

Y22wd(k)= Yowd(k);

Y23wd(k)=-(YDSwd(k)+gmewd(k));

Y31wd(k)= - $($ cgewd $(k)+\operatorname{gmewd}(k))$;

$\mathrm{Y} 32 \mathrm{wd}(\mathrm{k})=-\mathrm{YDS} w \mathrm{~d}(\mathrm{k})$;

$Y 33 w d(k)=$ cgewd $(k)+g m e w d(k)+Y D S w d(k)+Y R L w d(k)$;

$\mathrm{C}=[\mathrm{Y} 11 \mathrm{wd}(\mathrm{k}) \mathrm{Y} 12 \mathrm{wd}(\mathrm{k}) \mathrm{Y} 13 w d(\mathrm{k}) ; \mathrm{Y} 21 \mathrm{wd}(\mathrm{k}) \mathrm{Y} 22 w d(\mathrm{k}) \mathrm{Y} 23 w d(k) ;$ Y31wd(k) Y32wd(k) Y33wd(k)];

$\operatorname{deltawd}(k)=\operatorname{det}(C)$;

term $21 w d(k)=1 /\left(1+\left(R^{*}(w d(k) \star C g s 1 * I)\right)\right)$

term22wd(k) $=$ YLwd(k)* $(Y D S w d(k)+Y R L w d(k))$;

term23wd(k)= YRLwd(k)*(YDSwd(k)+(wd(k)*Cgd1*I));

term24wd(k) $=(w d(k) * C g d 1 * I) *(Y R L w d(k)+Y S)$;

term25wd(k) $=\mathrm{YLwd}(\mathrm{k}) *(\mathrm{YS}+(\mathrm{wd}(\mathrm{k}) \star \mathrm{Cgd} 1 * I))$;

term26wd(k)= YDSwd(k)* $(Y R L w d(k)+Y S)$; 
$\mathrm{H} 2 \mathrm{cwd}(\mathrm{k})=(1 /$ deltawd $(\mathrm{k})))^{\star}$ term $21 \mathrm{wd}(\mathrm{k}) *\left(\mathrm{H} 1 \mathrm{cw} 1(\mathrm{k}){ }^{\wedge} 2 *((-\mathrm{wd}(\mathrm{k}) \star \mathrm{Cgs} 2 * \mathrm{I}) \star(\mathrm{t}\right.$ erm22wd(k)+term23wd(k))-gm2*(term24wd(k)+term25wd(k)))-H1gdw1(k) ${ }^{\wedge} 2 *\left(\mathrm{wd}(\mathrm{k}){ }^{\star} \mathrm{Cgd} 2 * \mathrm{I}\right) *($ term $22 \mathrm{wd}(\mathrm{k})+$ term $26 \mathrm{wd}(\mathrm{k}))-\mathrm{H} 1 \mathrm{dsw} 1(\mathrm{k}){ }^{\wedge} 2{ }^{\star} \mathrm{gds} 2 *($ ter $\operatorname{m} 24 w d(k)+$ term $25 w d(k)))$;

term27wd(k)= cgewd(k)* $(Y L w d(k)+Y R L w d(k))$;

term $28 w d(k)=Y S^{\star}($ cgewd $(k)+Y R L w d(k))$;

term29wd(k)=(YRLwd(k)+YLwd(k))*(gmewd(k)+YDSwd(k));

term210wd(k)=YLwd(k)* $(Y R L w d(k)+$ cgewd(k));

term $211 w d(k)=(Y S+Y L w d(k)+Y R L w d(k)) *(\operatorname{cgewd}(k)+\operatorname{gmewd}(k)+Y R L w d$ (k));

term212wd(k)=YDSwd(k)*(YS+YLwd(k));

$\mathrm{H} 2 \mathrm{gdwd}(\mathrm{k})=(1 /$ deltawd(k) $) *\left(\mathrm{H} 1 \mathrm{cw} 1(\mathrm{k})^{\wedge} 2^{*}(\mathrm{gm} 2 *(\right.$ term $27 \mathrm{wd}(\mathrm{k})+$ term $28 \mathrm{wd}($ k) $\left.)-\left(w d(k){ }^{\star} \mathrm{Cgs} 2 * \mathrm{I}\right) \star(\operatorname{term} 29 \mathrm{wd}(\mathrm{k})+\operatorname{term} 210 \mathrm{wd}(\mathrm{k}))\right)-\mathrm{H} 1 \mathrm{gdw} 1(\mathrm{k}){ }^{\wedge}{ }^{\star}(\mathrm{wd}(\mathrm{k})$ * $\mathrm{Cgd} 2 \star 1) \star(t e r m 211 \mathrm{wd}(\mathrm{k})+$ term $212 \mathrm{wd}(\mathrm{k}))+\mathrm{H} 1 \mathrm{dsw} 1(\mathrm{k}){ }^{\wedge} 2 \star \mathrm{gds} 2 *($ term27wd(k )$+\operatorname{term} 28 w d(k)))$;

term213wd(k)=YRLwd(k)*((-wd(k)*Cgd1*I)+gmewd(k));

term214wd(k)=YLwd(k)* $(\operatorname{cgewd}(\mathrm{k})+\operatorname{gmewd}(\mathrm{k}))$;

term215wd(k)=(YS+YLwd(k)+YRLwd(k))* $(w d(k) \star C g d 1 * I+\operatorname{cgewd}(k))$;

term216wd(k)=YS*(YRLwd(k)+YLwd(k));

term217wd(k) $=(Y S+Y L w d(k)+Y R L w d(k)) *(\operatorname{cgewd}(k)+\operatorname{gmewd}(k))$;

term $218 w d(k)=Y S * Y R L w d(k)$;

$\mathrm{H} 2 \mathrm{dswd}(\mathrm{k})=(1 / \text { deltawd }(\mathrm{k}))^{\star}\left(\mathrm{H} 1 \mathrm{cw} 1(\mathrm{k}){ }^{\wedge} 2^{\star}\left(\mathrm{wd}(\mathrm{k}){ }^{\star} \mathrm{Cgs}{ }^{\star}{ }^{*}{ }^{\star}(\operatorname{term} 213 \mathrm{wd}(\mathrm{k})+\mathrm{t}\right.\right.$ erm214wd(k))-gm2*(term215wd(k)+term 216wd(k)))+H1gdw1(k)^2*wd(k) ${ }^{*} \mathrm{Cgd} 2{ }^{*} I^{*}($ term $217 \mathrm{wd}(\mathrm{k})+\operatorname{term} 218 w d(k))-\mathrm{H} 1 \mathrm{dsw} 1(\mathrm{k}){ }^{\wedge} 2{ }^{\star} \mathrm{gds} 2{ }^{*}(\operatorname{term} 215 \mathrm{wd}($ k)+term216wd(k)));

term219wd(k)=YS* (cgewd(k)+YRLwd(k));

term220wd(k)=YRLwd(k)* $(w d(k) \star C g d 1+c g e w d(k))$;

term221wd(k)=(-wd(k)*Cgd1*I)*(cgewd(k)+gmewd(k)+YDSwd(k)+YRLw $\mathrm{d}(\mathrm{k}))$;

term222wd(k)=gmewd(k)*YRLwd(k) - YDSwd(k)*cgewd(k); term223wd(k)=YS* $(Y D S w d(k)+Y R L w d(k))$; term224wd(k) $=(Y S+Y R L w d(k)) *(\operatorname{cgewd}(k)+\operatorname{gmewd}(k))$; 
H2wd(k) $=(1 /$ deltawd(k) $) *\left(\right.$ H1cw $1(k){ }^{\wedge} 2^{\star}(-$ gm $2 *($ term $219 w d(k)+$ term $220 w d($ $\left.k))+w d(k) * C g s{ }^{\star} I^{*}(\operatorname{term} 221 w d(k)+\operatorname{term} 222 w d(k))\right)+H 1 g d w 1(k) \wedge 2 * w d(k) *$ $\mathrm{Cgd} 2 * I^{\star}(\operatorname{term} 223 w d(k)+\operatorname{term} 224 w d(k))-H 1 d s w 1(k){ }^{\wedge}{ }^{\star}$ gds2*(term219wd(k )$+\operatorname{term} 220 \mathrm{wd}(\mathrm{k})))$;

term31(k)=YS* $(\operatorname{cge} 1(\mathrm{k})+\mathrm{YRL1}(\mathrm{k}))$;

term 32(k)=YRL1(k)*((w1(k)*Cgd1* $)+\operatorname{cge} 1(k))$;

term33(k) $=\left(-\mathrm{w} 1(\mathrm{k}){ }^{*} \mathrm{Cgd1} 1{ }^{*}{ }^{*}(\operatorname{cge} 1(\mathrm{k})+\mathrm{gme1}(\mathrm{k})+\mathrm{YDS} 1(\mathrm{k})+\mathrm{YRL1}(\mathrm{k}))\right.$;

term34(k)=gme1(k)*YRL1(k) - cge1(k)*YDS1(k);

term35(k)=YS* (cge1(k)+gmel(k)+YDS1(k)+YRL1(k));

term $36(k)=Y R L 1(k) *(g m e 1(k)+\operatorname{cge} 1(k))$;

$\mathrm{H} 3 \mathrm{a}(\mathrm{k})=\left(2{ }^{\star} \mathrm{H} 1 \mathrm{cw} 1(\mathrm{k}){ }^{\star} \mathrm{H} 2 \mathrm{cwd}(\mathrm{k})\right)^{\star}\left(-2^{\star} \mathrm{gm} 2{ }^{\star}(\operatorname{term} 31(\mathrm{k})+\operatorname{term} 32(\mathrm{k}))+\left(2{ }^{*} \mathrm{w} 1\right.\right.$ $(\mathrm{k}) \star \mathrm{Cgs} 2 * \mathrm{I}) *($ term $33(\mathrm{k})+\operatorname{term} 34(\mathrm{k})))$;

$\mathrm{H} 3 \mathrm{~b}(\mathrm{k})=(\operatorname{conj}(\mathrm{H} 1 \mathrm{cw} 1(\mathrm{k})) * \mathrm{H} 2 \mathrm{c} 2 \mathrm{w}(\mathrm{k}))^{\star}\left(-2^{*} \mathrm{gm} 2 *(\operatorname{term} 31(\mathrm{k})+\operatorname{term} 32(\mathrm{k}))+\left(2^{*}\right.\right.$ w1(k)*Cgs2* $)^{\star}($ term 33(k)+term34(k)));

$\mathrm{H} 3 \mathrm{c}(\mathrm{k})=\left(\mathrm{H} 1 \mathrm{cw} 1(\mathrm{k})^{\wedge} 2{ }^{\star} \operatorname{conj}(\mathrm{H} 1 \mathrm{cw} 1(\mathrm{k}))\right) *(-\mathrm{gm} 3 *(\operatorname{term} 31(\mathrm{k})+\operatorname{term} 32(\mathrm{k}))+(\mathrm{w}$ $\left.1(\mathrm{k}){ }^{*} \mathrm{Cgs} 3 * \mathrm{l}\right) *($ term $33(\mathrm{k})+$ term $\left.34(\mathrm{k}))\right)$;

$\mathrm{H} 3 \mathrm{~d}(\mathrm{k})=2{ }^{*} \mathrm{H} 1 \mathrm{gdw} 1(\mathrm{k}){ }^{\star} \mathrm{H} 2 \mathrm{gdwd}(\mathrm{k}){ }^{\star}\left(2 * \mathrm{w} 1(\mathrm{k}){ }^{\star} \mathrm{Cgd} 2 * \mathrm{I}\right) *(\operatorname{term} 35(\mathrm{k})+\operatorname{term} 36($ k));

$\mathrm{H} 3 \mathrm{~h}(\mathrm{k})=\operatorname{conj}(\mathrm{H} 1 \mathrm{gdw} 1(\mathrm{k})){ }^{\star} \mathrm{H} 2 \mathrm{gd} 2 \mathrm{w}(\mathrm{k}) *\left(2 * \mathrm{w} 1(\mathrm{k}){ }^{*} \mathrm{Cgd} 2 * \mathrm{I}\right) *($ term $35(\mathrm{k})+$ ter $\mathrm{m} 36(\mathrm{k}))$;

$\mathrm{H} 3 \mathrm{i}(\mathrm{k})=\mathrm{H} 1 \mathrm{gdw} 1(\mathrm{k}){ }^{\wedge}{ }^{*} \operatorname{conj}(\mathrm{H} 1 \mathrm{gdw} 1(\mathrm{k}))^{\star}\left(\mathrm{w} 1(\mathrm{k}){ }^{\star} \mathrm{Cgd} 3{ }^{\star} \mathrm{I}\right) \star(\operatorname{term} 35(\mathrm{k})+$ term 36(k));

$\mathrm{H} 3 \mathrm{j}(\mathrm{k})=2{ }^{\star} \mathrm{H} 1 \mathrm{dsw} 1(\mathrm{k}){ }^{\star} \mathrm{H} 2 \mathrm{dswd}(\mathrm{k}){ }^{\star} 2{ }^{\star} \mathrm{gds} 2{ }^{*}($ term $31(\mathrm{k})+$ term $32(\mathrm{k}))$;

$\mathrm{H} 3 \mathrm{k}(\mathrm{k})=\mathrm{conj}(\mathrm{H} 1 \mathrm{dsw} 1(\mathrm{k}))^{\star} \mathrm{H} 2 \mathrm{ds} 2 \mathrm{w}(\mathrm{k}){ }^{\star} 2{ }^{\star} \mathrm{gds} 2 *(\operatorname{term} 31(\mathrm{k})+\operatorname{term} 32(\mathrm{k}))$;

$\mathrm{H} 31(\mathrm{k})=\mathrm{H} 1 \mathrm{dsw} 1(\mathrm{k}){ }^{\wedge} 2{ }^{*}$ conj(H1dsw1(k))* gds3*(term31(k)+term32(k));

$\mathrm{H} 3(\mathrm{k})=(1 /$ delta $1(\mathrm{k})) \star(\mathrm{H} 3 \mathrm{a}(\mathrm{k})+\mathrm{H} 3 \mathrm{~b}(\mathrm{k})+\mathrm{H} 3 \mathrm{c}(\mathrm{k})+\mathrm{H} 3 \mathrm{~d}(\mathrm{k})+\mathrm{H} 3 \mathrm{~h}(\mathrm{k})+\mathrm{H} 3 \mathrm{i}(\mathrm{k})-\mathrm{H} 3 \mathrm{j}$ (k)-H3k(k)- H3l(k));

$\operatorname{vo3}(k)=(3 / 4) \star V s^{\wedge} 3 * a b s(H 3(k))$;

io3 $(k)=\operatorname{vo3}(k) / Z L$;

$\operatorname{po3}(\mathrm{k})=\operatorname{real}(\operatorname{vo3}(\mathrm{k}) * \operatorname{conj}(\mathrm{io3}(\mathrm{k})))$;

po3db $(k)=10 * \log 10($ po3 $(\mathrm{k}))$;

po3dbm $(\mathrm{k})=10^{*} \log 10\left(\mathrm{po} 3(\mathrm{k}) / 10^{\wedge}(-3)\right)$;

ip3dbm $(k)=(3 *$ poldbm $(k)-$ po3dbm(k) $) / 2$;

end 
save mesfet.dat $\mathrm{f} 1$ po $3 \mathrm{dbm}$ ip $3 \mathrm{dbm} /$ ascii

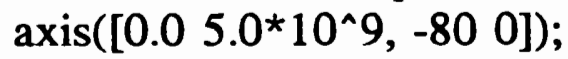

plot(f1,po3dbm),title('plot of freq. dependence of IM at $\left.-18 \mathrm{dBm}^{\prime}\right)$;

xlabel('freq. (GHz)');

ylabel('po3 $\left.(\mathrm{dBm})^{\prime}\right)$;

meta mesfet 


\section{APPENDIX C}

The following is a class project that shows one of the standard methods for intermodulation distortion calculations. In general, the procedure is lengthy and it is clear that the analytical expressions, developed in Chapter III, will simplify the procedure greatly. 


\title{
DESIGN OF MESFET SMALL-SIGNAL AMPLIFIER
}

\author{
BY \\ JOHN KUZMACK AND IMAD AHMAD \\ COURSE \\ ADVANCED MICROWAVE CIRCUIT DESIGN \\ DATE \\ DECEMBER 16TH, 1992
}

Use the MESFET small-signal equivalent circuit shown in Figure 1 for the Avantek AT10650-00 low-noise Ku-band device.

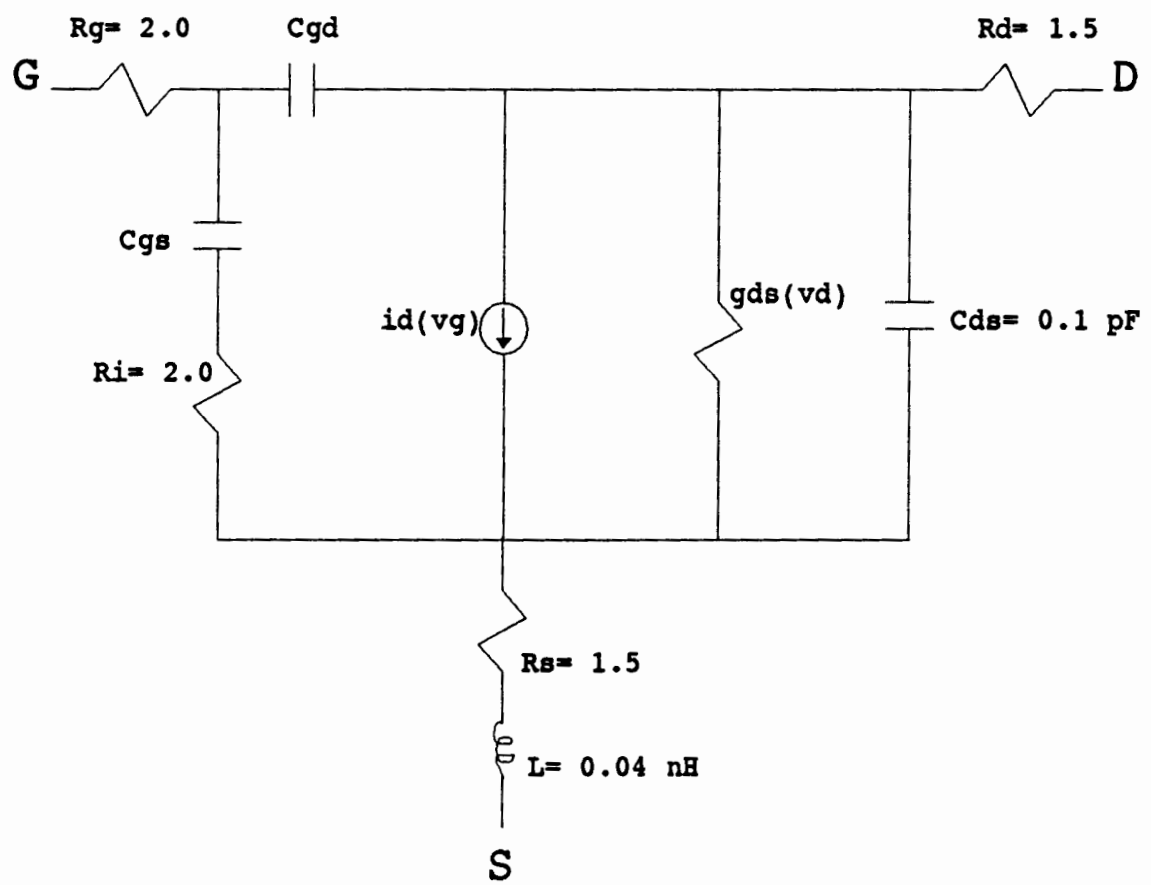

Figure 1. Small-signal nonlinear MESFET equivalent circuit. Four elements $\left(\mathrm{C}_{\mathrm{g} g}, \mathrm{C}_{\mathrm{gd}}, \mathrm{i}_{\mathrm{d}}\right.$, and $\left.\mathrm{g}_{\mathrm{ds}}\right)$ are nonlinear, although Cgd often can be treated as a linear element. 
AT $10 \mathrm{GHz}$

$$
\begin{aligned}
& S_{11}=0.83 \cdot \exp \left[-90 i \cdot \frac{\pi}{180}\right] \quad S_{12}=0.092 \cdot \exp \left[41 i \cdot \frac{\pi}{180}\right] \\
& S_{21}=1.71 \cdot \exp \left[109 i \cdot \frac{\pi}{180}\right] \quad S_{22}=0.63 \cdot \exp \left[-51 i \cdot \frac{\pi}{180}\right] \\
& \text { del }=S_{11} \cdot S_{22}-S_{12} \cdot S_{21} \\
& \text { del }=-0.27-0.408 i \\
& \mid \text { del } \mid=0.489 \\
& K:=\frac{1-\left[\left|S_{11}\right|\right]^{2}-\left[\left|S_{22}\right|\right]^{2}+(|d e l|)^{2}}{2 \cdot\left|S_{12}\right| \cdot\left|S_{21}\right|} \quad K=0.488
\end{aligned}
$$

Therefore potentially unstable.

Since $\quad S_{12} \neq 0 \quad$ the amplifier is bilateral.

$r_{L}=\frac{\left|\frac{s_{12} \cdot s_{21}}{\left[\left|s_{22}\right|\right]^{2}-(\mid \text { del } \mid)^{2}}\right|}{c_{L}=\frac{\overline{\left[s_{22}-\text { del } \cdot \overline{s_{11}}\right]}}{\left[\left|s_{22}\right|\right]^{2}-(\mid \text { del } \mid)^{2}}}$

$$
r_{L}=0.998
$$

$$
\begin{aligned}
& C_{L}=0.368+1.683 i \\
& \left|C_{L}\right|=1.723 \\
& \arg \left[C_{L}\right] \cdot \frac{180}{\pi}=77.661
\end{aligned}
$$

$$
\begin{array}{ll}
r_{S}:=\left|\frac{S_{12} \cdot S_{21}}{\left[\left|S_{11}\right|\right]^{2}-(\mid \text { del } \mid)^{2}}\right| & r_{S}=0.35 \\
c_{S}:=\frac{\overline{\left[S_{11}-\text { del } \cdot \overline{S_{22}}\right]}}{\left[\left|S_{11}\right|\right]^{2}-(\mid \text { del } \mid)^{2}} & C_{S}=-0.206+1.192 i \\
& \left|C_{S}\right|=1.21 \\
& \arg \left[C_{S}\right] \cdot \frac{180}{\pi}=99.793
\end{array}
$$




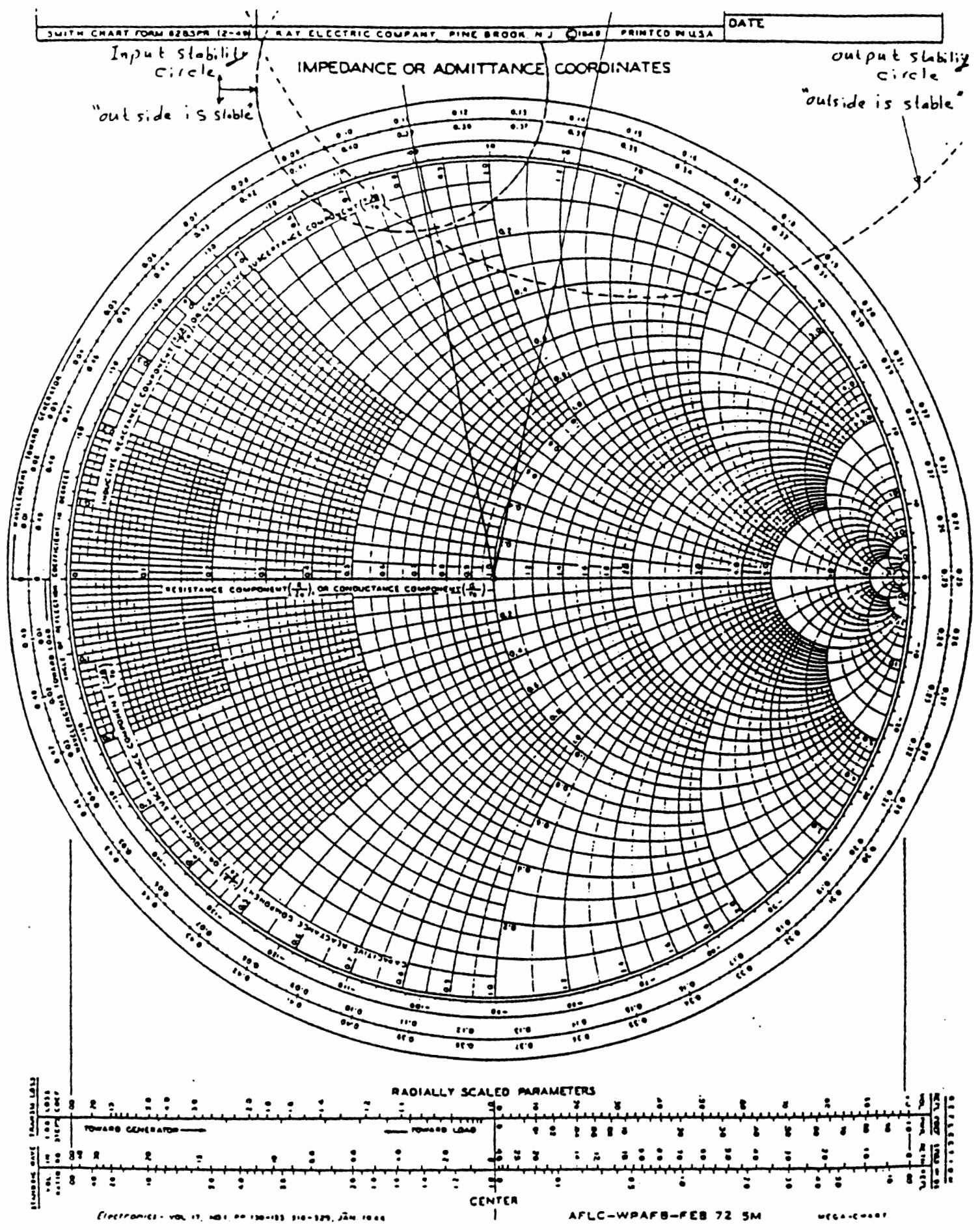


Solve for Qgs and Qgd for model

$C=\frac{C_{0}}{\left[1-\frac{V}{\phi}\right]^{\Gamma}} \quad \Gamma=\frac{1}{2} \quad \operatorname{Cov}=\frac{C_{0}}{\left[1-\frac{V}{\phi}\right]^{\Gamma}} \cdot d V_{0} \quad d Q=C d V_{0}$

$Q=\int_{1}^{\infty} \frac{C_{0}}{\left[1-\frac{V}{\phi}\right]^{\Gamma}} d V_{0} \quad Q:=C_{0} \cdot\left[1-\frac{V}{\phi}\right]^{\Gamma+1} \cdot \frac{-\phi}{1-\Gamma} 0$

$Q:=-2 \cdot C_{0} \cdot \phi \cdot\left[1-\frac{V}{\phi}\right]^{\Gamma}$,

For Cgs $=.25 \mathrm{pf}$ at Vgs $=-1.5$ and $\phi \theta .7$

$\mathrm{Cgs}_{0}=0.25 \cdot 10^{-12} \cdot\left[1-\frac{-1.5}{0.7}\right]^{0.5}$

$$
\mathrm{Cgs}_{0}=4.432 \cdot 10^{-13}
$$

For $\mathrm{Cgd}=.03 \mathrm{pf}$ at Vgs $=-1.5$ and $\mathrm{Vds}=3.0$ and $=0.7$

$\operatorname{Cgd}_{0}=0.03 \cdot 10^{-12} \cdot\left[1-\frac{-4.5}{0.7}\right]^{0.5}$

$\operatorname{Cgd}_{0}=8.177 \cdot 10^{-14}$

From series expansion:

$(1+x)^{n}:=1+n \cdot x+\frac{n \cdot(n-1)}{2 !} \cdot x^{2}+\frac{n \cdot(n-1) \cdot(n-2)}{3 !} \cdot x^{3}+\ldots 0$

For Qgs:

Qgs $:=-2 \cdot \operatorname{Cgs}_{0} \cdot 7 \cdot\left[.5 \cdot \frac{-V}{.7}+\frac{.5 \cdot(-.5)}{2} \cdot\left[\frac{-V}{.7}\right]^{2}+\frac{.5 \cdot(-.5) \cdot(-1.5)}{6} \cdot\left[\frac{-V}{7}\right]^{3}\right]_{0}$

Qgs : $=\mathrm{Cgs}_{1} \cdot V+\mathrm{Cgs}_{2} \cdot \mathrm{V}^{2}+\mathrm{Cgs}_{3} \cdot \mathrm{V}^{3} \mathrm{o}$

Qgs $=0.443 \cdot 10^{-12} \cdot \mathrm{Vgs}+0.158 \cdot 10^{-12} \cdot \mathrm{Vgs}^{2}+0.1128 \cdot 10^{-12} \cdot \mathrm{Vgs}^{3}$ a

For egd:

Qgd $=-2 \cdot \operatorname{Cgd}_{0} \cdot .7 \cdot\left[.5 \cdot \frac{-V}{.7}+\frac{.5 \cdot(-.5)}{2} \cdot\left[\frac{-V}{.7}\right]^{2}+\frac{.5 \cdot(-.5) \cdot(-1.5)}{6} \cdot\left[\frac{-V}{.7}\right]^{3}\right]$

Qgd $=\operatorname{Cgd}_{1} \cdot V+\operatorname{Cgd}_{2} \cdot V^{2}+\operatorname{Cgd}_{3} \cdot V_{0}^{3}$ 
Define constants and variables.
$R_{g}-2$
$L-0.04 \cdot 10^{-9}$
$j-\sqrt{-1}$
$R_{i}=2$
$C_{\text {gs }}=0.25 \cdot 10^{-12}$
$v_{s}=0.8$
$R_{S}=1.5$
$c_{\text {ds }}=0.03 \cdot 10^{-12}$
$Z_{L}=36+j \cdot 68$
$R_{d}=1.5$
$C_{\text {gd }}=0.03 \cdot 10^{-12}$
$z_{s}=36+j \cdot 50$
$g_{d s}=0.00367$
$g_{m}:=0.03311$
$i=1 . .5$

First order frequencies.

$f_{1}=10 \cdot 10^{9} \quad f_{2}=-10.1 \cdot 10^{9}$

Second order frequencies (of interest).

$f_{3}=2 \cdot f_{1}$

$f_{4}:=f_{1}+f_{2}$

Third order frequencies (of interest).

$f_{5}:=2 \cdot f_{1}+f_{2}$

For all frequencies

$\omega_{i}:=2 \cdot \pi \cdot f_{i}$

Solve for Y-parameters.

$$
\begin{array}{lll}
Y 11_{i}:=\frac{1}{R_{i}}+j \cdot \omega_{i} \cdot C_{g s} & \\
Y 12_{i}:=\frac{-1}{R_{i}} \quad Y 13_{i}:=Y 12_{i} & Y 31_{i}:=Y 12_{i} \\
Y 14_{i}:=0 & Y 11_{i}:=Y 14_{i} & Y 15_{i}:=Y 41_{i} \\
Y 21_{i}:=\frac{-1}{R_{i}}+g_{m} & Y 14_{i} & \\
Y 22_{i}:=\frac{1}{R_{i}}+\left[\left[\frac{1}{R_{d}}+\frac{1}{Z_{s}+R_{g}}\right]^{-1}+R_{s}+j \cdot \omega_{i} \cdot L\right]^{1}+j \cdot \omega_{i} \cdot C_{d s}+g_{d s} \\
Y 44_{i}:=\left[\left[\frac{1}{R_{s}+j \cdot \omega_{i} \cdot L}+\frac{1}{Z_{s}+R_{g}}\right]^{1}+R_{d}\right]^{-1}+\frac{1}{Z_{L}}
\end{array}
$$


83

$$
\begin{aligned}
& Y 55_{i}=\left[\left[\frac{1}{R_{s}+j \cdot \omega_{i} \cdot L}+\frac{1}{R_{d}}\right]^{-1}+Z_{s}+R_{g}\right]^{1} \\
& Y 24_{i}=\left[\frac{1}{Z_{L}}-Y 44_{i}\right] \cdot\left[\frac{Z_{s}+R_{g}}{R_{s}+R_{g}+j \cdot \omega_{i} \cdot L+Z_{s}}\right] \quad Y 42_{i}=Y 24_{i} \\
& Y 25_{i}=-Y 55_{i} \cdot\left[\frac{R_{d}}{R_{s}+R_{d}+j \cdot \omega_{i} \cdot L}\right] \\
& Y 52_{i}=Y 25_{i} \\
& Y 23_{i}=\frac{1}{R_{i}}-Y 25_{i} \\
& Y 32_{i}=Y 23_{i} \\
& Y 33_{i}=Y 55_{i}+\frac{1}{R_{i}}+j \cdot \omega_{i} \cdot C_{g d} \\
& Y 34_{i}=\left[Y 44_{i} \frac{1}{Z_{L}}\right] \cdot\left[\frac{R_{s}+j \cdot \omega_{i} \cdot L}{R_{s}+R_{g}+j \cdot \omega_{i} \cdot L+Z_{s}}\right] \\
& Y 35_{i}:=-Y 55_{i} \quad Y 53_{i}:=-Y 55_{i} \quad Y 43_{i}=Y 34_{i} \\
& Y 54_{i}=-Y 34_{i} \quad Y 45_{i}=-Y 34_{i} \\
& Y(i)=\left[\begin{array}{llll}
Y 11_{i} & Y 12_{i} & Y 13_{i} & Y 14_{i} \\
Y 21_{i} & Y 22_{i} & Y 23_{i} & Y 24_{i} \\
Y 31_{i} & Y 32_{i} & Y 33_{i} & Y 34_{i} \\
Y 41_{i} & Y 42_{i} & Y 43_{i} & Y 44_{i}
\end{array}\right] \\
& Y \operatorname{inv}(i):=Y(i)^{-1}
\end{aligned}
$$

Solve for 1 st order voltages at $\omega 1$ and $-\omega 2$.

At $\omega 1$ :

$\left[\begin{array}{l}V 11_{1} \\ V 21_{1} \\ V 31_{1} \\ V 41_{1}\end{array}\right]=-Y \operatorname{inv}(1) \cdot\left[\begin{array}{l}Y 15_{1} \\ Y 25_{1} \\ Y 35_{1} \\ Y 45_{1}\end{array}\right] \cdot V_{S}$
At - $\omega 2$ :

$\left[\begin{array}{l}V 11_{2} \\ V 21_{2} \\ V 31_{2} \\ V 41_{2}\end{array}\right]:=-Y i n v(2) \cdot\left[\begin{array}{l}Y 15_{2} \\ Y 25_{2} \\ Y 35_{2} \\ Y 45_{2}\end{array}\right] \cdot V_{S}$ 
The second-order port voltages are found via the method of nonlinear currents: the term vs $(t)$ is set to zero $\left(V_{5,2, k}=0 ; k=1 \ldots k\right)$, nonlinear current sources at the second-order frequencies are placed at each port, and the second-order port voltages are found from the network's $Y$ matrix. No current source is placed at port 4 , the output port, because there is no nonlinear element in parallel with it. The resulting circuit is shown in Figure 2.

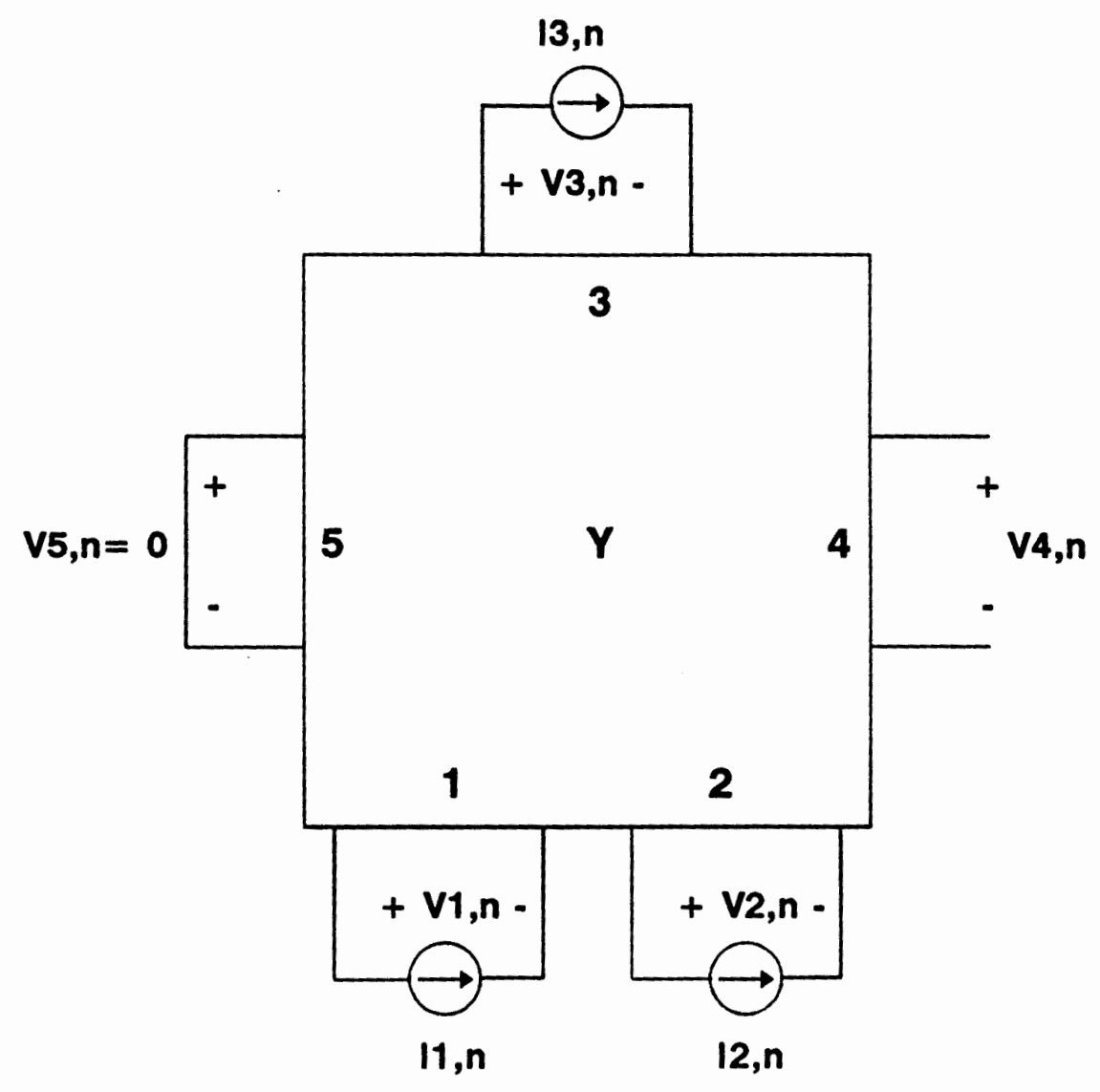

FIGURE 2. Equivalent circuit for determining mixing products of second and higher orders. The multiport represents the linearized MESFET equivalent circuit and the source and the load impedances; $I_{p, n}$ is the nthorder nonlinear current source at port $\mathrm{p}$. 
85

Solve for second order source currents at $2 \omega 1$ and $\omega 1-\omega 2$.

$\mathrm{t} 2 \mathrm{ka}=1$

ta kb $=2$

PORT ONE - capacitive

C12Vgs $=0.158 \cdot 10^{-12}$

At $2 \omega 1$

$\omega 2 \kappa \alpha=2 \cdot \omega_{1}$

$112 \mathrm{ka}=0.5 \cdot \mathrm{j} \cdot \omega 2 \mathrm{~K} \alpha \cdot \mathrm{C} 12 \mathrm{Vgs} \cdot \mathrm{t} 2 \mathrm{ka} \cdot \mathrm{V} 11_{1} \cdot \mathrm{V} 11_{1}$

$112 \mathrm{ka}=-0.004-0.009 \mathrm{i}$

At $\omega 1-\omega 2$

$\omega 2 \kappa \beta=\omega_{1}+\omega_{2}$

$112 \mathrm{~kb}=0.5 \cdot \mathrm{j} \cdot \omega 2 \kappa \beta \cdot \mathrm{C} 12 \mathrm{Vgs} \cdot \mathrm{t} 2 \mathrm{~kb} \cdot \mathrm{V} 11_{1} \cdot \mathrm{V} 11_{2}$

$112 \mathrm{~kb}=-3.538 \cdot 10^{-5}-4.015 \cdot 10^{-6} \mathrm{i}$

Total

$112 k:=112 k a+112 k b$

$112 k=-0.004-0.009 i$

PORT TWO - conductive

g22 Vg $:=.00401 \mathrm{~g} 22 \mathrm{Vd}:=-.000370$

At $2 \omega 1$

$122 \mathrm{kVda}:=0.5 \cdot \mathrm{g} 22 \mathrm{Vd} \cdot \mathrm{t} 2 \mathrm{ka} \cdot \mathrm{V} 21_{1} \cdot \mathrm{V} 21_{1}$

$122 \mathrm{kVda}=0.001+9.317 \cdot 10^{-4} \mathrm{i}$

$122 \mathrm{kVga}:=0.5 \cdot \mathrm{g} 22 \mathrm{Vg} \cdot \mathrm{t} 2 \mathrm{ka} \cdot \mathrm{V} 11_{1} \cdot \mathrm{V} 11_{1}$

$122 \mathrm{kVga}=-0.002+8.457 \cdot 10^{-4} i$

$122 \mathrm{ka}=122 \mathrm{kVda}+122 \mathrm{kVga}$

$122 \mathrm{ka}=-7.517 \cdot 10^{-4}+0.002 \mathrm{i}$

At $\omega 1-\omega 2$

$122 \mathrm{kVdb}:=0.5 \cdot \mathrm{g} 22 \mathrm{Vd} \cdot \mathrm{t} 2 \mathrm{~kb} \cdot \mathrm{V} 21_{1} \cdot \mathrm{V} 21_{2}$

$122 k V d b=-6.405 \cdot 10^{-4}-1.14 \cdot 10^{-4} i$

$122 \mathrm{kVgb}:=0.5 \cdot \mathrm{g} 22 \mathrm{Vg} \cdot \mathrm{t} 2 \mathrm{~kb} \cdot \mathrm{V} 11_{1} \cdot \mathrm{V} 11_{2}$

$122 \mathrm{kVgb}=1.622 \cdot 10^{-4}-0.001 \mathrm{i}$

$122 \mathrm{~kb}:=122 \mathrm{kVdb}+122 \mathrm{kVgb}$

$122 \mathrm{~kb}=-4.783 \cdot 10^{-4}-0.002 \mathrm{i}$ 
Total

$122 k=122 k a+122 k b$

$122 k=-0.001+2.342 \cdot 10^{-4} i$

PORT THREE - capacitive

C32Vgd $=.0293 \cdot 10^{-12}$

At $2 \omega 1$

$132 \mathrm{ka}=0.5 \cdot \mathrm{j} \cdot \omega 2 \mathrm{~K} \alpha \cdot \mathrm{C} 32 \mathrm{Vgd} \cdot \mathrm{t} 2 \mathrm{ka} \cdot \mathrm{V} 31_{1} \cdot \mathrm{V} 31_{1}$

$132 k a=0.01-0.021 i$

At $\omega 1-\omega 2$

$132 \mathrm{~kb}=0.5 \cdot \mathrm{j} \cdot \omega 2 \mathrm{~K} \beta \cdot \mathrm{C} 32 \mathrm{Vgd} \cdot \mathrm{t} 2 \mathrm{~kb} \cdot \mathrm{V} 31_{1} \cdot \mathrm{V} 31_{2}$

$132 \mathrm{~kb}=-1.955 \cdot 10^{-5}-5.493 \cdot 10^{-5} i$

Total

$132 \mathrm{k}:=132 \mathrm{ka}+132 \mathrm{~kb}$

$132 k=0.01-0.021 i$

PORT FOUR - output

$$
\begin{aligned}
& 142 \mathrm{ka}:=0 \quad 142 \mathrm{~kb}:=0 \\
& 142 \mathrm{k}:=142 \mathrm{ka}+142 \mathrm{~kb} \\
& 142 \mathrm{k}=0
\end{aligned}
$$

Solve for second order voltages from Eq 8.2.20

$\left[\begin{array}{l}V 12 k a \\ V 22 k a \\ V 32 k a \\ V 42 k a\end{array}\right]:=-Y i n v(3) \cdot\left[\begin{array}{l}112 k a \\ 122 k a \\ 132 k a \\ 142 k a\end{array}\right]$

$$
\begin{aligned}
& \mathrm{V} 12 \mathrm{ka}=0.947+0.22 \mathrm{i} \\
& \mathrm{V} 22 \mathrm{ka}=-1.077-3.261 \mathrm{i} \\
& \mathrm{V} 32 \mathrm{ka}=2.002+3.522 \mathrm{i} \\
& \mathrm{V} 42 \mathrm{ka}=-1.043-3.089 \mathrm{i}
\end{aligned}
$$

$$
\left[\begin{array}{l}
V 12 k b \\
V 22 k b \\
V 32 k b \\
V 42 k b
\end{array}\right]:=-Y i n v(4) \cdot\left[\begin{array}{l}
112 k b \\
122 k b \\
132 k b \\
142 k b
\end{array}\right]
$$

$$
\begin{aligned}
& \mathrm{V} 12 \mathrm{~kb}=1.977 \cdot 10^{-4}+0.007 \mathrm{i} \\
& \mathrm{V} 22 \mathrm{~kb}=-0.043+0.079 \mathrm{i} \\
& \mathrm{V} 32 \mathrm{~kb}=0.043-0.073 \mathrm{i} \\
& \mathrm{V} 42 \mathrm{~kb}=-0.045+0.076 \mathrm{i}
\end{aligned}
$$




$\left[\begin{array}{l}V 12 k \\ V 22 k \\ V 32 k \\ V 42 k\end{array}\right]=\left[\begin{array}{l}V 12 k a \\ V 22 k a \\ V 32 k a \\ V 42 k a\end{array}\right]+\left[\begin{array}{l}V 12 k b \\ V 22 k b \\ V 32 k b \\ V 42 k b\end{array}\right]$

$\left[\begin{array}{l}V 12 k \\ V 22 k \\ V 32 k \\ V 42 k\end{array}\right]=\left[\begin{array}{c}0.947+0.226 i \\ -1.12-3.181 i \\ 2.044+3.449 i \\ -1.088-3.013 i\end{array}\right]$

Solve for third order (intermodulation) source currents at $2 \omega 1-\omega 2$.

$\mathrm{t} 3 \mathrm{~m}=3$ $\omega 3 \mu:=2 \cdot \omega_{1}+\omega_{2}$

PORT ONE - capacitive

C13Vgs : $=0.1128 \cdot 10^{-12}$

$113 \mathrm{~m}=\mathrm{j} \cdot \omega 3 \mu \cdot\left[\mathrm{C} 12 \mathrm{Vgs} \cdot \mathrm{V} 11_{1} \cdot \mathrm{V} 12 \mathrm{ka}+\frac{\mathrm{C} 13 \mathrm{Vgs} \cdot \mathrm{t3m}}{4} \cdot \mathrm{V} 11_{1} \cdot \mathrm{V} 11_{1} \cdot \mathrm{V} 11_{2}\right]$

$113 m=0.009-0.002 i$

PORT TWO - conductive

g23Vd $:=0.000144$ g23Vg $:=-0.00426$

$123 \mathrm{mVd}:=\mathrm{g} 22 \mathrm{Vd} \cdot \mathrm{V} 21_{1} \cdot \mathrm{V} 22 \mathrm{ka}+\frac{\mathrm{g} 23 \mathrm{Vd} \cdot \mathrm{t} 3 \mathrm{~m}}{4} \cdot \mathrm{V} 21_{1} \cdot \mathrm{V} 21_{1} \cdot \mathrm{V} 21_{2}$

$123 m V d=-0.004+2.477 \cdot 10^{-4} i$

$123 \mathrm{mVg}:=\mathrm{g} 22 \mathrm{Vg} \cdot \mathrm{V} 11_{1} \cdot \mathrm{V} 12 \mathrm{ka}+\frac{\mathrm{g} 23 \mathrm{Vg} \cdot \mathrm{t} 3 \mathrm{~m}}{4} \cdot \mathrm{V} 11_{1} \cdot \mathrm{V} 11_{1} \cdot \mathrm{V} 11_{2}$

$123 m V g=0.001-0.004 i$

Total

$123 m:=123 m V d+123 m V g$ $123 m=-0.003-0.004 i$

PORT THREE - capacitive

C33Vgd $:=0.0209 \cdot 10^{-12}$

$133 m=j \cdot \omega 3 \mu \cdot\left[C 32 \mathrm{Vgd} \cdot \mathrm{V} 31_{1} \cdot V 32 \mathrm{ka}+\frac{\mathrm{C} 33 \mathrm{Vgd} \cdot \mathrm{t} 3 \mathrm{~m}}{4} \cdot \mathrm{V}_{3} 1_{1} \cdot \mathrm{V}_{3} 1_{1} \cdot \mathrm{V}_{31} 1_{2}\right]$

$133 m=0.019+0.024 i$

PORT FOUR - output

$143 m:=0$ 
Solve for third order voltages using Eq. 8.2.23.

$\left[\begin{array}{l}V 13 m \\ V 23 m \\ V 33 m \\ V 43 m\end{array}\right]=-Y i n v(5) \cdot\left[\begin{array}{l}113 m \\ 123 m \\ 133 m \\ 143 m\end{array}\right]$
$\left[\begin{array}{l}V 13 m \\ V 23 m \\ V 33 m \\ V 43 m\end{array}\right]=\left[\begin{array}{c}-3.024+0.836 i \\ 8.168+5.619 i \\ -11.199-4.88 i \\ 7.843+5.504 i\end{array}\right]$

The nth-order load current at some mixing frequency, $\omega$, is simply:

$\operatorname{ILn}(\omega)=\frac{V(\omega)_{4}}{Z_{L}} \mathrm{D}$

At $2 \omega 1-\omega 2$

IL3: $=\frac{V 43 m}{Z_{L}}$

$\mathrm{IL} 3=0.111-0.057 \mathrm{i}$

$P L 3:=0.5 \cdot(|I L 3|)^{2} \cdot \operatorname{Re}\left[Z_{L}\right]$

$\mathrm{PL3}=0.279 \mathrm{Natts}$

$P L 3 d B m:=10 \cdot \log (P L 3 \cdot 1000)$

$\mathrm{PL} 3 \mathrm{dBm}=24.458 \mathrm{~m}$

At $\omega 1$

$\mathrm{IL} 1_{1}:=\frac{\mathrm{V} 41_{1}}{\mathrm{Z}_{\mathrm{L}}}$

$\mathrm{IL} 1_{1}=0.022+0.026 \mathrm{i}$

$P L 1_{1}=0.5 \cdot\left[\left|L 1_{1}\right|\right]^{2} \cdot \operatorname{Re}\left[Z_{L}\right]$

$\mathrm{PL}_{1}=0.021 \mathrm{Watts}$

$P L 1 d B m_{1}:=10 \cdot \log \left[P L 1_{1} \cdot 1000\right]$

$\mathrm{PL} 1 \mathrm{dBm} \mathrm{m}_{1}=13.227 \mathrm{~m}$

At $-\omega 2$

$\mathrm{IL}_{2}=\frac{\mathrm{V} 41_{2}}{\mathrm{Z}_{\mathrm{L}}}$

$\mathrm{IL}_{2}=-0.008-0.003 \mathrm{i}$

$P L 1_{2}=0.5 \cdot\left[\left|I L 1_{2}\right|\right]^{2} \cdot \operatorname{Re}\left[Z_{L}\right]$

$\mathrm{PL}_{2}=0.001$ Natts

$P L 1 d B m_{2}=10 \cdot \log \left[\mathrm{PL1}_{2} \cdot 1000\right]$

$\mathrm{PL1dBm_{2 }}=1.398 \mathrm{~m}$ 
At $2 \omega 1$

$\mathrm{LL}_{1}=\frac{\mathrm{V} 42 \mathrm{ka}}{Z_{L}}$

$I L 2_{1}=-0.042-0.007 i$

$P L 2_{1}=0.5 \cdot\left[|| L 2_{1} \mid\right]^{2} \cdot \operatorname{Re}\left[Z_{L}\right]$

$P L 2_{1}=0.032 \mathrm{Watts}$

$P L 2 \mathrm{dBm}_{1}=10 \cdot \log [P L 2, \cdot 1000]$

$\mathrm{PL}_{2 \mathrm{dBm}_{1}}=15.096 \mathrm{lBm}$

At $\omega 1-\omega 2$

$\mathrm{IL}_{2}=\frac{\mathrm{V} 42 \mathrm{~kb}}{\mathrm{Z}_{\mathrm{L}}}$

$1 L 2_{2}=6.061 \cdot 10^{-4}+9.773 \cdot 10^{-4} i$

$P L 2_{2}=0.5 \cdot\left[|| L 2_{2} \mid\right]^{2} \cdot \operatorname{Re}\left[Z_{L}\right]$

$\mathrm{PL} 2_{2}=2.38 \cdot 10^{-e}$ Watts

$P L 2 \mathrm{dBm}_{2}=10 \cdot \log \left[\mathrm{PL2} 2_{2} \cdot 1000\right]$

$P L 2 \mathrm{dBm}_{2}=-16.2333 \mathrm{~m}$ 